\title{
Non-marine fishes of the late Santonian Milk River Formation of Alberta, Canada - evidence from vertebrate microfossil localities
}

\author{
Donald B. Brinkman, ${ }^{\star, 1,2}$ Andrew G. Neuman ${ }^{1}$ and Julien D. Divay ${ }^{1}$ \\ ${ }^{1}$ Royal Tyrrell Museum of Palaeontology Drumheller, Alberta, T0J 1B0, Canada; don.brinkman@gov.ab.ca \\ ${ }^{2}$ Adjunct, Department of Biological Sciences, University of Alberta Edmonton, Alberta Canada T6G 2E9
}

\begin{abstract}
The diversity of fishes from the late Santonian Milk River Formation of southern Alberta, Canada, is investigated using a combined taxonomic/morphotype approach. Twenty taxa are present, including four elasmobranchs, six basal actinopterygians, and ten teleosts.

The Milk River fish assemblage is more similar to assemblages from the Turonian to Campanian from southern Utah than it is to the younger late Campanian assemblage of Alberta in the presence of the elasmobranch Lonchidion, cf. Melvius, and teleost type $\mathrm{O}$, the relatively high abundance of the ostariophysan teleost $\mathrm{U} 3 / \mathrm{BvD}$, and the absence of sturgeon, Holostean A, Holostean B, and Coriops. This similarity is hypothesized to be the result of a northern shift in the distribution of these taxa during times of high global temperature, resulting in the presence of a "southern" faunal assemblage in Alberta during the late Santonian.

In the relative abundance patterns of major groups of fish, the Milk River Formation assemblage is similar to late Campanian assemblages of Alberta and Utah and different from the late Maastrichtian assemblages of the Hell Creek Formation of Montana in that amiids and lepsisoteids are of relatively low abundance. The abundance of acanthomorph teleosts in the Milk River Formation is similar to that of contemporaneous assemblages from Utah, which supports a pattern of increasing abundance of acanthomorphs from their first occurrence in non-marine vertebrate assemblages of the Western Interior in the Coniacian through to the end of the Cretaceous.
\end{abstract}

Key Words: Cretaceous; faunal assemblage; North America; palaeocommunities

\section{INTRODUCTION}

Fishes are an important component of Late Cretaceous non-marine paleocommunities and understanding their diversity and distribution is important for a full understanding of the taxonomic composition of these paleocommunities and changes in their organization over time. However, the fossil record of non-marine fishes from the Late Cretaceous of North America presents challenges because they are represented primarily by isolated elements. Elasmobranchs and basal actinopterygians are generally well understood but teleosts are much more poorly known because they are difficult to identify on the basis of such material. To help get a more accurate understanding of teleosts in the Late Campanian of Alberta, Brinkman and Neuman (2002) and Neuman and Brinkman (2005) adopted a combined

\section{*corresponding author}

Published April 10, 2017

(c) 2017 by the authors

submitted Nov. 11, 2016; revisions received March 22 2017; accepted March 23 2017. Handling editor: Robert Holmes. taxonomic/morphotype approach. Identifiable elements were included in a formal taxonomic framework and distinctive elements that could not be identified below the level of Teleostei were given alpha-numeric designations. These were then evaluated as to whether or not they represented distinct taxonomic groups, and when it was concluded that this was most likely the case, they were treated as taxonomically distinct indeterminate teleosts. This approach allowed all available elements to be included in the analysis of diversity and distribution, which increases the likelihood that paleoecologically significant patterns of faunal changes through the Late Cretaceous can be recognized.

In subsequent papers, this combined taxonomic/morphotype approach was used to document non-marine teleost fishes from vertebrate microfossil localities of Utah and Montana ranging in age from the Cenomanian to the late Maastrichtian (Brinkman et al. 2013; Brinkman et al. 2014). An overall increase in diversity of teleosts through the Late Cretaceous punctuated by two periods during which major faunal changes occurred was recognized. One of these periods was between the Cenomanian and late 
Turonian, and the second was between the early Santonian and late Campanian (Brinkman et al. 2013, 2014). During both periods of major faunal change, new taxonomic groups appeared, likely as a result of intercontinental dispersal in some cases.

In addition, latitudinal patterns of distribution of the fishes within the Western Interior Basin could be identified by comparison of contemporaneous assemblages from Utah, Montana and Alberta (Fig. 1C). Distinct latitudinal patterns were recognized, with some taxa either being restricted to, or being more abundant in, southern or northern regions. Changes in latitudinal distribution patterns could be correlated with changes in climate, southern taxa extending further north during times of higher mean annual temperatures. In this paper, the combined taxonomic/morphotype approach of Neuman and Brinkman (2005) and Brinkman et al. $(2013,2014)$ is used to evaluate the diversity and relative abundance of fishes from the late Santonian Milk River Formation of southern Alberta, Canada. Previous studies have documented the presence of a diverse assemblage of elasmobranchs and basal actinopterygians in this formation (Larson 2010; Cook et al. 2014) but only two teleosts have been described. These are the esocoid Estesesox and the clupeomorph Horseshoeichthys. Estesesox was reported by Wilson et al. (1992) on the basis of isolated dentaries that shared apomorphic features of the tooth implantation with extant members of the group. Horseshoeichthys was reported by Newbrey et al. (2010) on the basis of vertebral centra and jaw elements that matched those of the type specimen, one of the few articulated non-marine teleost specimens known from the Late Cretaceous of the Western Interior Basin. The morphotype approach adopted here demonstrates that the diversity of teleosts from the Milk River Formation is much greater than previously recognized. With this increased understanding of fish diversity in the Milk River Formation, the stratigraphic and paleobiogeographic patterns of distribution of fishes in the Late Cretaceous of the Western Interior proposed by Brinkman et al. (2013) are tested and refined.

\section{GEOLOGY}

The Milk River Formation was deposited on the western side of the Interior Seaway during the beginning of a regressive cycle following the major marine transgression represented by the Wapiabi Formation (TuronianSantonian) of the Colorado Group (Meyer 1994; Tobias et al. 2003). The general paleoshoreline during deposition of the formation was striking northwest-southeast. To the west, the Milk River Formation is laterally equivalent to the marine Lea Park Formation, to the south-east, it is equivalent to the Deadhorse Coulee Member of the Eagle
Formation (Payenberg et al. 2002), and to the south, it is equivalent to the lowest part of the Two Medicine Formation (Rogers et al. 1993). Further south, the Milk River Formation is equivalent to the upper portion of the John Henry Member and the Drip Tank Member of the Straight Cliffs Formation (Brinkman et al. 2013). The Milk River Formation is overlain by the marine Pakowki Formation (Meyer 1994).

The Milk River Formation is subdivided into three members. In ascending order, these are the Telegraph Creek Member, the Virgelle Sandstone Member, and the Deadhorse Coulee Member (Fig. 1A). The Telegraph Creek and Virgelle Sandstone members are marine units overlain by the non-marine Deadhorse Coulee Member. Although the Milk River Formation has been considered to be early Campanian in age, more recent studies based on palynology and magnetostratigraphy have indicated that most, if not all, of the Deadhorse Coulee Member is latest Santonian (Braman 2002).

Exposures of the non-marine Deadhorse Coulee Member of the Milk River Formation are present along the Milk River and the adjacent Verdigris Coulee in South-central Alberta (Fig. 1B). Vertebrate fossils are abundant in this unit, although most of the material is isolated and fragmentary. Small elements typically occur in vertebrate microfossil localities; concentrations that could be sampled by underwater screen-washing processes. Two sites sampled during the course of this study are located in the Verdigris Coulee. One of these (L1145) is at the base of a laterally-extensive sandstone that is broadly exposed near the top of the section in Verdigris Coulee. The second (Michael's Site) is exposed in a lenticular muddy siltstone near the base of the Deadhorse Coulee Member. In addition, material in the collections of the University of Alberta Laboratory for Vertebrate Paleontology (UALVP) was used in this study. The UALVP collections were assembled by R. C. Fox as a result of a program of intensive screen-washing of vertebrate microfossil localities in the search for mammals. Material from four localities sampled by Fox was included in this study. These are UALVP localities MR4, MR6, MR8, and MR20 Fishes were particularly well represented at two of these sites, MR6 and MR8, and counts of centra from these localities are included in Table 1. These localities are located in Verdigris Coulee, although their stratigraphic position is not known.

\section{Methods}

Both surface collected and screen-wash samples were used in establishing the diversity and relationships of teleosts pesent. Localities that were sampled during the course of this study were screen-washed using a screen with $0.85 \mathrm{~mm}$ openings. 

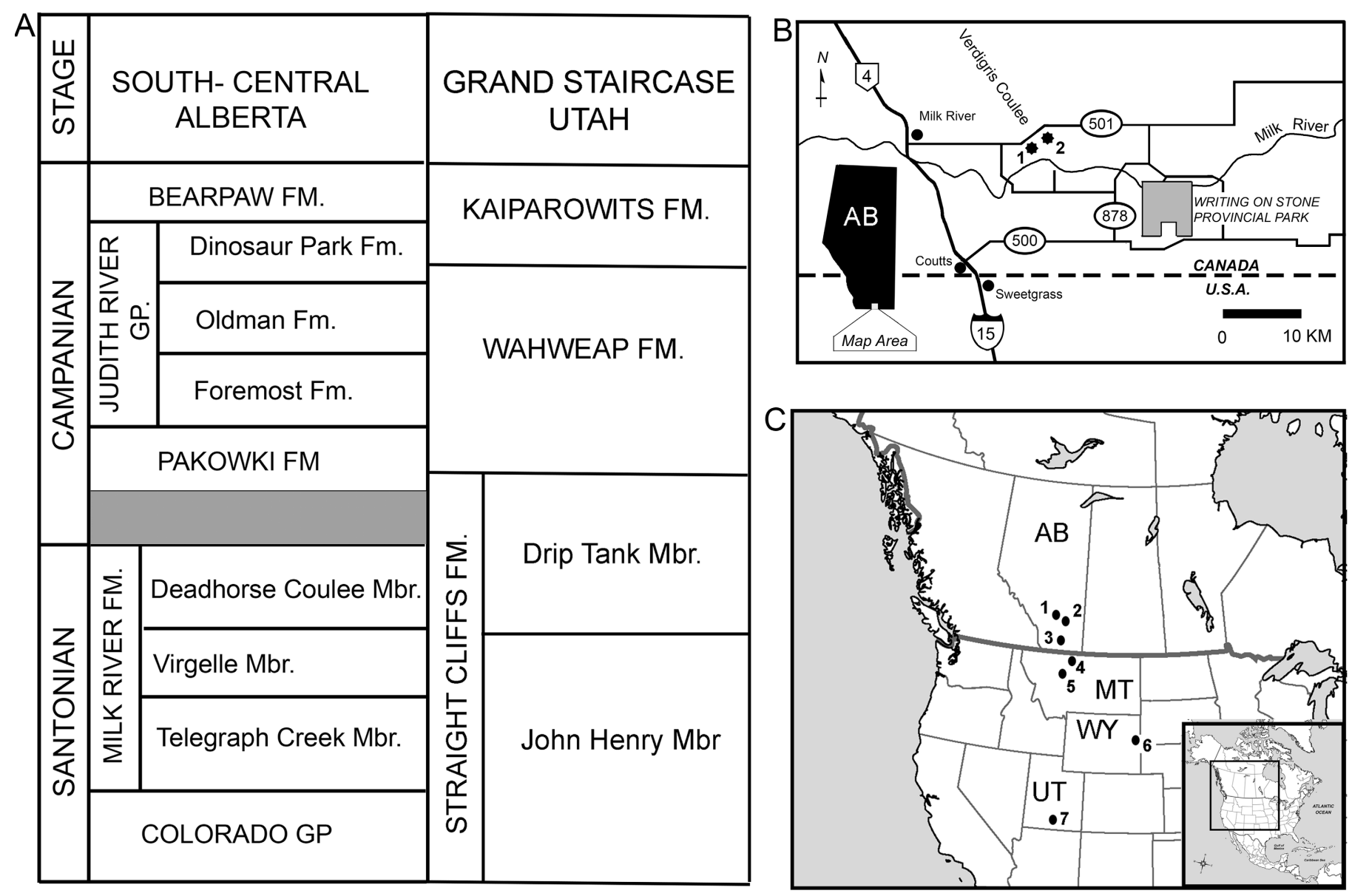

Figure 1. A) stratigraphic chart showing the formations in South-central Alberta and the correlation with formations in the Grand Staircase region of Utah. The ages of the formations in Alberta are based on Braman (2002). The correlation of the formations of Utah and Alberta is from Brinkman et al. (2013). B) locality map showing the position of vertebrate microfossil localities in the Milk River Formation that were sampled by underwater screen-washing techniques by the Royal Tyrrell Museum of Palaeontology. 1, TMP locality Michael's Site; 2, TMP locality L1145. C) Outline map of North America showing the geographic distribution of the major fossil-bearing localities referred to in this paper. 1, Dry Island Provincial Park area, Alberta, Canada, location of vertebrate microfossil localities in the Scollard and Horseshoe Canyon Formation; 2, Dinosaur Provincial Park, Alberta, Canada, location of microfossil localities in the Belly River Group Formation; 3, Verdigris Coulee, Alberta, Canada, location of microfossil localities in the Milk River Formation; 4, Kennedy Coulee, Montana, USA, location of microfossil localities in the Judith River Formation; 5, Jordan, Montana, USA, location of microfossil localities in the Hell Creek and Tullock Formation; 6, Niobrara County, Wyoming, USA, location of Bushy Tail Blowout, microfossil locality in the Lance Formation; 7, Grand Staircase-Escalante area, Utah, USA, location of microfossil localities in the Cenomanian to late Campanian localities in southern Utah, including the late Turonian Smokey Hollow Member of the Straight Cliffs Formation, the Santonian John Henry Member of the Straight Cliffs Formation, and the late Campanian Kiparowits Formation.

For the classification of fishes present, the system of Nelson et al. (2016) is followed. As with previous studies of fishes from Late Cretaceous vertebrate microfossil localities (Brinkman and Neuman 2002; Neuman and Brinkman 2005), interpretations of the diversity of teleosts are based primarily on precaudal centra, dentaries, and other tooth-bearing elements. While morphologically distinct dentaries can generally be considered to be taxonomically distinct, vertebral elements must be evaluated more cautiously because of variation along the column. The range in variation along the column in extant teleosts provides a framework in which to evaluate whether distinct morphotypes are from different regions of the vertebral column or represent taxonomically distinct groups. As well, hypotheses of association of morphologically distinct centra were tested using distribution patterns. Since elements from the same kind of fish should have the same distribution pattern, a strong correlation in the occurrence of distinct elements would support the hypothesis that they are associated. This approach was also used to test the hypothesis that centra and tooth-bearing elements are from a single kind of fish. Since many of the morphotypes present in the Milk River Formation were previously recognized in Utah and the Hell Creek Formation of Montana, the 
Table 1. Counts of centra of fishes and amphibians from four localities in the Milk River Formation sampled by through the use of underwater screen-washing techniques*.

\begin{tabular}{lcccc}
\hline & MR 8 & MR6 & L1145 & Michael's Site \\
Orectolobidae & 0 & 6 & 1 & 2 \\
Pseudomyledaphus & 7 & 76 & 8 & 17 \\
Lepisosteidae & 7 & 17 & 3 & 7 \\
Amiinae indet. & 5 & 25 & 3 & 5 \\
Elopomorpha indet. & 1 & 3 & 1 & 1 \\
?Ostariostoma & 0 & 3 & 0 & 0 \\
Wilsonichthys & 12 & 41 & 6 & 16 \\
Hiodontidae & 2 & 11 & 0 & 7 \\
Horseshoeichthys & 1 & 26 & 0 & 0 \\
Teleost U-3/BvD & 8 & 64 & 3 & 9 \\
Esocoidea & 0 & 0 & 0 & 0 \\
Acanthomorpha & 4 & 11 & 4 & 6 \\
Teleost indet. type O & 2 & 10 & 2 & 1 \\
Teleost indet. type U-4 & 12 & 20 & 5 & 19 \\
Albanerpeton & 0 & 1 & 0 & 0 \\
Urodela & 6 & 104 & 25 & 9 \\
Anura & 0 & 2 & 0 & 0
\end{tabular}

*Fishes without centra, such as Belonostomus, are not included in the table. Cf. Melvius is not included in this list because its centra were not present in the samples derived from screen-washing bulk matrix. Centra in locality L1145 are are catalogued under accession number TMP 2000.1. Centra in locality Michael's Site are catalogued under accession number TMP 2000.2. Centra in UALVP locality MR6 were originally included in lot numbers UALVP 17417, and UALVP 17411. Specimens in UALVP 17417 have been recatalogued under UALVP numbers 56839 to 56854. Specimens in UALVP 17411 have been recatalogued under UALVP numbers 56887 to 56905 . Centra in UALVP locality MR8 were originally catalogued as UALVP 17397 and have been recatalogued under numbers UALVP 56823 to 56838 .

alpha-numeric designations used by Brinkman et al. (2013, 2014) to refer to these morphotypes are adopted here.

In an attempt to identify many of the morphologically distinct teleost elements that are present, comparisons were made with extant and fossil specimens. The osteological collections of the Royal Ontario Museum (Toronto, Ontario, Canada), Canadian Museum of Nature (Ottawa, Ontario, Canada), and University of Michigan (Ann Arbor, Michigan, USA), University of California Museum of Paleontology (Berkeley, California, USA), and Royal Tyrrell Museum of Palaeontology (Drumheller, Alberta, Canada) provided a broad range of comparative specimens of recent fishes. The collections of fossil fishes in the University of Alberta (Edmonton, Alberta) and the Royal Tyrrell Museum of Palaeontology were also particularly useful. In addition to articulated specimens of teleosts of Cretaceous age, Eocene Green River Formation fishes were examined because Divay (2015) and Divay and Murray (2016) were able to use articulated Green River specimens to identify isolated elements of Diplomystus and a gonorynchiform in the Wasatch Formation, and these taxa are known to be present in the Cretaceous.

To document the morphological variation within the taxonomic units recognized, an extensive series of photographs of the elements reported here is included. Specimens were whitened with ammonium chloride before photography to emphasize relief.

Comparison of faunal assemblages preserved in different localities or formations were made using both presence/ absence and relative abundance data. We follow Badgley (1986) and Grayson (1984), who concluded that where formerly articulated material has been widely dispersed and has accumulated as isolated specimens, the minimum number of elements of a taxon is the best basis for documenting differences in the abundance of taxa between sites. Badgley (1986) distinguished between minimum number of elements and minimum number of specimens in part to eliminate the effect of recent breakage. Since different taxa are represented by different elements, the abundance of an element within a locality does not necessarily reflect the abundance of the taxon in the original community from which the sample was derived. However, since the fossil assemblages included in this study accumulated under generally similar taphonomic conditions, major differences in abundance of taxa in localities being compared is interpreted as a result of differences in abundance of taxa in the original communities being compared. As argued by Brinkman (2008), the biases introduced by the taphonomic processes can be further minimized by focusing on taphonomically similar elements. Thus, for quantifying the abundance of aquatic vertebrates at localities being compared, only centra were used. The counts of centra from four localities sampled is given in Table 1.

Institutional abbreviations: MNA: Museum of Northern Arizona; OMNH: Oklahoma Museum of Natural History; TMP: Royal Tyrrell Museum of Palaeontology; UALVP: University of Alberta Laboratory for Vertebrate Palaeontology; UCMP: University of California Museum of Paleontology; UMNH, Utah Museum of Natural History.

\section{SYSTEMATIC PALAEONTOLOGY}

\author{
Class CHONDRICHTHYES Huxley, 1880 \\ Subclass EUSELACHII Hay, 1902 \\ Infraclass HYBODONTA Owen, 1846 \\ Order HYBODONTIFORMES Maisey, 1975 \\ Family LONCHIDIIDAE Herman, 1977 \\ Lonchidion Estes, 1964
}


Lonchidion sp.

Fig. 2 A, C-D

Voucher specimens: TMP 91.114.5, tooth, TMP locality L1145, Verdigris Coulee, Alberta; UALVP 15271, tooth, UALVP locality MR8; UALVP 15275, tooth, UALVP locality MR6; UALVP 17421, cephalic spine, UALVP locality MR8; UALVP 17420, cephalic spine, UALVP locality MR8; UALVP 15273, cephalic spine, UALVP locality MR8; UALVP 56045, dorsal fin spine, UALVP locality MR20, Verdigris Coulee, Alberta.

Description: Lonchidion is represented in the Milk River Formation by teeth, fin spines, and cephalic spines. Teeth are mesiodistally elongated, have smooth labial and lingual crown faces, and a low, triangular median cusp that is joined with a prominent labial protuberance by a well-developed ridge. This median cusp, which is often worn, bears a well-marked transverse crest that continues to run the length of the crown. Teeth of Lonchidion from the Milk River Formation (Fig. 2A) differ little from Lonchidion teeth from the John Henry Member of the Straight Cliffs Formation of Southern Utah.

Fin spines, similar to those Estes (1964) and Cook et al. (2014) attributed to Lonchidion are present in the Milk River Formation (Fig. 2C). As noted by Kirkland et al. (2014), the spines of Lonchidion differ from those of Hybodus in being smooth. They differ from the Lonchidion spines illustrated by Estes (1964: fig. 4a-b) in that the serrations on the posterior edge of the spine are lower and longer.

Elasmobranch cephalic spines that are present in the Milk River Formation (Fig. 2D) are referred to Lonchidion because they are similar to those described by Estes(1964). The strongly curved spine has fine ridges on the posterior surface and small tubercles on the anterior surface. The lateral lobes of the base are missing on all available specimens. A strong, flat-topped midline ridge is present posterior to the spine.

Remarks: The taxonomic history of Lonchidion was reviewed by Cook et al. (2014). A single species, L. selachos Estes, 1964, was recognized in the late Maastrichtian of North America. Kirkland et al. (2013) noted that the species diversity in older assemblages is not resolved. Thus, the Milk River taxon is considered specifically indeterminate.

Lonchidion was one of the taxa that Brinkman et al. (2013) interpreted as being a member of a southern assemblage because it is consistently present in the Kaiparowits Formation of Utah, as well as earlier localities in that region, but absent in the Belly River Group of Alberta and the Judith River Formation of Montana. Its presence in the Milk River Formation suggests that in the late Santonian southern taxa extended further north than they did in the late Campanian.
Family HYBODONTIDAE Owen, 1846

Hybodus Agassiz, 1837

Hybodus sp.

Fig. 2B

Voucher specimen: UALVP 15274, two teeth from UALVP locality MR 4, Verdigris Coulee, Alberta.

Description: The presence of a species of Hybodus is documented by two teeth from locality MR4. The most complete tooth (Fig. 2B) includes the principal cusp and the shoulder region of one side. The principal cusp is relatively tall, its height being greater than the width of the shoulder region. The shoulder region bears two well-developed lateral cusplets

Remarks: Hybodontid teeth from the Late Cretaceous non-marine deposits of the Western Interior are generally included in the genus Hybodus, but a separate genus, Meristodonoides, was erected by Underwood and Cumbaa (2010) for teeth with a single, well-developed principle cusp. The hybodont present in the Dinosaur Park Formation of Alberta, initially described as Hybodus montanensis Case, 1978, was removed to Meristodonoides by Cumbaa (2010). The hybodontid teeth from the Milk River Formation are similar to Meristodonoides montanensis in that the principal cusp is relatively tall. However, they are different from the teeth of Meristodonoides montanensis and similar to Hybodus sp. from the Grand Staricase/Escalante region of Utah described by Kirkland et al. (2013) in that they have two or more lateral cusplets. Thus, the Milk River Formation hybodont is included in the genus Hybodus.

Infraclass ELASMOBRANCHII Bonaparte, 1838 EUSELACHI Hay, 1902

Order ORECTOLOBIFORMES Applegate, 1972

Family ORECTOLOBIDAE Jordan and Fowler, 1903 Genus indet.

Fig. 2E, J

Voucher specimens: UALVP 48854, centrum, UALVP locality MR20, Verdigris Coulee, Alberta; UALVP 56905, centra, from UALVP locality MR6, Verdigris Coulee, Alberta; UALVP 56839, two centra, from UALVP locality MR6, Verdigris Coulee, Alberta; TMP 2000.1.51, three denticles, TMP locality L1145, Verdigris Coulee, Alberta; TMP 2000.1.62, centrum, TMP locality L1145, Verdigris Coulee, Alberta.

Remarks: The presence of an orectolobid in the Milk River Formation is attested by centra and denticles. The denticles are like those Neuman and Brinkman (2005) attributed to the Orectolobidae in being tall and having a fluted base and a pointed cusp that is slightly distally 

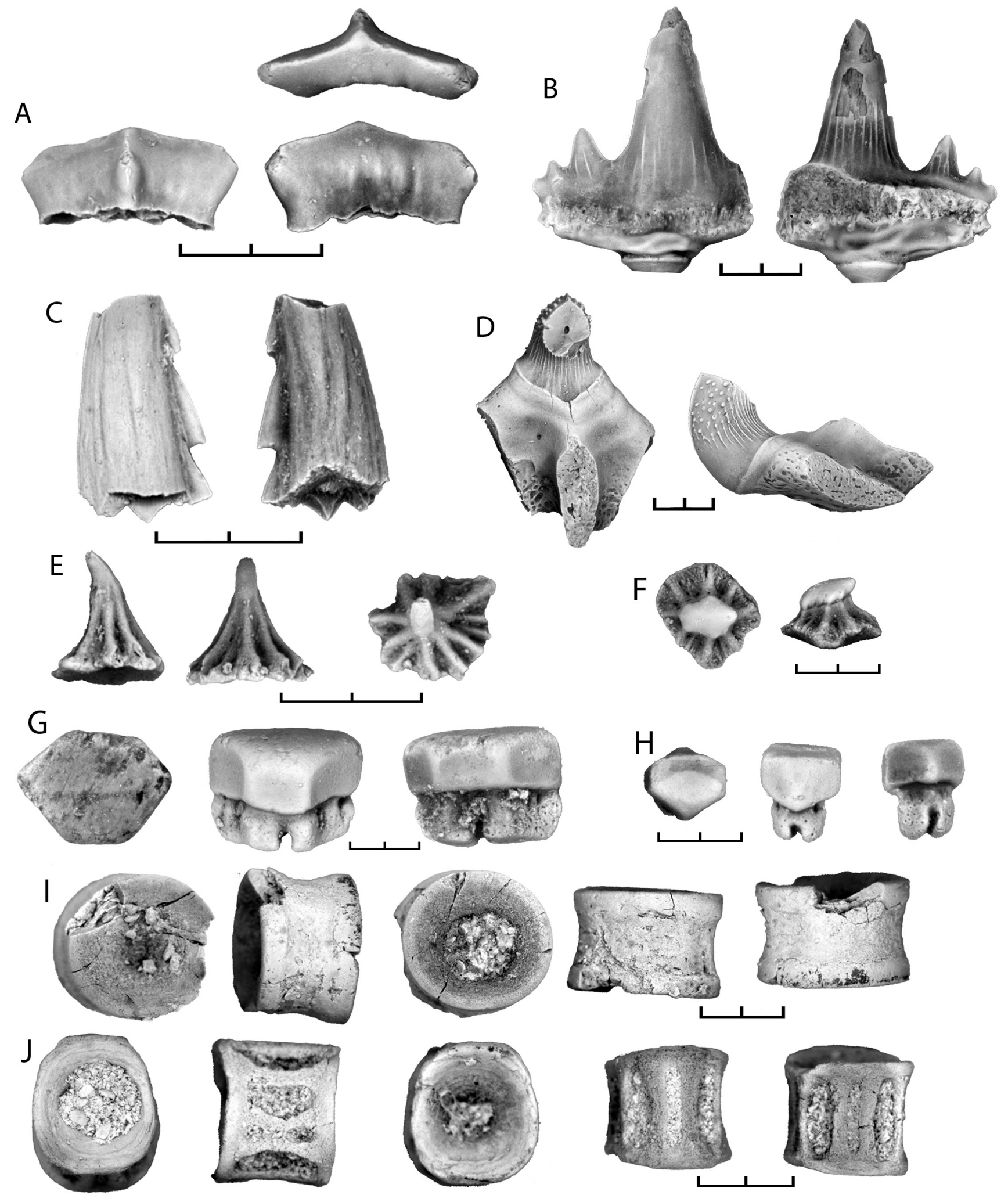

Figure 2. Elasmobranch elements from the Milk River Formation. A) Lonchidion sp., tooth, TMP 91.114.5, shown in labial (left), lingual (right) and occlusal (above) views. B) Hybodus sp. tooth, UALVP 15274, shown in labial (left) and lingual (right) views. C) Lonchidion sp., fin spine, UALVP 56045. D) cephalic spine attributed to Lonchidion sp., UALVP 15273. E) denticle attributed to Orectolobidae gen. indet., TMP 2000.1.51. F) denticle attributed to Pseudomyledaphus madsesni, TMP 2000.1.7. G-H) teeth of Pseudomyledaphus madsesni, showing variation in shape, both TMP 2000.1.2. I) centrum of Pseudomyledaphus madsesni, UALVP 48853. J) centrum attributed to Orectolobidae gen. indet., UALVP 48854. Centra shown in anterior, left lateral, posterior, dorsal and ventral views. Scale equals $2 \mathrm{~mm}$. 
inclined (Fig. 2E). The centra, which are characterized by the presence of multiple bars extending between the ends of the centrum (Fig. 2J), are morphologically similar to those that Neuman and Brinkman (2005) referred to the Orectolobidae and that Cook et al. (2014) referred to Restesia. However, no orectolobid teeth were recovered, so the generic assignment of this taxon is uncertain.

\section{Division BATOMORPHI Cappetta, 1980 \\ Order RAJIFORMES Berg, 1937 \\ Suborder RHINOBATOIDEI Fowler 1941 \\ Family incertae sedis \\ Pseudomyledaphus Kirkland et al., 2013 \\ Pseudomyledaphus madseni Kirkland et al., 2013}

Fig. 2F-I.

Voucher specimens: TMP 2000.1.2, teeth, from TMP locality L1145, Verdigris Coulee, Alberta; TMP 2000.1.7, denticle, from TMP locality L1145, Verdigris Coulee Alberta; UALVP 48853, centrum, from UALVP locality MR8, Verdigris Coulee, Alberta; UALVP 56834, seven centra, from UALVP locality MR8, Verdigris Coulee, Alberta; UALVP 56840, thirteen centra, from UALVP locality MR6, Verdigris Coulee, Alberta; UALVP 56904, sixty-three centra, centra, from UALVP locality MR6, Verdigris Coulee, Alberta; TMP 2000.1.59, centrum, from TMP locality L1 145 Verdigris Coulee Alberta; TMP 2000.2.51, centrum, from TMP locality Michael's Site, Verdigris Coulee Alberta.

Description: Pseudomyledaphus madseni is represented by teeth, centra, and dentilces. As in Myledaphus, the teeth are tall and 4 or 6 sided, the occlusal surface of the crown is divided by a C-shaped transverse ridge, and the root is divided into two lobes by a deep nutrient groove (Fig. 2G-H). In contrast to species of Myledaphus, where labiolingually directed parallel enameloid folds are present on the surface and sides of the crown of the tooth, the unworn teeth of Pseudomyledaphus madseni are smooth.

Centra are simple spools, without distinct pits for neural arches or parapophyses (Fig. 2F). As in Myledaphus centra from the Belly River Group, growth lines are well developed and are obvious in broken surfaces.

Low, blunt denticles with a rounded base similar to those that have been attributed to Myledaphus (Fig. 2H) are assumed to be from Pseudomyledaphus madseni.

Remarks: Pseudomyledaphus madseni was erected by Kirkland et al. (2013) to include teeth that are similar to those of Myledaphus in general form but differ in having a smooth crown. The teeth of Pseudomyledaphus from the Milk River Formation do not differ from those from the John Henry Member of the Straight Cliffs Formation of Utah so are interpreted as being conspecific. Pseudomyledaphus madseni is abundant in the Milk River Formation.
Class OSTEICHTHYES Huxley, 1880

Subclass ACTINOPTERYGII Klein, 1885 Infraclass CHONDROSTEI Müller, 1844 Order ACIPENSERIFORMES Berg, 1940

(sensu Grande et al., 2002)

Family POLYODONTIDAE Bonaparte, 1838

Genus et sp. indet.

Fig. 3

Voucher specimen: UALVP 49032, denticle, UALVP locality MR 20, Verdigris Coulee, Alberta.

Description: The presence of at least one kind of paddlefish in the Milk River Formation is documented by denticles that conform to those described by McAlpine (1947) in having a thin dorsal plate ending in posteriorly projecting spines and a pair of ventral projections that typically extend at right angles to the dorsal plate (Fig. 3).

Remarks: In Utah, paddlefish denticles are present in the middle Campanian Wahweap Formation, but not in older beds. Thus the paddlefish denticles from the late Santonian Milk River Formation document the earliest occurrence of a paddlefish in non-marine sediments of the Western Interior of North America.

Infraclass HOLOSTEI Müller, 1844 (sensu Grande, 2010) Order LEPISOSTEIFORMES Hay, 1929 Family LEPISOSTEIDAE Cuvier, 1825 Gen. et sp. indet.

Fig. 4A-I

Voucher specimens: UALVP48859, centrum, UALVP locality MR6, Verdigris Coulee, Alberta; UALVP 56841, twelve centra, from UALVP locality MR6, Verdigris Coulee, Alberta; UALVP 56900, five centra, centra, from UALVP locality MR6, Verdigris Coulee, Alberta;

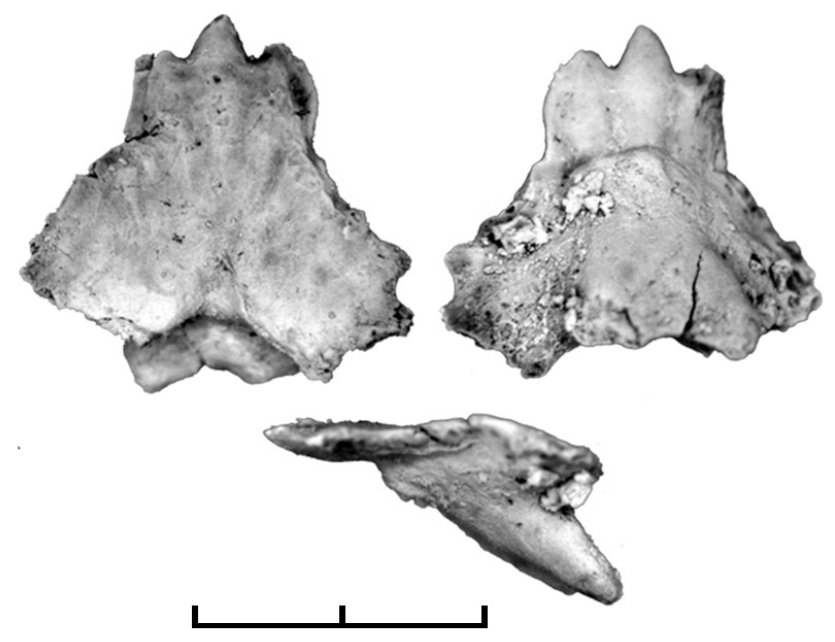

Figure 3. Paddlefish denticle from the Milk River Formation, UALVP 49032. Scale bar equals $2 \mathrm{~mm}$. 
UALVP 56824, seven centra, from UALVP locality MR8, Verdigris Coulee, Alberta; TMP 2000.1.9, teeth, TMP locality L1 145, Verdigris Coulee, Alberta; TMP 2000.2.40, Gar scale type 1, TMP locality Michael's Site, Verdigris Coulee, Alberta; TMP 2000.1.1, Gar scale type 2, TMP locality Michael's Site, Verdigris Coulee, Alberta; TMP 2000.2.28, three centra, TMP locality Michael's Site, Verdigris Coulee; TMP 2000.1.50, centra, TMP locality L1145, Verdigris Coulee, Alberta.
Description: Lepisosteid teeth, centra, and scales are abundant in the Milk River Formation. The teeth conform to those of extant Lepisosteus in being conical, striated, and having a clear tip, often with a constriction at the base of the tip (Fig. 4C-D). Variation is present in the proportions of the teeth, presumably reflecting variation in the length of teeth along the jaw.

Lepisosteiform centra are distinctive in being opisthocoelous with well-developed concave and convex articular surfaces
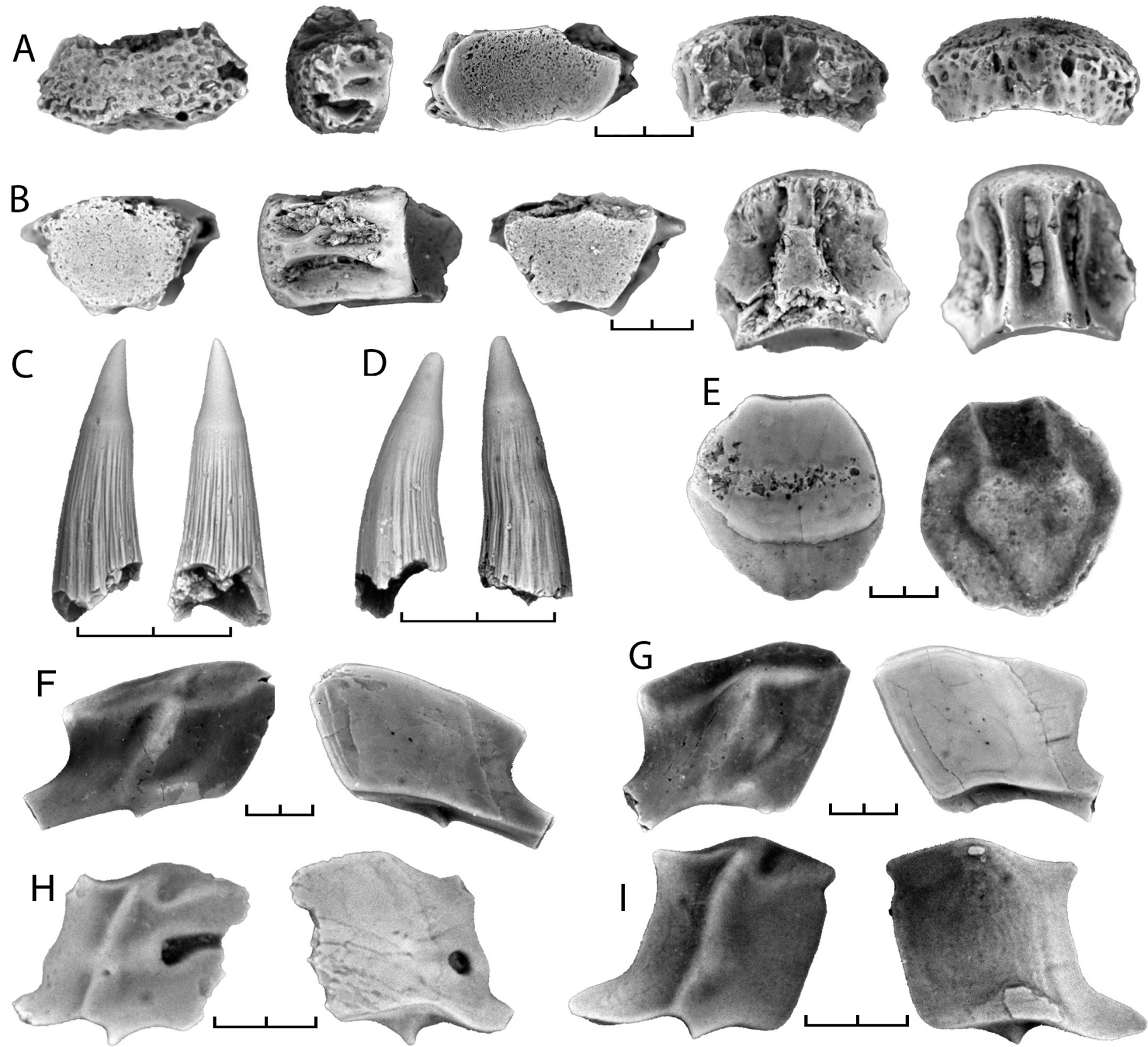

Figure 4. Lepisosteidae elements from the Milk River Formation. A) first centrum of the vertebral column, specimen TMP 2000.2.28. B) mid-dorsal centrum, specimen UALVP48859, from UALVP locality MR6, Verdigris Coulee, Alberta. C, D) Lepisosteidae teeth, showing variation in the degree of curvature of the tooth, both specimens TMP 2000.1.9. E) mid-dorsal scale of Lepisosteidae scale type 1 morphology, TMP 2000.2.40a. F, G) Lepisosteidae scales type 1, presumed scales of Atractosteus, both specimens from TMP 2000.2.40b. H, I) Lepisosteidae scale type 2, presumed scales of Lepisosteus, both specimens TMP 2000.1.1. Centra shown in anterior, left lateral, posterior, dorsal and ventral views. Scale bar equals $2 \mathrm{~mm}$. 
that lack any notochordal pit (Fig. 4A, B). The anterior-most centrum is short and has a bilobed anterior articular surface (Fig. 4A) for articulation with the basioccipital. More posterior precaudal centra are more elongate, with anterior and posterior articular surfaces that are oval in end view and are wider than high (Fig. 4B).

Lepisosteid scales (Fig. 4E-I) are thick and enamel-covered, with the antero-ventral corner of the scale extending as a distinct tab. Brinkman et al. (2013) recognized that two morphotypes of lepisosteid scales are present in the Kaiparowits Formation, which they designated Gar Scale Type 1 and Gar Scale Type 2. Type 1 scales are thick and are without a distinct peg and socket joint (Fig. 4E-G). Type 2 scales are thinner and have a distinct dorso-ventrally oriented ridge on the inner surface extending between a distinct, but small, peg and socket joint (Fig. 4H, I). Both types of scales are present in the Milk River Formation, although Type 1 scales are more abundant.

Remarks: Lepisosteid elements from vertebrate microfossil localities of Late Cretaceous age have formerly been referred to Lepisosteus. However, in a recent study of the group by Grande (2010), Atractosteus spatula, the alligator gar, was considered to be generically distinct, with several extant forms - and some fossil forms as old as the Late Cretaceous - being included in the genus. Grande (2010) recognized that, in part, these taxa differ in the develop- ment of a dorsal peg on the flank scales. In Lepisosteus, this is distinct, while in Atractosteus, a dorsal peg is absent or only weakly developed. Thus the two morphotypes of gar scales present in the Milk River Formation conform to the difference between the scales of the extant genera Atractosteus and Lepisosteus with Scale Type 1 similar to those of Atractosteus, and Scale Type 2 being similar to those of Lepisosteus, and suggest that both taxa are present in the Milk River Formation assemblage. In the presence of large flank scales of both morphotypes, the fish assemblage of the Milk River Formation is similar to vertebrate microfossil assemblages from southern Utah but different from the Belly River Group, where only Scale Type 1 (the scale morphotype present in Atractosteus) is present.

Order AMIIFORMES Hay, 1929

Family AMIIDAE Bonaparte, 1838

Subfamily VIDALAMIINAE Grande and Bemis, 1998 cf. Melvius sp. Bryant, 1987

Fig. 5

Voucher specimens: TMP 2000.2.8, teeth, TMP locality Michael's Site, Verdigris Coulee, Alberta; TMP 2000.1.23, partial maxilla, TMP locality L1145, Verdigris Coulee, Alberta; UALVP 17391. Teeth, UALVP localityMR8, Verdigris Coulee, Alberta; TMP
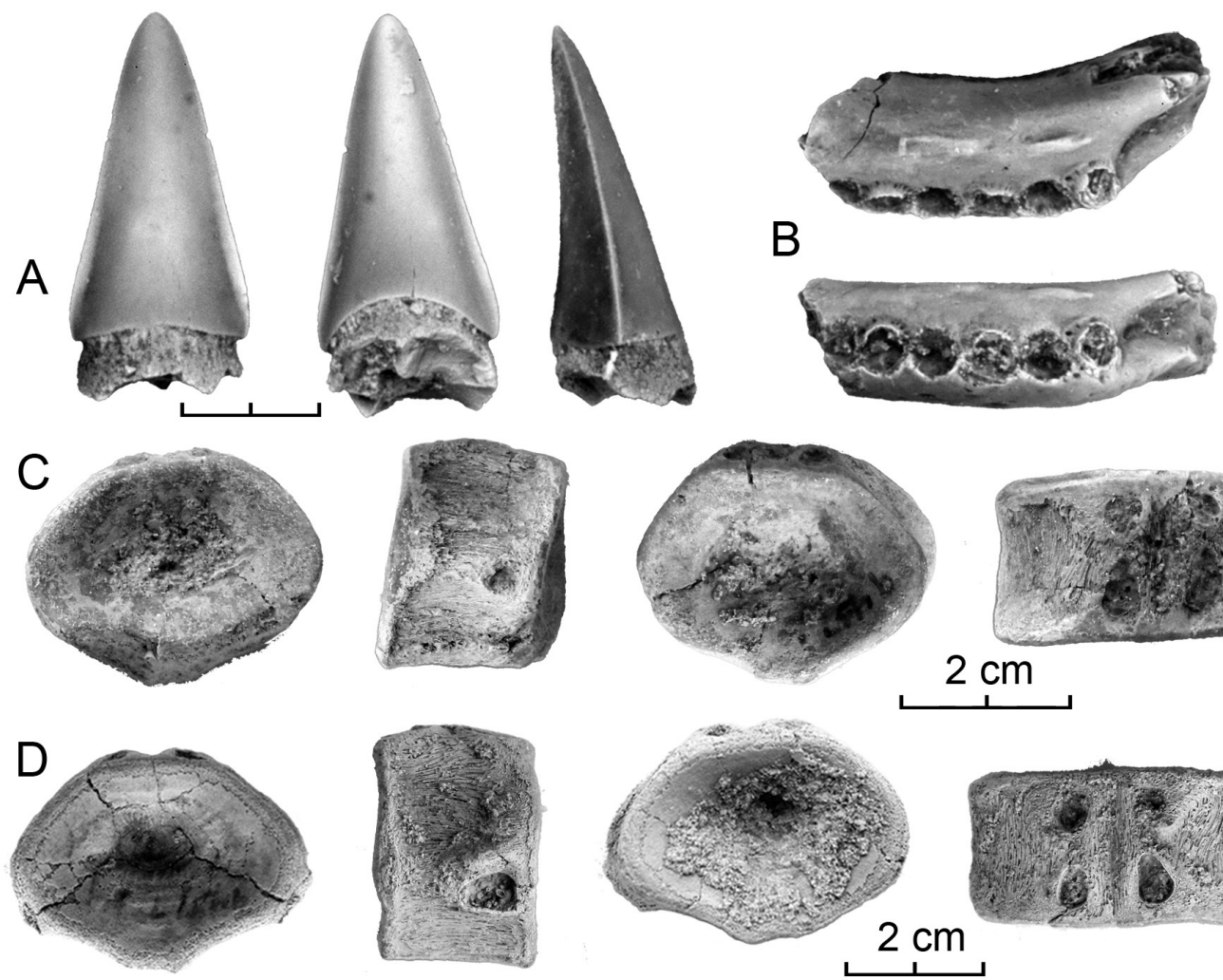
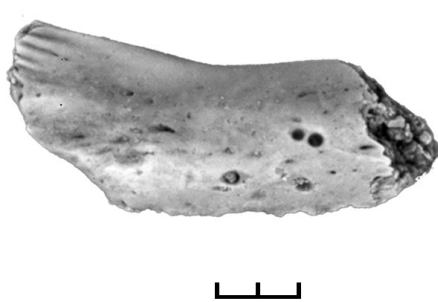

Figure 5. Cf. Melvius elements from the Milk River Formation. A) cf. Melvius tooth in three views, TMP 2000.2.8. B) maxilla fragment referred to cf. Melvius on the basis of the presence of round tooth-bases just touching adjacent teeth, TMP 2000.1.23. C-D) precaudal centra, both included in TMP 94.377.14. Scale bar for A and B equals $2 \mathrm{~mm}$. 
94.377.14, two centra, LSD 6, Sec 32, TP 12, Rg 1, W4, east of Writing on Stone Provincial Park, Alberta; ROM 56610, centrum, Deadhorse Coulee, East of Writing on Stone Provincial Park Alberta.

Description: Large-bodied vidalamiines are represented in vertebrate microfossil localities from the Milk River Formation by marginal teeth, centra, and a maxilla fragment. The teeth are elongate, laterally compressed, symmetrical blades (Fig. 5A). Vidalamiine centra, because of their large size, are rarely encountered in vertebrate microfossil localities but have been encountered during surface collections. A large centrum in the collections of the Royal Ontario Museum (ROM 56610) was illustrated by Larson (2010; Fig. 3, 4A). This centrum is approximately 3.5 $\mathrm{cm}$ wide, which is comparable in size to centra of Melvius thomasi Bryant, 1987 from the Hell Creek Formation of Montana (Bryant, 1987). Two slightly smaller centra (Fig. 5C, D) agree with Melvius thomasi in being broadly oval in end view and having deeply excavated ventro-lateral surfaces. However, they differ in being relatively elongate. Also, the neural arch articular surface is divided into two separate round scars, rather than a single 8-shaped surface. An amiid maxilla with a single row of teeth (Fig. 5B) is tentatively referred to cf. Melvius because it is similar to Melvius thomasi in having teeth that are round in cross section section and with the bases of adjacent teeth making tangential contact (Bryant 1987: fig.10). This contasts with the teeth in amiines where the bases of the teeth are typically oval and pressed closely together.

Remarks: Vidalamiines were one of the groups of fish that Brinkman et al. (2013) interpreted as being members of a southern assemblage because they are consistently present in the Kaiparowits Formation of Utah, as well as earlier localities in that region, but absent in the Belly River Group of Alberta and the Judith River Formation of Montana. Their presence in the Milk River Formation shows that in the late Santonian, the range of vidalamiines extended further north than it did in the late Campanian.

\section{Subfamily AMIINAE Bonaparte, 1838 Genus et sp. indet. \\ Fig. 6}

Voucher specimens: UALVP 48860, precaudal centrum morphotype A, UALVP locality MR6, Verdigris Coulee, Alberta; UALVP 17417, three precaudal centra, UALVP locality MR6, Verdigris Coulee, Alberta; UALVP 48861, precaudal centrum morphotype B, UALVP locality MR6, Verdigris Coulee, Alberta; UALVP 48862, caudal centrum, UALVP locality MR6, Verdigris Coulee, Alberta; UALVP 56825, centrum from UALVP locality MR8, Verdigris Coulee, Alberta; UALVP 56842, five centra, from UALVP locality MR6,
Verdigris Coulee, Alberta; centrum, from UALVP locality MR6, Verdigris Coulee, Alberta; UALVP 56899, centrum, from UALVP locality MR6, Verdigris Coulee, Alberta.

Description: Amiinae are represented in the Milk River Formation by centra. Two distinct centrum morphotypes are present, here designated amiid centrum morphotype $A$ and amiid centrum morphotype B. Amiid centrum morphotype A (Fig 6A, B) includes centra that are short and wide, have neural arch articular pits that are distinctly bilobed in shape, and have a pair of closely spaced, elongate narrow aortal facets ventrally. The parapophyses are short or represented by small, circular opening located on the lateral surface of the centrum. Based on a comparison with the extant genus Amia calva as described and illustrated by Grande and Bemis (1998), the centra of this morphotype are from all but the anterior-most few vertebrae of the precaudal portion of the vertebral column.

The centra included in amiid centrum morphotype B (Fig. 6C-E) lack parapophyses and have small, circular aortal arch facets. As well, the neural arch articular facets are wider medio-laterally and tend to be more nearly rectangular in shape. The height of the centrum varies from wider than high (Fig. 6C) to higher than wide (Fig. 6E). Based on comparison with Amia calva, the centra of this morphotype are from the anterior few vertebrae of the vertebral column.

Remarks: The diversity of small-bodied amiids in the non-marine Late Cretaceous is currently poorly understood. Based on the morphological diversity of amiine centra from localities in the Grand Staircase-Escalante region of southern Utah, Brinkman et al. (2013) assumed that multiple taxa were present, although they did not attempt to diagnose individual taxa. Brinkman et al. (2014) recognized two distinct amiines in the Hell Creek Formation differing in size. The differences were considered taxonomic rather than age related because growth trajectories interpreted on the basis of growth lines on the ends of the centrum differed, with the small centra being from indivduals with a slower growth rate.

Order ASPIDORHYCHIFORMES Bleeker, 1859 Family ASPIDORHYNCHIDAE Nicholson and Lydekker, 1889

Belonostomus longirostris (Lambe 1902)

Fig. 7

Voucher specimen: UALVP 17423, presymphyseal element, UALVP locality MR6, Verdigris Coulee, Alberta.

Description: The aspidorhynchiform, Belonostomus is represented in the Milk River Formation by a fragment of a presymphyseal element (Fig. 7). This is similar to Belonostomus jaw elements in being a narrow U-shape in cross section and in containing a single row of large teeth along the midline and tiny close-set teeth along the lateral 
margin. Enamel is present on the external surface of the element, as in adult specimens of Belonostomus longirostris from younger formations.

Remarks: Belonostomus was present in South America in the Jurassic (Leanza and Zeiss 1990) and is present in marine localities of Early Cretaceous age in North America. It is absent in the Cenomanian to Campanian localities in
Utah (Brinkman et al. 2013).

Division TELEOSTEOMORPHA Arratia, 2001 Subdivision TELEOSTEI Müller, 1845 (sensu Patterson and Rosen, 1977)

Cohort ELOPOMORPHA Greenwood, Rosen,

Weitzman, and Myers, 1966
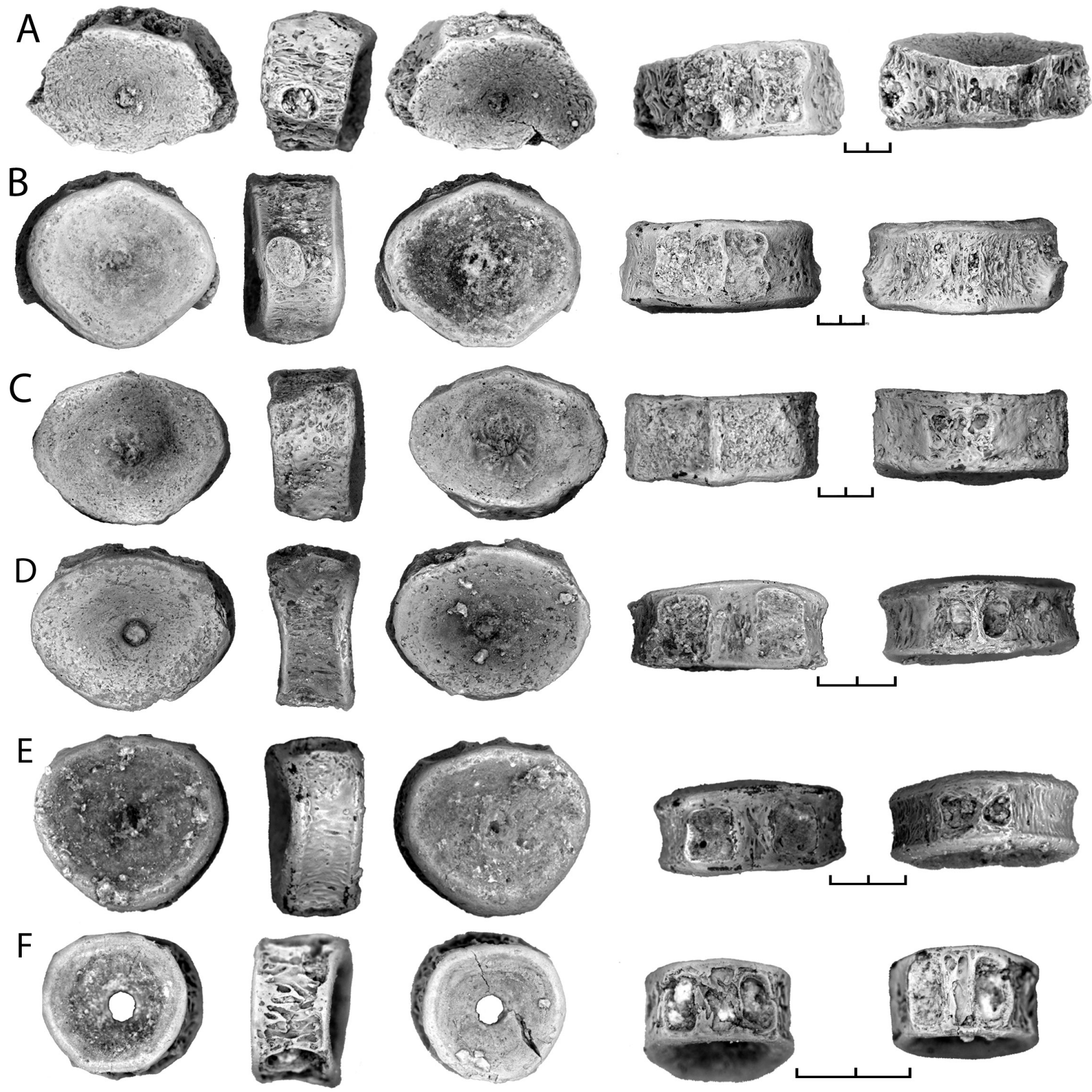

Figure 6. Amiinae centra from the Milk River Formation. A) Amiinae centrum morphotype A, UALVP 48860. B) Amiinae centrum morphotype A, UALVP 17417. C) Amiinae centrum morphotype B, UALVP 17417. D) Amiinae centrum morphotype B, UALVP 17417. E) Amiinae centrum morphotype B, UALVP 48861. F) Amiinae caudal centrum, UALVP 48862. Centra shown in anterior, left lateral, posterior, dorsal and ventral views. Scale bar equals $2 \mathrm{~mm}$. 

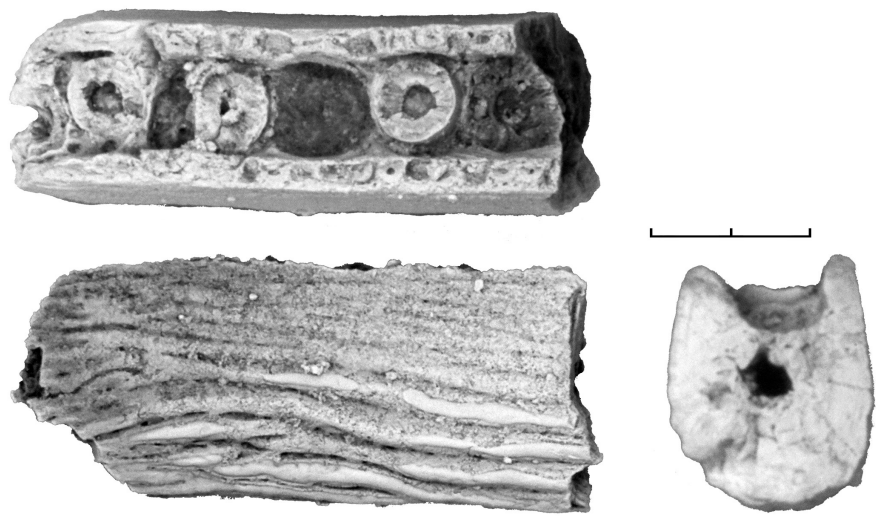

Figures 7. Belonostomus sp. jaw fragment. UALVP 17423.
Order ELOPIFORMES Greenwood, Rosen, Weitzman, and Myers, 1966

Suborder indet.

Genus et sp. indet.

Fig. 8A.

Voucher specimen: UALVP 48863, precaudal centrum, from UALVP locality MR6, Verdigris Coulee, Alberta; UALVP 56826, centrum, from UALVP locality MR8, Verdigris Coulee, Alberta; UALVP 56843, from UALVP locality MR6, Verdigris Coulee, Alberta; UALVP 56889, partial centrum, from UALVP locality MR6, Verdigris Coulee, Alberta; TMP 2000.1.66 two precaudal centra, from TMP locality L1145, Verdigris Coulee, Alberta.
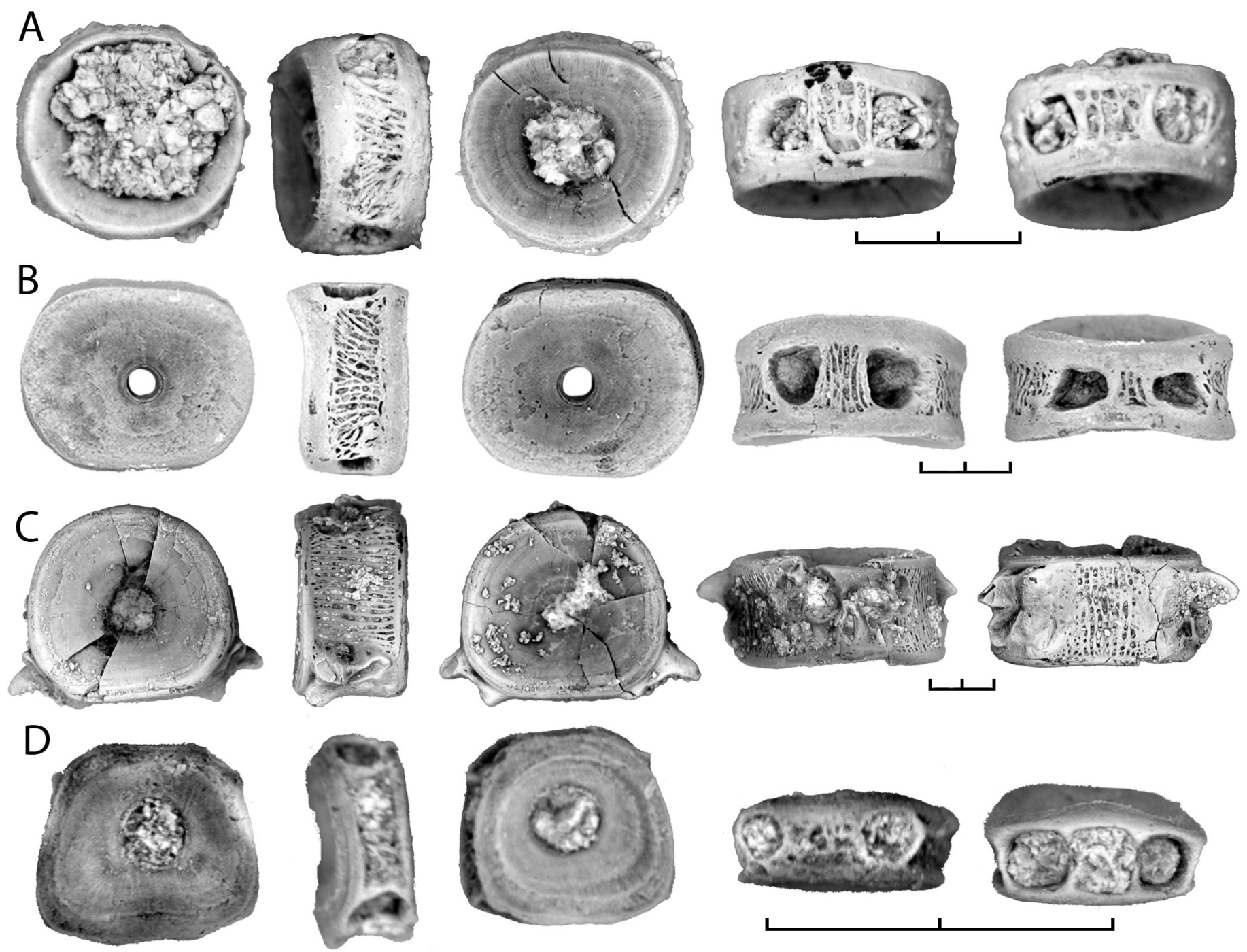

Figure 8. Elopomorpha gen. indet. centra from the Milk River Formation compared with small elopomorph centra from the Turonian of Utah and Campanian of Alberta. A) Elopomorpha gen. indet. centrum from Milk River Formation, UALVP 48863. B) Elopomorpha gen. indet. centra from the late Campanian Dinosaur Park Formation, TMP 97.19.11. C) Elopomorpha gen. indet. centrum from the Cenomanian Dakota Formation of Utah, specimen MNA V10321. D) Elopomorpha gen. indet. centrum from the Turonian Smoky Hollow Member of the Straight Cliffs Formation, specimen OMNH 31248. Centra shown in anterior, left lateral, posterior, dorsal and ventral views. C from Brinkman et al. (2014: fig. 10.14B)Scale bar equals 2 mm. 
Description: The presence of a small elopomorph in the Milk River Formation fish assemblage is documented by centra (Fig. 8A) that resemble those of the extant genus Elops Forsskål, 1775, in being anteroposteriorly short, having a wide space between the neural arch and parapophyseal articular pits, and in that the lateral wall of the centrum has numerous fibers of bone extending between the anterior and posterior ends of the centrum. The neural arch articular pits are small, shallow, circular, pits bordered posterolaterally by a raised edge. Parapophyseal pits are spaced slightly further apart from one another than are the neural arch pits. Variation in the spacing of the parapophyseal articular pits likely reflects variation along the column.

Remarks: As discussed by Brinkman et al. (2013), elopomorphs are represented in Cretaceous microvertebrate sites in Alberta and Utah by both elopiforms and albuliforms. Elopiform centra can be distinguished from those of albuliforms by the arrangement of the bony fibers that extend between the ends of the centrum. Albuliforms, such as the extant genus Albula and the Albula-like centra that Neuman and Brinkman (2005) referred to Paralbula, have bony fibers that are grouped together into bundles forming ridges, whereas the centra of the small-bodied elopomorph from the Milk River Formation are similar to the centra of the extant elopiforms Megalops and Elops in having bony fibers that are evenly spaced. Furthermore, these centra are unlikely to be those of an albuliform because the only albulid that is known to occur in non-marine sediments of Campanian age, Paralbula, is typically represented by isolated teeth, and these are not represented in the Milk River Formation.

At least two elopiforms are present in the Belly River Group of Alberta: the large bodied Paratarpon, which has centra that are typically $2 \mathrm{~cm}$ in diameter (Brinkman and Neuman 2002), and a small-bodied taxon with centra that are typically about $5 \mathrm{~mm}$ in diameter (Fig. 8B). Paratarpon is restricted to the Dinosaur Park Formation of Alberta, but the small elopiform is also present in the Late Cretaceous of southern Utah (Fig.8C, D). Since the distribution of the small elopiform differs from that of Paratarpon, the small elopiform centra are interpreted as taxonomically distinct, rather than juvenile individuals of the much larger taxon. The elopiform centra from the Milk River Formation most closely match those of the small elopiform centra of the Dinosaur Park Formation and southern Utah.

\section{Cohort ?OSTEOGLOSSOMORPHA Greenwood, Rosen, Weitzman, and Myers, 1966 Order INCERTAE SEDIS Family OSTARIOSTOMIDAE Shaeffer, 1949 Ostariostoma Shaeffer, 1949}

\section{Ostariostoma sp.}

Fig. 9

Voucher specimens: UALVP 40928 dentary, UALVP locality MR6, Verdigris Coulee, Alberta; UALVP 56047, dentary, from UALVP locality MR20, Verdigris Coulee, Alberta.

Description: The presence of Ostariostoma in the Milk River Formation is documented by dentaries (Fig. 9B-D) that are similar to those of the type specimen of Ostariostoma wilseyi (Fig. 9A) in having a relatively dorso-ventrally shallow anterior end with a single row of large teeth and a series of three very large sensory canal pores near the ventral edge of the anterior end of the dentary. Tooth bases, when preserved, are circular with the bases of adjacent teeth just touching one another. The Milk River specimens differ from the dentary visible in the type specimen slightly in that the sensory canal pores are antero-posteriorly elongate and the length of the pores is greater than the distance between individual pores. However, this difference is interpreted as significant at a low taxonomic level.

Remarks: Ostariostoma is one of the few teleosts from the Late Cretaceous or early Paleocene represented by an articulated skeleton (Shaeffer 1949; Grande and Cavender 1991). The single specimen, which is from the late Maastrichtian to lower Paleocene Livingstone Group in Montana, is preserved as an impression in a hard mudstone. Fine detail is present in the natural mold, allowing for detailed descriptions based on latex peels taken from the original specimen (Grande and Cavender 1991). The dentaries here referred to Ostariostoma provide the first evidence for the genus outside the Livingstone Formation. In addition to the Milk River Formation, Ostariostoma dentaries are present in the late Campanian Belly River Group of Alberta (Fig. 9E), where they were described by Neuman and Brinkman (2005; fig. 9.7D) as teleost unidentified dentary \#4. They are also present in the late Maastrichtian Lance Formation of Wyoming (Fig. 9F). These Campanian and Maastrichtian dentaries differ from the Milk River Formation specimens in that the sensoy canal pores are smaller and more circular and the tooth bases are larger and medio-laterally elongate, rather than circular in cross section. These differences are likely the result of low-level taxonomic diversity within the genus. Dentaries of Ostariostoma were not observed in the vertebrate microfossil localities in Utah (Brinkman et al. 2013), or the Hell Creek Formation of Montana (Brinkman et al. 2014). These occurrences indicate that Ostariostoma had a patchy distribution in the Late Cretaceous but was not latitudinally restricted. 


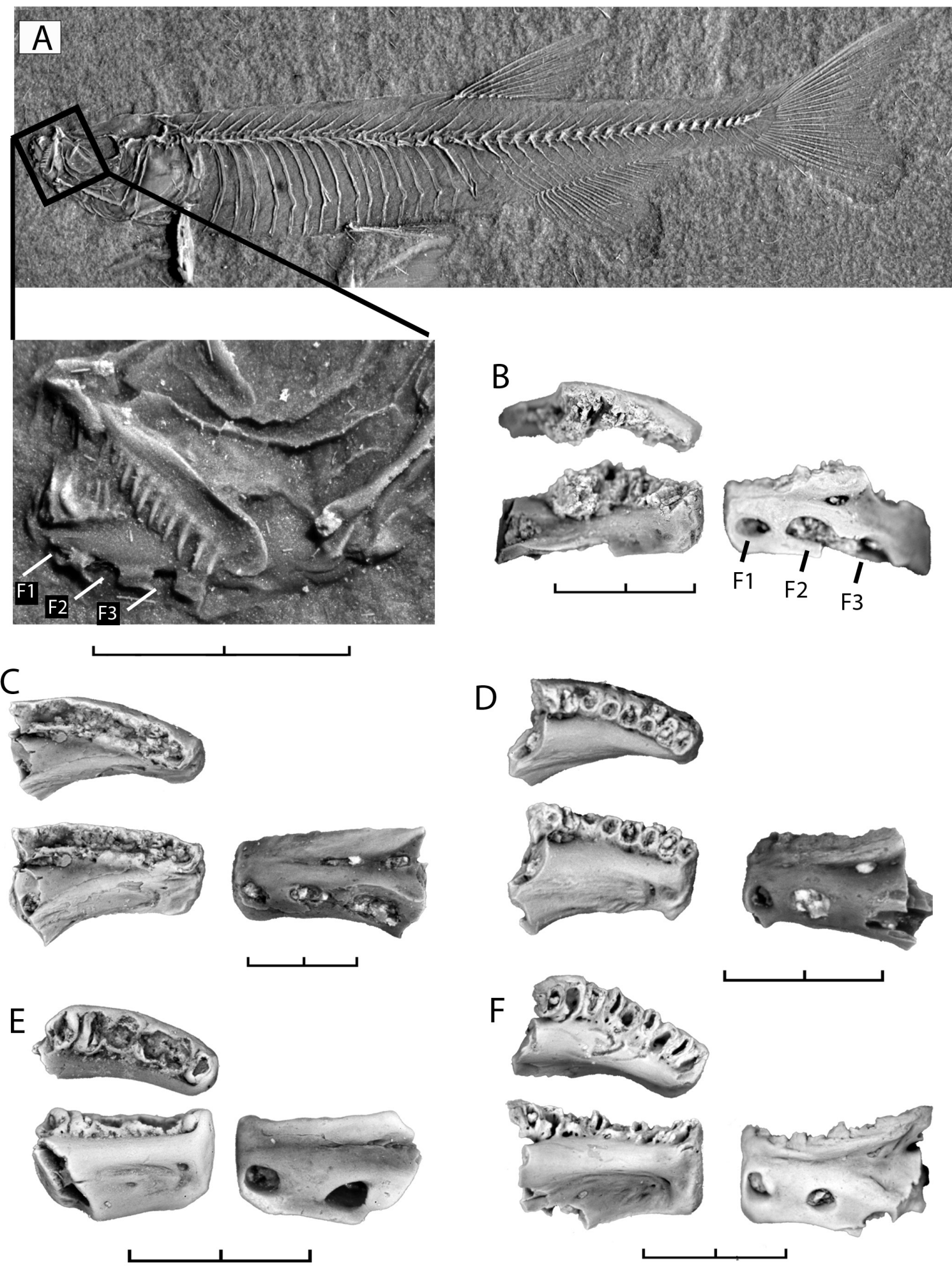

Figure 9. Ostariostoma sp. dentaries and maxilla from the Milk River Formation compared with the type specimen of Ostariostoma wilseyi and specimens from the late Campanian of Alberta and the late Maastichtian of Wyoming. A) Ostariostoma wilseyi skeleton with close-up of the skull showing dentary, and maxilla, photograph of UALVP 52610, cast of type specimen. B-D) dentary of Ostariostoma sp. from the Milk River Formation, showing variation in development of tooth row and sensory canal pores: B, UALVP 40928. C-D, both UALVP 56047. E) dentary of Ostariostoma sp. from the late Campanian Dinosaur Park Formation, TMP 2017.60.1. F) dentary of Ostariostoma sp. from the late Maastrichitan Lance Formation, UALVP 56053. Abbreviations: F1, foramen 1; F2, foramen 2; F3, foramen 3 of the sensory canal on the dentary. Scale bar equals $2 \mathrm{~mm}$. 


\section{? Ostariostoma sp.}

Figs. 10B, C; 11A, B

Voucher specimens: UALVP 48897, mid precaudal centrum, UALVP locality MR6, Verdigris Coulee, Alberta; UALVP 48895, posterior precaudal centrum, UALVP locality MR6, Verdigris Coulee, Alberta;UALV 56898, three centra, centra, from UALVP locality MR6, Verdigris Coulee, Alberta; UALVP 48899, anterior-most precaudal centrum, UALVP locality MR6, Verdigris Coulee, Alberta; UALVP 48901, anterior-most precaudal centrum, UALVP locality MR20, Verdigris Coulee, Alberta.

Description: The likelihood that Ostariostoma sp. centra are present in the Milk River Formation is thought to be high since dentaries, which are relatively abundant, are generally underrepresented in vertebrate microfossil sites compared with centra. Although details of the structure of the vertebrae of Ostariostoma are not visible on the type specimen, a number of general features can be recognized (Fig. 10A). Most notably, centra are relatively elongate and the neural arches have a ridge extending from the lateral surface of the arch onto the anterior half of the centrum. Ribs articulate with the lateral surface of the centrum below this ridge. Parapophyses are not visible, so would have been fully covered by the rib.

Only one of all the teleost centrum morphotypes from the Milk River Formation, here designated teleost centrum morphotype $\mathrm{H}$, is similar to the centra of Ostariostoma in being elongate and having a ridge that extends from the neural arch to the parapophyseal articular pit. The parapophyses of mid-precaudal centra of morphotype $\mathrm{H}$, which are occasionally preserved in place (Fig. 10B), are short, as is likely also the case in Ostariostoma since the head of the ribs fully cover the parapophyses. Also, the parapophysis is located on the side of the centrum, although this in a more anterior position in Ostariostoma than in centra morphotype $\mathrm{H}$. Teleost centrum morphotype $\mathrm{H}$ is represented by two variants, $\mathrm{HvB}$ and $\mathrm{HvA}$. These are interpreted as representing different regions from along the vertebral column, with $\mathrm{HvB}$ being the anterior-most precaudal centrum, and HvA being more posterior precaudal centra.

Centrum morphotype HvA (Fig. 10B-E) include the centra that are most similar to those of Ostariostoma. The centrum is longer than wide. Neural arches are fused to the centrum, and a narrow ridge extends along the side of the neural arch base to the parapophyseal articular pit. Parapophyses are autogenous in the mid and anterior regions of the precaudal series (Fig. 10B) and fused to the centrum in the posterior region (Fig. 10C). The parapophyses, which are occasionally preserved in place (Fig. 10B), are short. The ventral surface of the centrum is flat and has a mid-ventral pit. Specimens of centrum morphotype HvA from the Milk River Formation (Fig. 10B, C) differ little from the centra of this morphotype from the Dinosaur Park Formation described by Brinkman and Neuman (2005) (Fig. 10D) or the Lance Formation of Wyoming (Fig. 10E).

Centrum morphotype $\mathrm{HvB}$ is similar to HvA in being longer than wide and having a flat ventral surface with a distinctive, sub-rectangular mid-ventral pit. These centra differ in that neural arches are not fused to the centrum and parapophyses are absent. The neural arch articular pits are distinctive oval pits that and are separated from each other by a narrow bar of bone. Centra from the Milk River Formation included in morphotype HvB (Fig. 11A, B) differ little from centra of this morphotype from the Dinosaur Park Formation described by Neuman and Brinkman (2005) (Fig. 11C) and the Smokey Hollow Member of the Straight Cliffs Formation described by Brinkman et al. (2013) (Fig. 11D). Signficantly, centrum morphotype $\mathrm{HvB}$ are also present in the Eocene Wasatch Formation, where it was identified by that Divay and Murray (2016) as the Weberian centrum of a gonorynchiform. The Cretaceous specimens (Fig. 11A-D) are similar to the Eocene specimens (Fig. 11E) in proportions, shape of the neural arch pit, development of the mid-ventral pit on the ventral surface of the centrum, and in the lack of parapophyses.

Remarks: Centrum morphotype $\mathrm{H}$ is questionably attributed to Ostariostoma because it is the only centrum morphotype present in the Late Cretaceous of the Western Interior that is similar to the type specimen of Ostariostoma in being relatively elongate and having a ridge extending from the side of the neural arch to the dorsal edge of the parapophyses. However, the conclusion that teleost centrum morphotype $\mathrm{H}$ is from Ostariostoma has implications for interpretations of the phylogenetic relationships of the genus since the similarity of centrum morphotype $\mathrm{HvB}$ and the Weberian centrum of a gonorynchiform illustrated by Divay and Murray (2016) points to ostariophysan rather than an oseoglosomorph affiliations. Ostariophysan relationships were rejected by Grande and Cavender (1991) because no modification of the anterior vertebral elements could be seen in the articulated skeleton of Ostariostoma wilseyi. However, in gonorynchiforms such as Notogoneus the first three centra are modified but the modifications are difficult to observe in articulated specimens. Thus although phylogenetic questions are raised, to minimize the risk that diversity of the assemblage is inflated as a result of different parts of the skeleton of a single kind of fish being referred to different taxa, centrum morphotype $\mathrm{H}$ is questionably referred to Ostariostoma. Although ostariophysan relationships are indicated by the apparent presence of a gonorhynchiform-like Weberian centrum, pending a comprehensive phylogenetic analysis, Ostariostoma is retained in the Osteoglossiformes. 

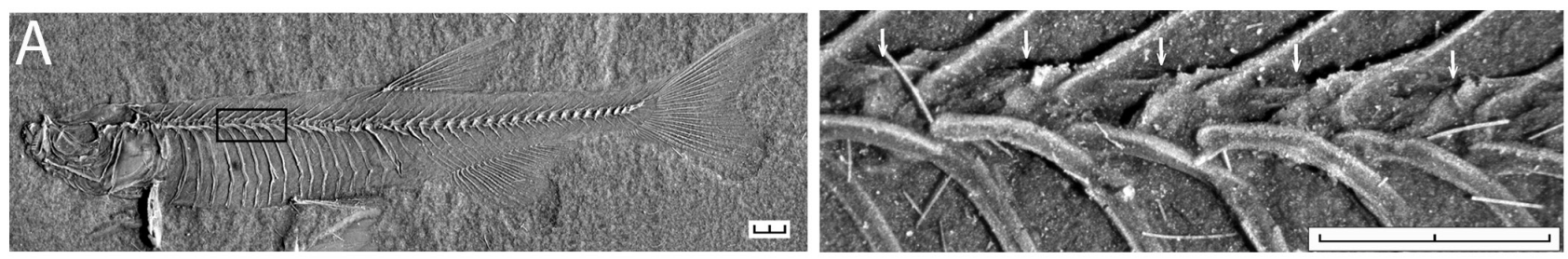

$\mathrm{B}$
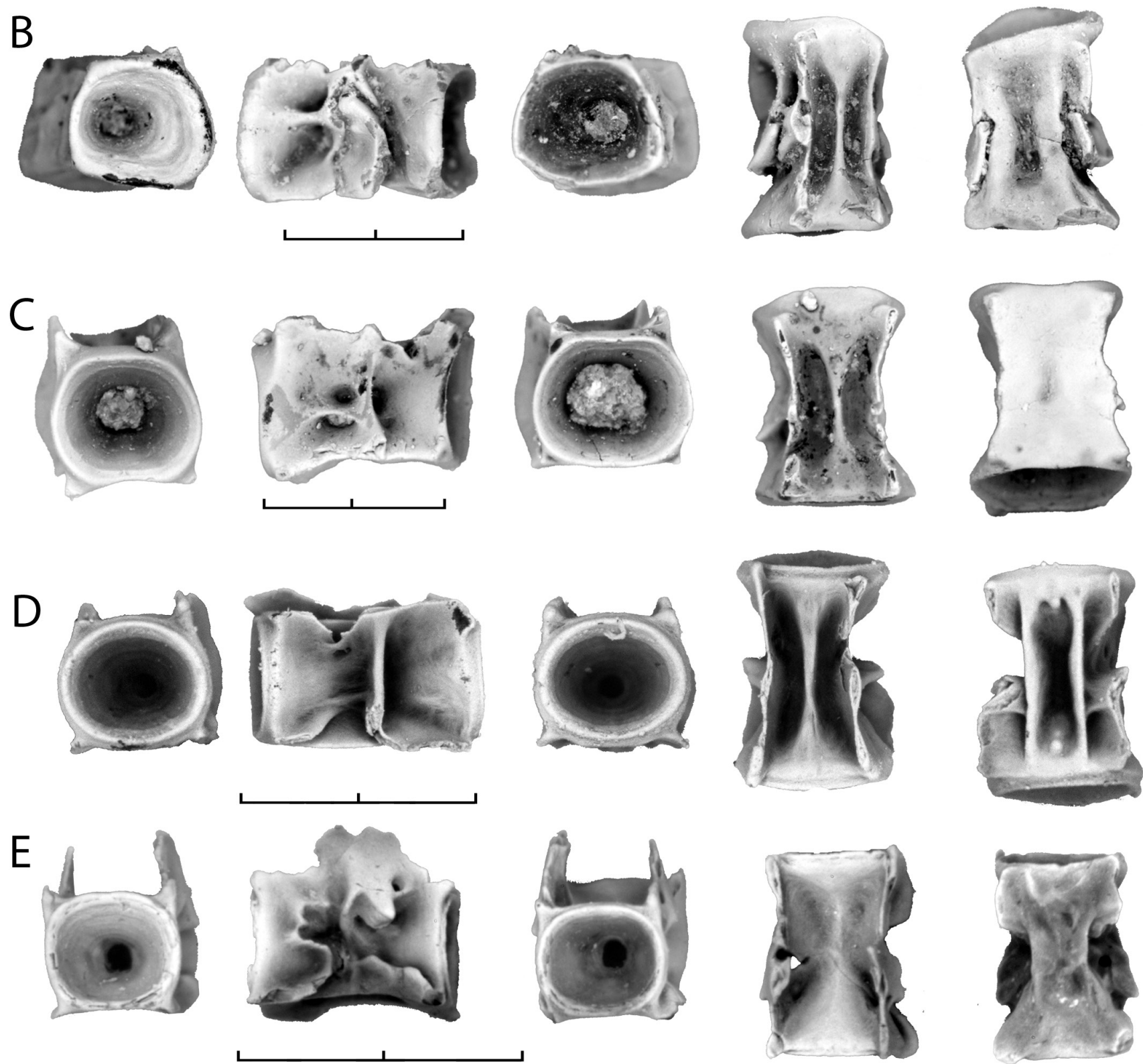

Figure 10. Centrum morphotype HvA from the Milk River Formation compared with vertebrae of the type specimen of Ostariostoma wilseyi and with specimens from the Belly River Group and Lance Formation. A) Ostariostoma wilseyi skeleton with close-up of the mid-precaudal region of the vertebral column showing proportions of precaudal centra. Arrows indicate the approximate position of the ends of the centra. Photograph of UALVP 52610, cast of type specimen. B, C) examples of centrum morphotype HvA from the Milk River Formation showing variation in the development of the parapophyses: B, mid precaudal centrum with autogenous parapophyses preserved in articulation with the centrum, UALVP 48897; C, posterior precaudal centrum with parapophyses fused to the centrum, UALVP 48895. D) Centrum morphotype HvA from the Belly River Group, specimen TMP 1993.91.29. E) Centrum morphotype HvA from the Lance Formation, uncatalogued UALVP specimen from Bushy Tail Blowout locality, Lance Formation, Wyoming. Scale bar equals $2 \mathrm{~cm}$. 

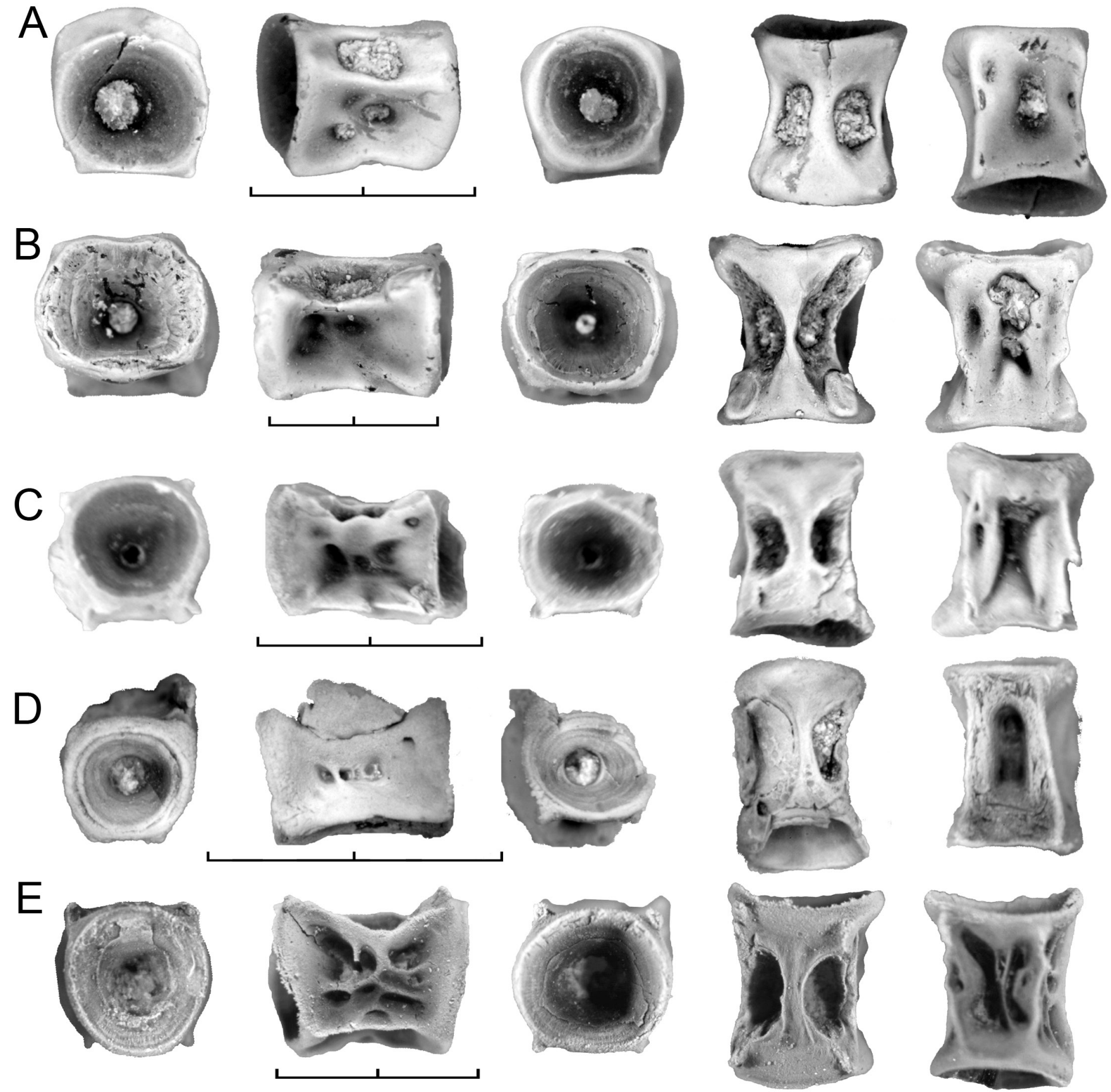

Figure 11. Centra morphotypes HvB from the Milk River Formation compared with specimens from the Belly River Group, Smokey Hollow Member of the Straight Cliffs Formation of Utah, and Wasatch Formation of Wyoming. A, B) centrum morphotype HvB from the Milk River Formation, showing variation in the development of the neural arch articular pits; A, specimen UALVP 48899; B, specimen UALVP 48901. C) Centrum morphotype HvB from the Dinosaur Park Formation of Alberta, specimen TMP 2000.22.11. D) Centrum morphotype HvB from the Smokey Hollow Member of the Straight Cliffs Formation of Utah, specimen OMNH 31322. E) Weberian centrum (UCMP V198889 Illa) of the Wasatch Formation gonorynchiform. C and D from Brinkman et al. (2013: Fig. 10.26) E from Divay and Murray (2016: fig. 4A). Centra shown in anterior, left lateral, posterior, dorsal and ventral views. Scale bar equals $2 \mathrm{~mm}$. 
Order OSTEOGLOSSIFORMES Berg, 1940

Family Incertae sedis

Wilsonichthys Murray, Newbrey, Neuman, and Brinkman, 2016 Wilsonichthys sp.

Figs. 12, 13

Voucher specimens: UALVP 49030, dentary, UALVP locality MR20, Verdigris Coulee, Alberta; UALVP 48888, centrum, UALVP locality MR6, Verdigris Coulee, Alberta; UALVP 48889, centrum, UALVP locality MR6, Verdigris Coulee, Alberta; UALVP 5844, ten centra, from UALVP locality MR6, Verdigris Coulee, Alberta; UALVP 56897, thirty-one centra, centra, from UALVP locality MR6, Verdigris Coulee, Alberta; UALVP 56827, twelve centra, from UALVP locality MR8, Verdigris Coulee, Alberta; TMP 2000.001.0070, six precaudal centra, TMP locality L1145, Verdigris Coulee, Alberta; TMP 2000.2.61, ten centra, TMP locality Michael's Site, Verdigris Coulee, Alberta.

Description: Wilsonichthys is a basal osteoglossomorph represented by two articulated skeletons from the late Maastrichtian Scollard Formation. From a comparison with elements visible in these specimens, isolated dentaries, maxillae, and centra from vertebrate microfossil localities of the same age were referred to this taxon by Murray et al. (2016). The dentary was represented by two isolated specimens (Fig. 12A, B) that matched the dentary of the type specimen (Fig. 12C) in proportions, relative size of teeth, and position of pores for the sensory canal. Based on comparison with these specimens, more complete dentaries from the Turonian Smokey Hollow Member of the Straight Cliffs Formation of Utah (Fig. 12D) and the Campanian Dinosaur Park Formation of Alberta (Fig. 12E) can also be referred to Wilsonichthys. As in the articulated specimen (Fig. $12 \mathrm{C}$ ), these isolated dentaries are relatively deep dorsoventrally. The tooth row consists of a single row of relatively large conical teeth on the anterior end of the dentary grading into a double row of slightly smaller teeth. The pores for the mandibular sensory canal are located in a groove that is located at about the middle of the lateral surface of the denary. The dorsal edge of the groove is formed by a sharp crest, while the ventral edge of the groove is smooth and rounded. Pores for the sensory canal are present on the middle of the external surface of the dentary, either in the form of a single, medio-laterally elongate pore (e.g., Fig. 12A) or a row of smaller pores located midway between the dorsal and ventral edges of the dentary (e.g., Fig. 12E). These form along a line in a narrow furrow that extends from the postero-ventral to antero-dorsal position on the dentary. The dentary is slightly thickened above this line of pores. On the inner surface of the isolated dentaries, there is a wide, smooth area below the tooth row. This ends in a sharp ridge that borders a broad, shallow groove on the ventral half of the inner surface of the bone. Both the smooth area below the tooth row and the shallow groove on the ventral half of the dentary extend anterior to the symphysis.

Dentaries of Wilsonichthys from the Milk River Formation are represented by relatively small sections of the tooth row (Fig. 12F, G). These are identified as Wilsonichthys because they share the presence of two rows of teeth and have a smooth area on the internal surface below the tooth row that forms the dorsal border of a broad shallow groove. As well, the absolute sizes of the element and the sizes of the tooth bases relative to the dorsoventral height of the element are similar to the referred dentaries.

Isolated maxillae from vertebrate microfossil localities in the Scollard Formation were referred to Wilsonichthys by Murray et al. (2016) on the basis of comparison with the articulated specimens. Similar elements are present in the Milk River Formation (Fig. 12H). As with the specimens from the Scollard Formation, the maxillae from the Milk River Formation are rod-like and bear teeth that are similar in size and implantation to those of the dentary.

Murray et al. (2016) concluded that centra previously described by Brinkman et al. (2014) as centrum morphotype BvarE were those of Wilsonichthys. These centra are abundant in the Milk River Formation (Fig. 13A, B). As with specimens from the late Campanian (Fig. 13C, D) and late Maastrichtian (Fig. 13D-F), the centra are slightly longer than wide, the neural arch is fused to the centrum, parapophyses are autogenous with a large shallow excavated area present on the side of the centrum for the parapophyses, a mid-dorsal pit is present, and the centrum is without processes on the posterior end. The range of variation in BvarE centra from the Milk River Formation differs from that described previously in that some specimens have a solid ventral surface (Fig. 13B) while others have a mid-ventral pit (Fig. 13A). This is assumed to be either a result of individual variation or of species-level significance.

Remarks: The isolated dentaries attributed to Wilsonichthys show that it extended from the Turonian to the end of the Late Cretaceous. Based on the relative number of centra recovered, Wilsonichthys is the second most abundant teleost in the Milk River Formation (Tab. 1).

Order HIODONTIFORMES McAllister, 1968

Family HIODONTIDAE Cuvier and Valenciennes, 1846 Genus et sp. indet.

Fig. 14A, D-F.

Voucher specimens: TMP 2000.2.55, seven centra, including one first centrum, TMP locality Michael's site; UALVP 56845, four centra, from UALVP locality MR6, Verdigris Coulee, Alberta; UALVP 56896, seven centra, centra, from UALVP locality MR6, Verdigris 

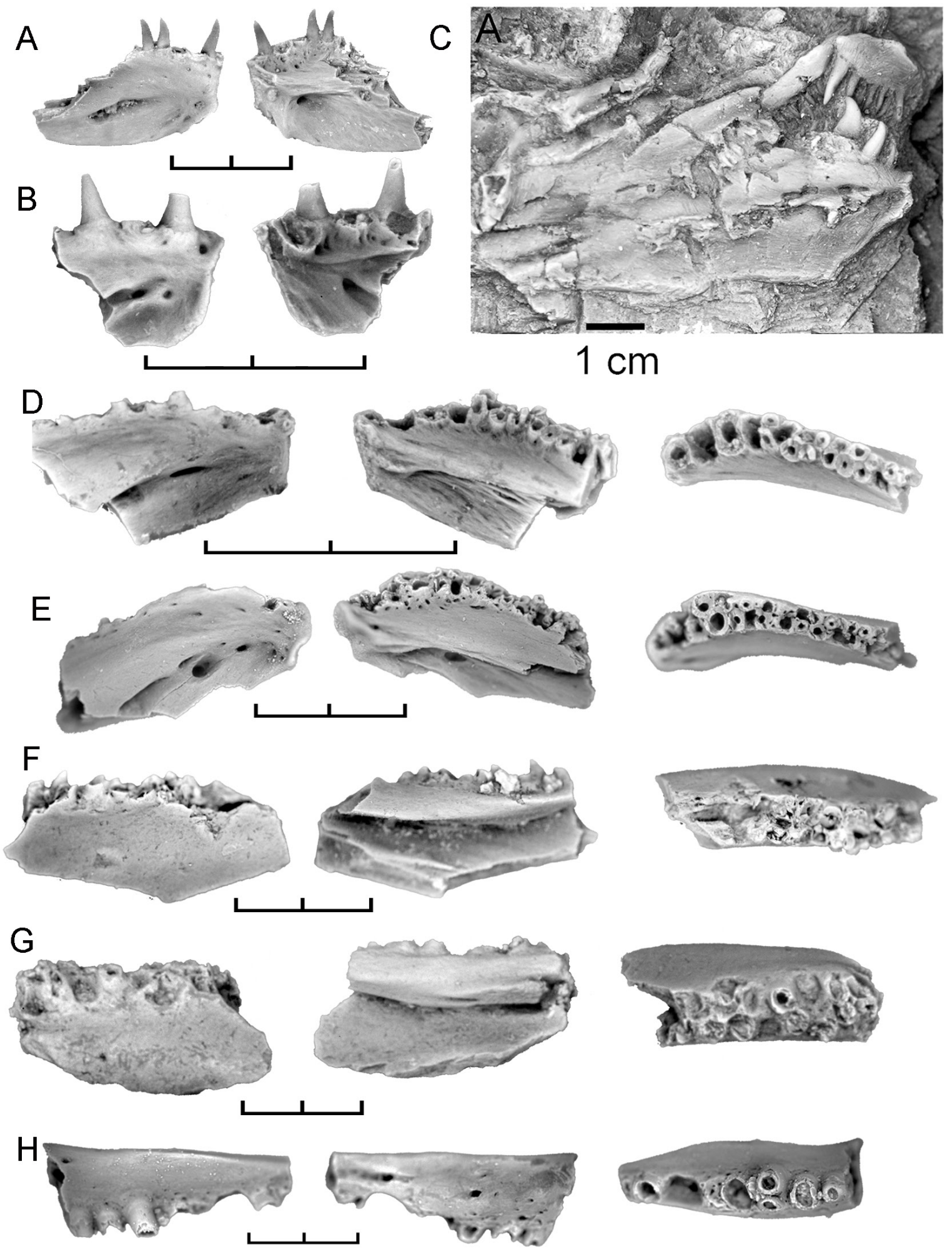

Figure 12. Dentaries and maxillae of Wilsonichthys from the Milk River Formation compared with specimens from late Maastrichtian of Alberta, and Montana and the Turonian of Utah. A) dentary referred to Wilsonicththys sp., from the Hell Creek Formation, UCMP 198883/V99369. B) dentary referred to Wilsonichthys sp., from the Scollard Formation, TMP 2009.13.62. C) close up photo of the dentary, maxilla, and premaxilla of the holotype of Wilsonichthys aridinsulensis, TMP 2012.020.1493, Scollard Formation. D) dentary referred to Wilsonichthys sp., from the late Turonian Smoky Hollow Member of the Straight Cliffs Formation of Utah, from locality MNA995. E) dentary referred to Wilsonichthys sp., from late Campanian Dinosaur Park Formation, TMP 95.180.61. F-G) dentary fragments from the Milk River Formation referred to Wilsonichthys sp. F, UALVP 49030; G, UALVP 34770. H) maxilla from the Milk River Formation referred to Wilsonichthys sp., UALVP 49029. A from Brinkman et al. (2014: fig. 12A). Scale bar equals 2 mm. 

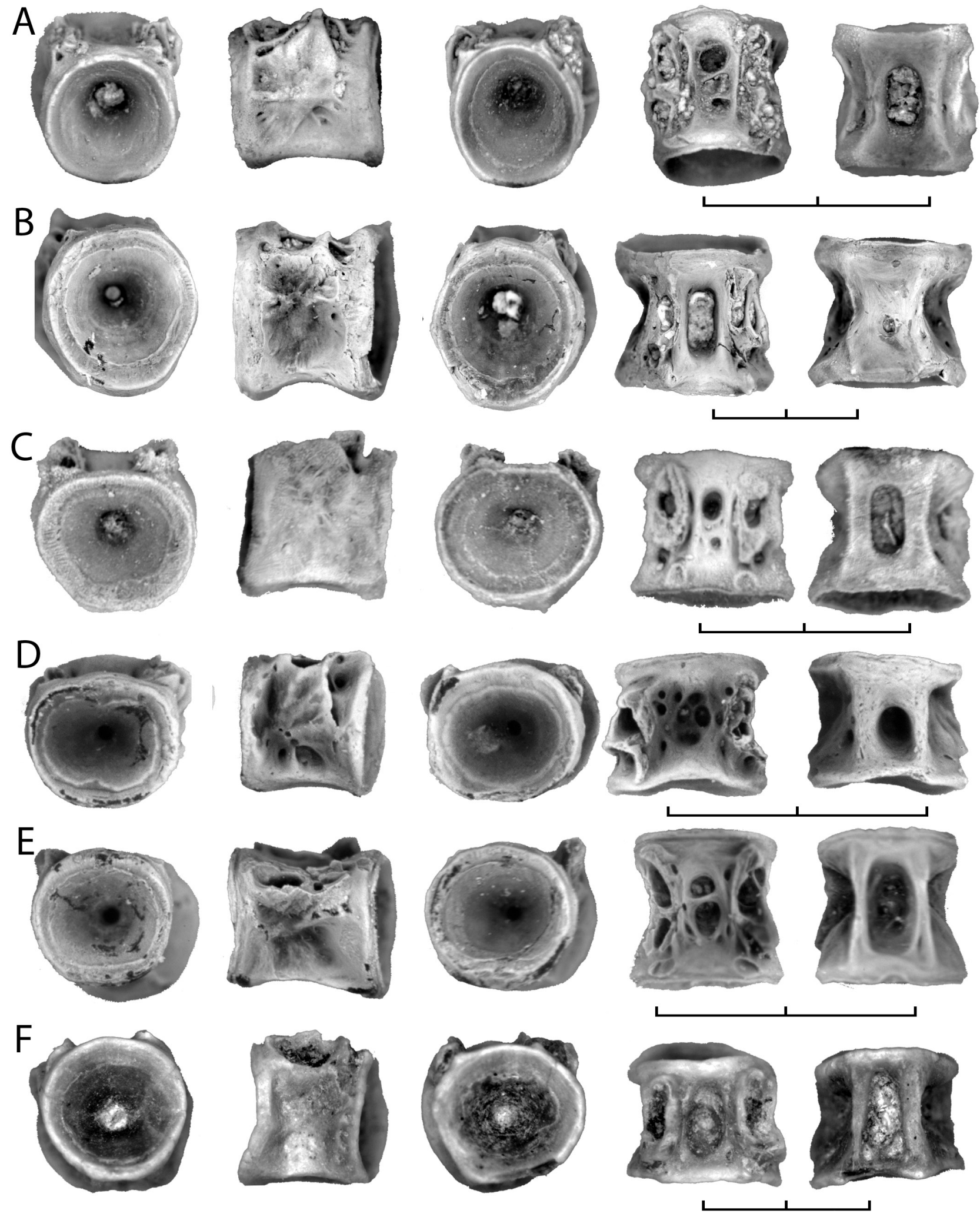

Figure 13. Centrum of morphotype BvarE, tentatively referred to Wilsonichthys, from the Milk River Formation, the late Campanian of Utah and Alberta, and the late Maastrichitan of Wyoming A-B) centra from the Milk River Formation, showing variation in the development of the mid-ventral pit: A, UALVP 48888; B, UALVP 48889. C) centrum from the late Campanian Kaiparowits Formation of Utah, OMNH 23786. D) centrum from the late Campanian Belly River Group of Alberta, TMP 95.182.50. E) centrum from the late Maastrichtian Hell Creek Formation of Montana, specimen UCMP 191697/V99369. F) centrum from the late Maastrichtian Lance Formation of Wyoming, UALVP 56054. Centra shown in anterior, left lateral, posterior, dorsal and ventral views. C from Brinkman et al. (2013: fig. 10.27A). Scale bar equals 2 mm. 
Coulee, Alberta; UALVP 17397, anterior precaudal centrum UALVP locality MR8; UALVP 48881, mid precaudal centrum, UALVP locality MR8; UALVP 48880, posterior precaudal centrum, UALVP locality MR8; UALVP 56828, 2 precaudal centra, from UALVP locality MR8, Verdigris Coulee, Alberta; UALVP 56049, dentary, UALVP locality MR20. All from the Milk River Formation, Verdigris Coulee, Alberta.

Description: The presence of a hiodontid in the Milk River Formation is documented by centra that closely resemble those of the hiodontid from the Campanian Dinosaur Park Formation described by Brinkman and Neuman (2002) in the shape of the neural arch articular pits, parapophyses, and shape of the rib articular pits on the side of the centrum posterior to the parapophyses. The first centrum (Fig. 14A) is particularly distinctive in hiodontids. This element, like that of the extant Hiodon (Fig. 14C), has a distinctive flat, four-lobed anterior articular surface (Fig. 14A). The shape of the first centrum from the Milk River Formation differs from the corresponding element from the Dinosaur Park Formation (Fig. 14B) primarily in that the notochordal canal is larger. The more posterior precaudal centra (Fig. 14D-F) conform to the general hiodontid morphology in having a shallow, oval neural arch articular pit and rib articular pits posterior to the parapophyses. Smaller precaudal centra tend to have flat ventral surfaces, and larger precaudal centra have a ventral surface that is formed by a network of bone, resulting in small pits evenly distributed across this surface. In the most posterior precaudal centra the neural arch is fused to the centrum (Fig. 14F).

Remarks: Hiodontid centra are present in both Utah and Alberta throughout the Late Cretaceous, typically in low abundance. This is also the case with the Milk River Formation.

Cohort OTOCEPHALA Johnson and Patterson, 1996 Superorder CLUPEOMORPHA Greenwood, Rosen, Weitzman, and Myers, 1966

Order ELLIMMICHTHYIFORMES Grande, 1985 Family Incertae Sedis Horseshoeichthys Newbrey, Murray, Brinkman, Wilson, and Neuman, 2010 Horseshoeichthys sp. Fig. 15

Voucher specimens: UALVP 48031, dentary, UALVP locality MR20, Verdigris Coulee, Alberta; UALVP 48874 , anterior precaudal centrum, UALVP locality MR6, Verdigris Coulee, Alberta; UALVP 48871, UALVP 48872, UALVP 48873, precaudal centra, UALVP locality MR20, Verdigris Coulee, Alberta; UALVP 17417, precaudal centra, UALVP locality MR6, Verdigris Coulee, Alberta; UALVP 56846, five anterior precaudal centra, from UALVP locality MR6,
Verdigris Coulee, Alberta; UALVP 56888, seven anterior precaudal centra, centra, from UALVP locality MR6, Verdigris Coulee, Alberta; UALVP 56887, 5 posterior precaudal centra, centra, from UALVP locality MR6, Verdigris Coulee, Alberta; UALVP 56847, nine posterior precaudal centra, from UALVP locality MR6, Verdigris Coulee, Alberta; UALVP 56829, precaudal centrum, from UALVP locality MR8, Verdigris Coulee, Alberta.

Description: Horseshoeichthys is represented in the Milk River Formation by a dentary and centra. The dentary is like that of the type specimen of Horseshoeichthys (Fig. 15A, B) in being robust, short, and relatively deep. The symphysis is a small, subovate, surface located in the upper half of the anterior end of the jaw. A large mandibular sensory canal pore is present near the anterior end of the jaw. The sensory canal also opens medially via a small round foramen located just below the symphysis. A thickened buttress extends posteriorly from the symphysis on the internal surface of the dentary.

All precaudal centra have autogenous neural arches and parapophyses. The anterior-most precaudal centrum (Fig. $15 \mathrm{D})$ is taller than long, and has a weakly concave anterior articular surface and a more deeply concave posterior articular surface. The neural arch articular pits extend for the anterior $75 \%$ of the length of the centrum and are deep and oval in shape. A pair of deep pits is present posterior to, and partially separating, the neural arch articular pits. The pits are separated from one another by a mid-dorsal ridge. Short ventro-laterally directed parapophyses are present. Distinct rib articular pits are absent. The ventral surface of the centrum between the parapophyses is relatively smooth and flat. This flat surface slopes ventrally from the anterior to the posterior end of the centrum. The more posterior precaudal centra (Fig. 15E, F) are as long as they are tall and are deeply amphicoelous. The arrangement of pits and ridges on the dorsal surface of the centrum are similar to the more anterior centra in that the neural arch articular pits are subcircular, deep, and partially separated by a pair of deep dorsal pits, which themselves are separated by a mid-dorsal ridge. Parapophyseal articular pits are present on the ventral half of the centrum. The centrum has a mid-ventral pit.

Remarks: Horseshoeichthys was erected by Newbrey et al. (2010) on the basis of a partial articulated skeleton from the Horseshoe Canyon Formation. This specimen is exceptional in that isolated three-dimensional precaudal centra are preserved, as well as clearly visible dentaries, allowing isolated elements to be referred to Horseshoeichthys with confidence, including a series of isolated centra and a dentary from the Milk River Formation. The genus was included in the family Sorbinichthyidae Bannikov and Bacchia, 2000 by Newbrey et al. (2010) because of its similarity to Diplomystus, which was included in that 

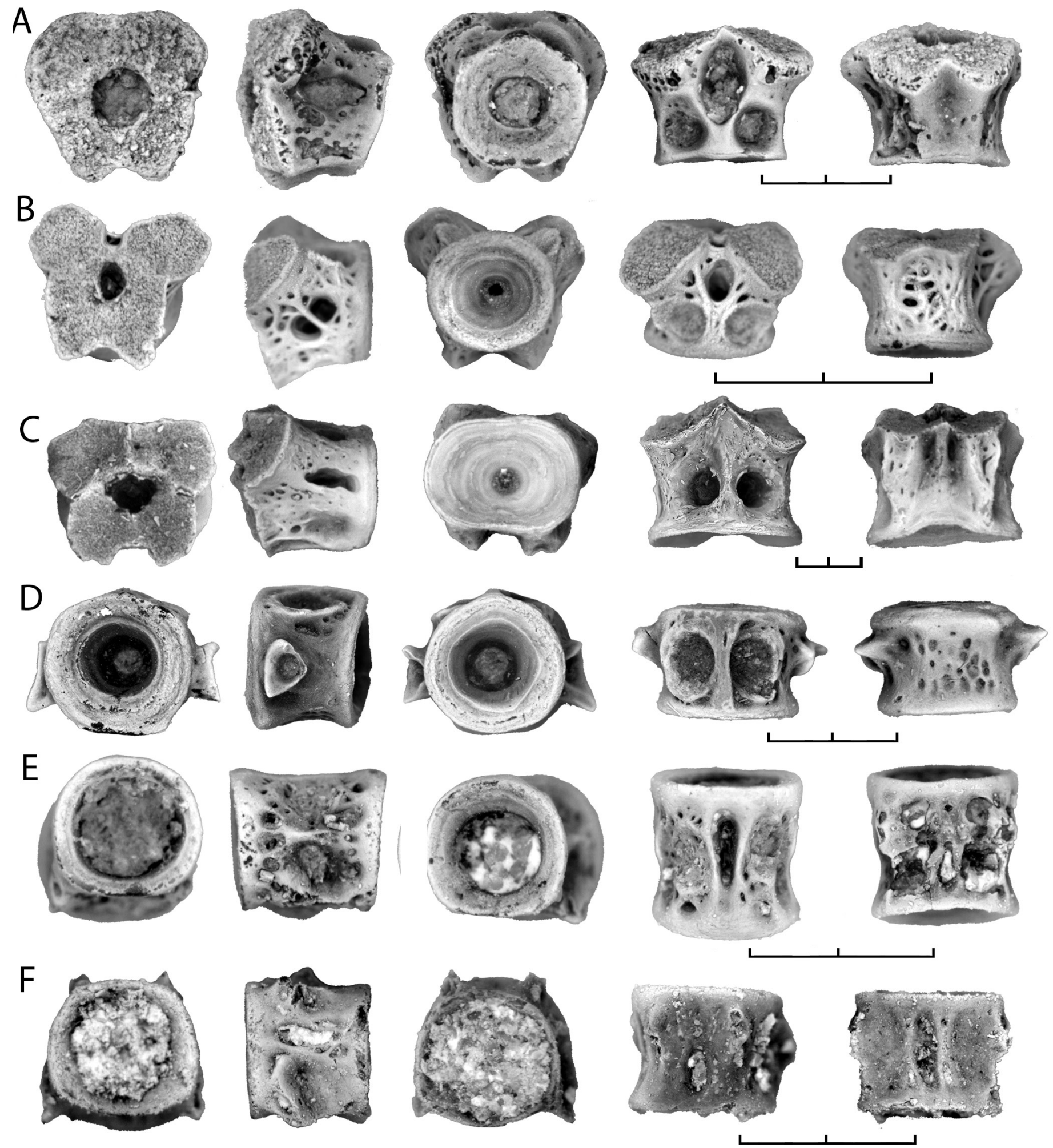

Figure 14. Centra of Hiodontidae gen. indet. from the Milk River Formation compared with specimens from the late Campanian of Alberta, and extant Hiodon alosoides. A) first centrum from the Milk River Formation, TMP 2000.2.55. B) first centrum from the Dinosaur Park Formation, TMP 2005.12.569. C) first centrum of Hiodon alosoides, specimen TMP 90.7.832. D) anterior precaudal centrum, from the Milk River Formation, UALVP 17397. E) mid-precaudal centrum from the Milk River Formation, UALVP 48881. F) posterior precaudal centrum from the Milk River Formation, UALVP 48880. Centra shown in anterior, left lateral, posterior, dorsal and ventral views. Scale bar equals $2 \mathrm{~mm}$. 
family. However, recent phylogenetic analyses have placed Diplomystus in the Armigatidae (Vernygora and Murray 2016). Horseshoeichthys was not included in these studies because of its incompleteness. Thus it is treated here as Ellimmichthyiformes incertae sedis.
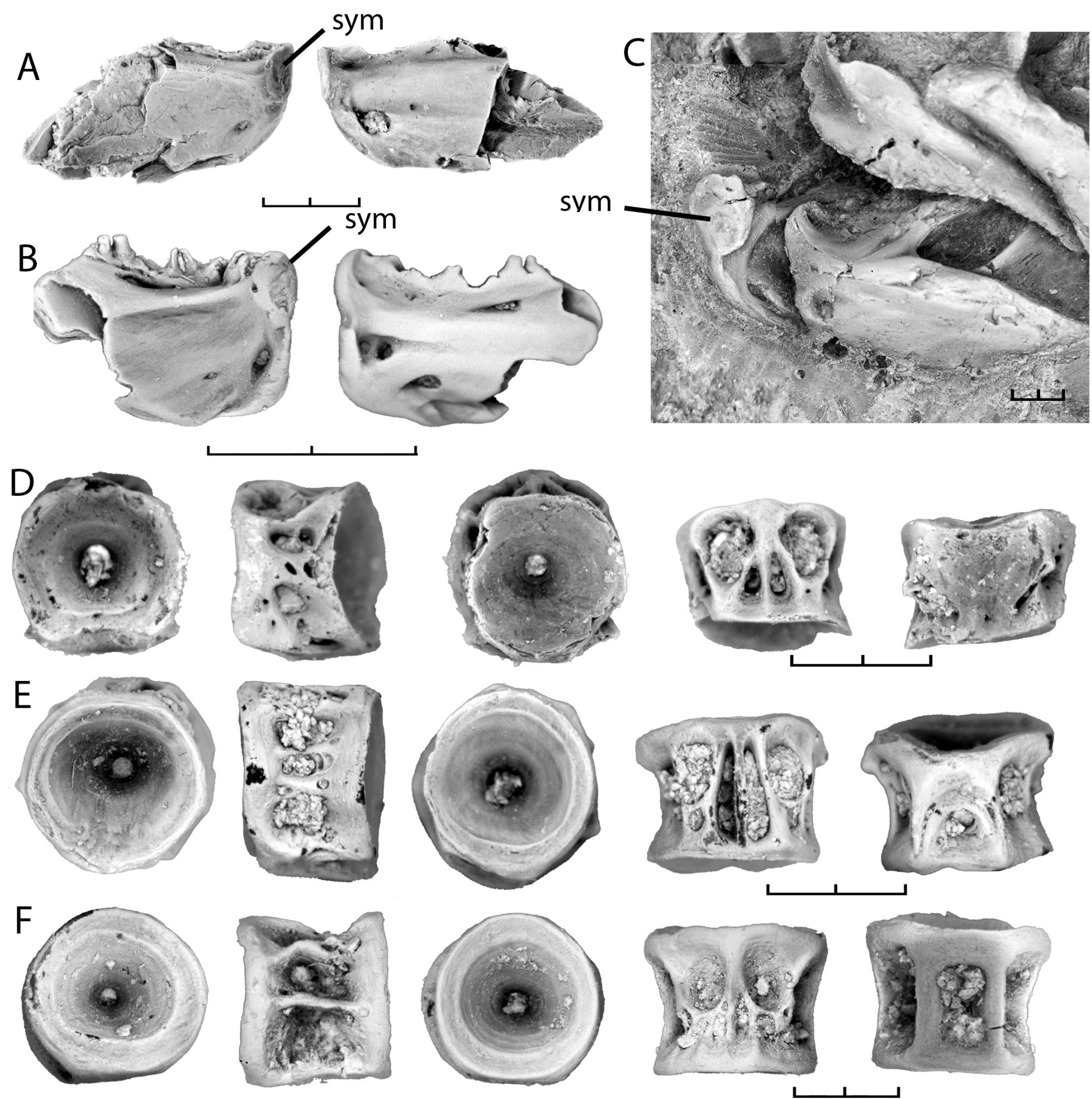

Figure 15. Dentary and centra Horseshoeichthys sp. from the Milk River Formation and the late Campanian of Alberta compared with the type specimen of Horseshoeichthys armaserratus. A) dentary from the Milk River Formation, UALVP 49031. B) dentary from the Dinosaur Park Formation, TMP 2015.60.24. C) close up view of dentaries of the type specimen of Horseshoeichthys armaserratus showing an internal view of the symphysis of right dentary and external surface of left dentary, specimen TMP 2001.45.93, from early Maastrichtian Horseshoe Canyon Formation. D) anterior precaudal centrum of Horseshoeichthys sp., specimen UALVP 48873, from the Milk River Formation. E) mid to posterior precaudal centrum of Horseshoeichthys sp., UALVP 48874, from the Milk River Formation. F) posterior precaudal centrum of Horseshoeichthys sp., UALVP 17417, from the Milk River Formation. Scale bar equals 2 mm. Abbreviations: sym: symphysis. 
Superorder OSTARIOPHYSI Sagemehl, 1885 (sensu Fink and Fink, 1996)

Series OTOPHYSI Garstang, 1931 (sensu Rosen and

Greenwood, 1970)

Order indet.

Genus et sp. indet. U-3/BvD

Figs. 16, 17

Voucher specimens: UALVP 25655, dentary, UALVP locality MR6, Verdigris Coulee, Alberta; UALVP 49024, dentary, UALVP locality MR20, Verdigris Coulee, Alberta; UALVP 49026, dentary, UALVP locality MR8, Verdigris Coulee, Alberta; UALVP 25655, four dentaries, UALVP locality MR6; UALVP 25657,two dentaries, UALVP locality MR6, Verdigris Coulee, Alberta; UALVP 25650, palatine, UALVP locality MR8, Verdigris Coulee, Alberta; UALVP 25656, four palatines, UALVP locality MR6; UALVP 56830, eight centra morphotype U-3, from UALVP locality MR8, Verdigris Coulee, Alberta; UALVP 56890, thirtythree centra morphotype U-3, tentatively identified as being the anterior-most centra of the Weberian apparatus, centra, from UALVP locality MR6, Verdigris Coulee, Alberta; TMP 2000.2.59, two centra morphotype U-3, tentatively identified as being from the first centrum of the Weberian apparatus, TMP locality Michael's Site, Verdigris Coulee, Alberta; TMP 2000.1.67, one centrum morphotype U-3, tentatively identified as being the first centrum of the Weberian apparatus, TMP locality L1145, Verdigris Coulee, Alberta; UALVP 56848 , nine centra morphotype U-3, tentatively identified as being the first centrum of the Weberian apparatus, centrum morphotype $\mathrm{BvC}$, tentatively identified as being from the Weberian apparatus, UALVP 48884 centrum morphotype U-3, tentatively identified as being the first centrum of the Weberian apparatus, UALVP locality MR6, Verdigris Coulee, Alberta; UALVP 48890, centrum morphotype BvC, tentatively identified as being from the Weberian apparatus, UALVP locality MR20, Verdigris Coulee, Albert; TMP 2000.1.67, centrum transitional between morphotype U-3 and BvD, TMP locality L1145, Verdigris Coulee, Alberta; UALVP 56849, centrum morphotype BvC, tentatively identified as being the third centrum of the Weberian apparatus, from UALVP locality MR6, Verdigris Coulee, Alberta; UALVP 56892, centrum morphotype BvC, tentatively identified as being the third centrum of the Weberian apparatus, from UALVP locality MR6, Verdigris Coulee, Alberta;TMP 2000.2.56, four centra of morphotype BvD, tentatively identified as being from the middle and posterior region of the precaudal series, TMP locality Michael's Site, Verdigris Coulee, Alberta; UALVP 56831, two centra morphotype BvD, from UALVP locality MR8, Verdigris Coulee, Alberta; UALVP 56850, three centra, from UALVP locality MR6, Verdigris Coulee, Alberta; UALVP 56891, seventeen centra morphotype $\mathrm{BvD}$, tentatively identified as being from the middle and posterior region of the precaudal series, from UALVP locality MR6, Verdigris Coulee, Alberta; TMP 2000.2.68, two centra of morphotype BvD, tentatively identified as being from the middle and posterior region of the precaudal series, TMP locality L1145, Verdigris Coulee, Alberta; UALVP 48894, centrum morphotype BvD, tentatively identified as being from the middle and posterior region of the precaudal series UALVP locality MR20, Verdigris Coulee, Alberta.

Description: Teleost U-3/BvD of Brinkman et al. (2013) is represented by tooth bearing elements and centra that Brinkman et al. (2013) concluded were from a single kind of otophysan. The dentaries of teleost $\mathrm{U} 3 / \mathrm{BvD}$ from the Milk River Formation (Fig.16A, B), like those referred to this teleost by Brinkman et al. (2013), have a broad tooth-bearing surface with multiple rows of small teeth. The tooth-bearing surface is convex in cross section with the size of the tooth bases showing little variation medio-laterally
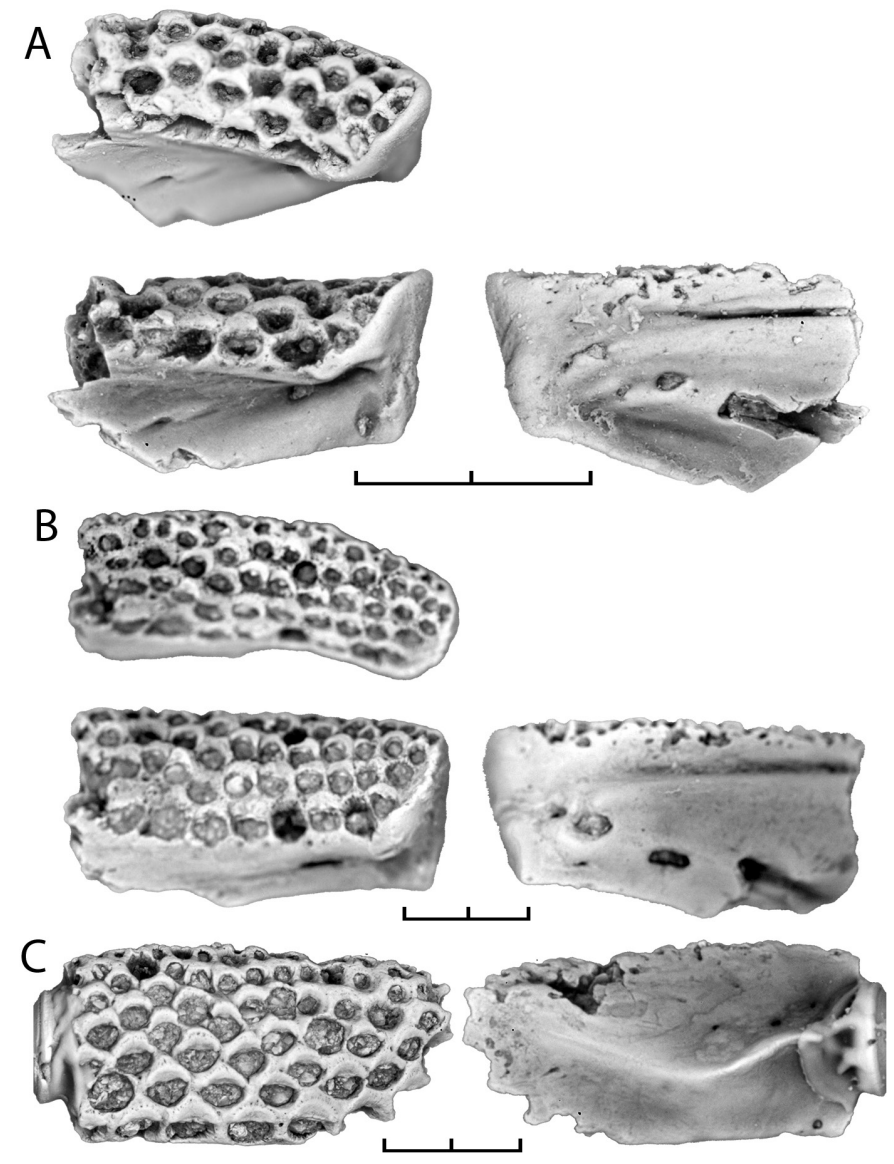

Figure 16. Jaw elements of the presumed ostariophysan designated Teleost U-3/BvD, from the Milk River Formation. A-B) dentaries showing variation in the development of sensory canal pores: A, UALVP 25655; B, UALVP 49026. C) tooth-bearing element tenatively identified as a palatine, UALVP 25650. Scale bar equals $2 \mathrm{~mm}$. 

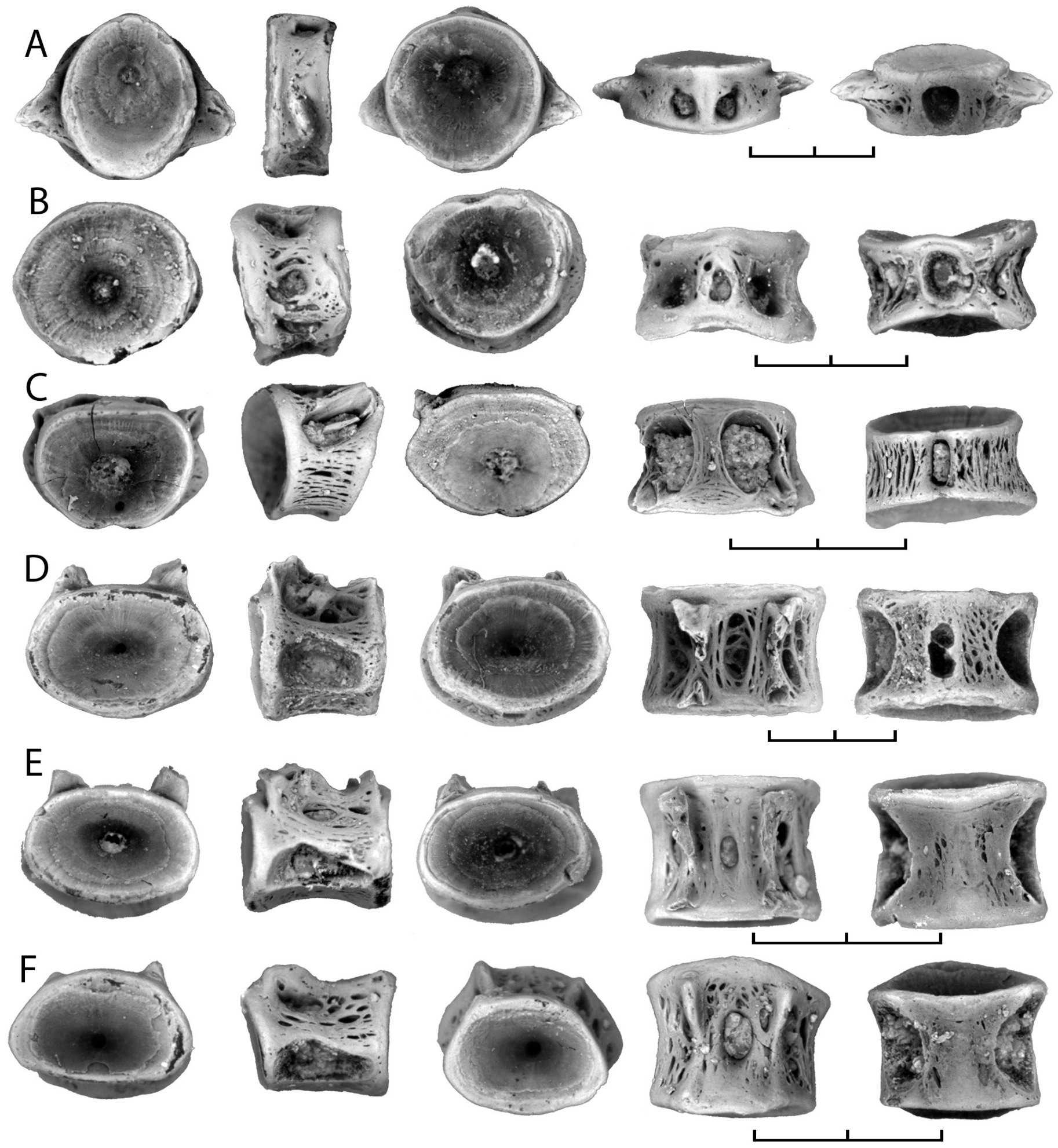

Figure 17. Centra of the presumed ostariophysan designated Teleost U-3/BvD from the Milk River Formation. A) First centrum of Weberian apparatus, TMP 2000.002.0059. B) anterior precaudal centrum, UALVP 48884. C) centrum tentatively identified as being from the Weberian apparatus, UALVP 48890. D) centrum transitional between anterior and mid-precaudal centra in the development of parapophyseal pit and mid-ventral pit, TMP 2000.001.0067. E, F) mid-posterior precaudal centra showing variation in development of the mid-ventral pit: E, TMP 2000.002.0056; F, UALVP 48894. Centra shown in anterior, left lateral, posterior, dorsal and ventral views. Scale bar equals $2 \mathrm{~mm}$. 
or antero-posteriorly along the length of the jaw, features that are shared with catfish. A large, enclosed sensory canal extends along the ventral edge of the dentary below the Meckelian fossa. A series of mandibular sensory canal pores of moderate size are evenly spaced along this canal.

A relatively flat element, with a pad of teeth similar to that of the dentary, is tentatively identified as a palatine (Fig. 16C).

Two morphologically distinct centra were referred to Teleost U3/BvD by Brinkman et al. (2013). These were initially treated as distinct morphotypes but were hypothesized as being from a single teleost taxon because of the presence of transitional features and a pattern of co-occurrence. The more anterior of the centrum morphotypes, designated centrum morphotype U-3 by Brinkman et al. (2013), is short and higher than wide in end view (Fig. $17 \mathrm{~A}, \mathrm{~B})$. The dorsal surface of the centrum bears a pair of small circular neural arch articular pits that are separated by a rounded bar of bone about equal in width to the diameter of the pits. These pits are morphologically similar to the pits on the first Weberian centrum of otophysans that receive the second pair of Weberian ossicles - the scaphium. A large, circular fossa is present on the ventral surface of the centrum. Parapophyses are represented by low ridges. Centrum morphotype U-3 was interpreted as the first centrum of the Weberian apparatus by Brinkman et al. (2013) because it is similar to this element in siluriforms and cypriniforms in being a very short, disc-shaped element and in having similarly-shaped pits on the dorsal surface of the centrum. The specimens of centrum morphotype U-3 from the Milk River Formation (Fig. 17A) do not differ from specimens from the contemporaneous John Henry Member described by Brinkman et al. (2013).

Centra that Brinkman et al. (2013) interpreted as being from a more posterior position along the vertebral column, initially designated centrum morphotype $\mathrm{BvD}$, are more elongate, low and wide, have a neural arch that is fused to the centrum, and large rectangular parapophyseal articular pits on the lateral surface of the centrum. Ventrally the centrum generally has a flat or gently curved surface pierced by small pores arranged in loose rows, although in some a narrow, elongate mid-ventral pit is present. The centra with an elongate mid-ventral pit are interpreted as transitional between the anterior disc-shaped centra and the more posterior precaudal centra. The morphology and range in variation of centra BvD from the Milk River Formation (Fig. 17D-F) matches that of centra from the John Henry Member and Kaiparowits Formation of Utah described by Brinkman et al. (2013). In the presence of large parapophyseal articular pits and a low wide centrum, morphotype $\mathrm{BvD}$ is similar to post-Weberian centra of cyprinids.

Based on features of the ventral surface of the centrum, a third morphologically distinct centrum morphotype present in the Milk River Formation, designated centrum morphotype $\mathrm{BvC}$ (Figs. 17C, 18B), is here interpreted as being transitional between centra U3 (Fig. 17B) and $\mathrm{BvD}$ (Fig 17D). The ventral surface of centrum morphotype $\mathrm{BvC}$ is transitional between centra $\mathrm{U} 3$ and $\mathrm{BvD}$ in the presence of an elongate mid-ventral pit with the ventral surface surrounding this pit bearing small pores arranged in loose rows. However, the dorsal surface of the centrum is distinct in having large, rectangular neural arch articular pits. On the lateral surface of the centrum a depression is present below the neural arch articular pit. The dorsal edge of this depression forms the lateral border of the neural arch articular pit and ends in a small dorsal process on the posterior end of the centrum. The depression on the lateral surface of the centrum is oriented postero-dorsally towards the postero-dorsal process.

Because centrum morphotype $\mathrm{BvC}$ appears to be from the anterior portion of the vertebral column based on the morphology of the ventral surface being transitional between that of centra $\mathrm{U} 3$ and $\mathrm{BvD}$, the possibility that centrum morphotype $\mathrm{BvC}$ is part of the Weberian apparatus was considered. This possibility is supported by comparison with the Weberian apparatus of the cyprinid Cyprinus (Fig. 18A), in which Weberian centra two and three fuse to form a compound centrum (Bird and Hernandez, 2007). Centrum morphotype $\mathrm{BvC}$ is similar to this compound centrum of the Weberian apparatus of Cyprinus in having large neural arch pits and a depression on the lateral surface of the centrum extending posterodorsally to the dorsal processes on the posterior end of the centrum. In cypriniforms, this postero-dorsally oriented groove serves as the site of articulation of the articular process of the tripus, the posterior-most Weberian ossicle (Bird and Hernandez, 2007). The most striking difference with the morphology observed in Cyprinus is the absence of a lateral processes in $\mathrm{BvC}$. However, this lateral process is a feature of the second centrum, which fuses with the third centrum in Cyprinus (Bird and Hernandez, 2007). Thus, the absence of lateral processes in centrum type $\mathrm{BvC}$ can be interpreted as an indication that the second and third Weberian centra did not fuse during ontogeny in teleost $\mathrm{U} 3 / \mathrm{BvD}$. Furthermore, centrum $\mathrm{BvC}$ lacks articular pits for the intercalarium, a Weberian ossicle formed by modification of the second neural arch (Rosen and Greenwood, 1970), which articulates with the second centrum via dorso-lateral articular pits that remain visible in the compound Weberian centrum of cyprinine cypriniforms. Centrum $\mathrm{BvC}$ also differs from the compound centrum of Cyprinus in that it is longer dorsally than ventrally, resulting in a triangular shape when seen in side view. However, the Weberian centra of other cypriniforms, such as catostomids, are similarly triangular in lateral view (Bird and Hernandez, 2007); the Weberian 
apparatus of teleost $\mathrm{U} 3 / \mathrm{BvD}$ may therefore show similar proportions in centrum BvC.

Remarks: Brinkman et al. (2013) concluded that centrum morphotype U-3 and $\mathrm{BvD}$, were from a single kind of fish because of the presence of morphologically transitional centra and a pattern of co-occurrence. The similarity of centrum morphotype U-3 and the anterior-most centrum of the Weberian apparatus suggests an affinity with otophysans. This is further supported by presence of features on centrum morphotype $\mathrm{BvC}$ that are associated with the presence of one of the Weberian ossicles in Cyprinus. Brinkman et al. (2013) argued that teleost U3/ $\mathrm{BvD}$ was more closely related to siluriforms than to other otophysans primarily on the basis of features of the dentary and the anterior-most precaudal centra. Of particular note is the similarity in the arrangement of teeth on the dentary as indicated by a comparison of the arrangement of teeth seen in figure $16 \mathrm{~A}, \mathrm{~B}$ of this paper with the dentary of Astephus illustrated in Figure 5A of Divay and Murray (2016). However, Brinkman et al. (2013) recognized that many of the apomorphies of siluriforms, such as the paired ventral processes that are characteristic of the first Weberian centrum and the elongate centrum of the Weberian apparatus of siluriforms, are absent. Thus if teleost $\mathrm{U} 3 / \mathrm{BvD}$ has affinities with the Siluriformes it must occupy a more basal position than any currently known member of the group. Teleost U3/BvD differs from siluriforms in having autogenous parapophyses with large parapophyseal pits. However, the presence of autogenous parapophyses is consistant with a basal position of teleost $\mathrm{U} 3 / \mathrm{BvD}$ within the group because they are autogenous in more basal otophysans, such as cypriniforms. Significantly, the shape of the parapophyseal pit in these more basal otophysans is similar to that of centrum type $\mathrm{BvD}$ in being large and rectangular in shape. Thus the presence of these features does not conflict with the interpretation that teleost $\mathrm{U} 3 / \mathrm{BvD}$ is a basal siluriform because these features can be interpreted as a plesiomorphic for the group. Given this combination of siluriform and more basal otophysan features, once a complete skeleton is found, teleost $\mathrm{U} 3 / \mathrm{BvD}$ is likely to provide significant new insight into the early diversification of otophysans and the structure of the Weberian apparatus in basal otophysans.

Order ESOCIFORMES Nelson, 1994

Family ESOCIDAE Cuvier, 1817

Estesesox Wilson, Brinkman, and Neuman, 1992

Estesesox foxi Wilson, Brinkman, and Neuman, 1992

Fig. 19 A-D

Voucher specimens: UALVP 56048, seven dentaries of Estesesox sp., UALVP locality MR20, Verdigris Coulee,
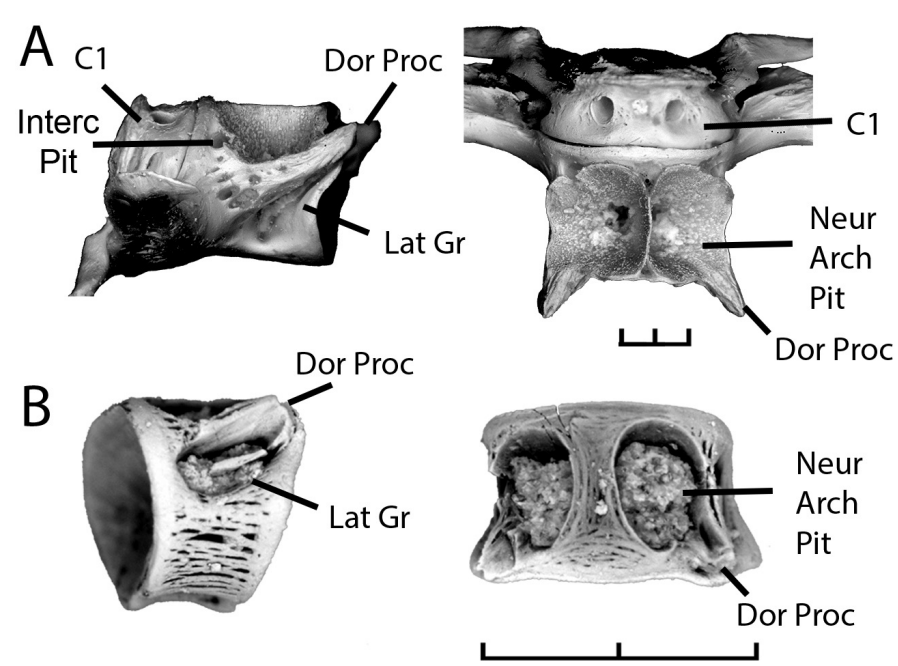

Figure 18. Centrum of Weberian apparatus of ostariophysan designated Teleost U-3/BvD compared with the fused second and third centra of the Weberian apparatus of the cyprinid Cyprinus carpio. A) first to third centra of the Weberian apparatus of Cyprinus carpio, TMP 2007.30.9. B) centrum tentatively identified as being from the third centrum of the Weberian apparatus of Teleost U-3/BvD, UALVP 48890. Centra left lateral and dorsal views. Scale bar equals $2 \mathrm{~mm}$. Abbreviations: C1, centrum one; Dor Proc, dorsal process; Interc Pit, interclarium articular pit; Lat Gr, lateral groove; Neur Arch Pit, neural arch articular pit.

Alberta; UALVP 25653, three dentaries, UALVP locality MR6; TMP 2000.2.31, dentary fragment of Estesesox sp., TMP locality Michael's Site, Verdigris Coulee, Alberta; TMP 2000.1.19, dentary fragment of Estesesox sp., TMP locality L1145, Verdigris Coulee, Alberta; UALVP 48866, esocoid precaudal centra, UALVP locality MR20, Verdigris Coulee, Alberta.

Description: Late Cretaceous esocoids were identified by Wilson et al. (1992) on the basis of the feature of C-shaped tooth bases on dentaries and palatines, a feature associated with a type of tooth implantation that allows the teeth to be folded posteriorly. As well, the palatines were similar to those of esocids in their general shape. Two genera were recognized, Estesesox and Oldmanesox, each with a single species. These differ in the size and arrangement of the teeth on the dentary: in Oldmanesox the teeth are larger and multiple tooth rows are absent or restricted to the anterior-most portion of the dentary, while in Estesesox the teeth are smaller and more extensive development of the multiple tooth rows is present. Subsequently, Brinkman et al. (2013) concluded that two species of Estesesox are present in the late Campanian Kaiparowits Formation, differing in the development of the multiple tooth rows. Estesesox foxi has three or more rows of teeth extending well posterior to the symphysis. The second taxon, referred to Estesesox sp., has two rows of teeth anteriorly with the outer row being relatively short (Brinkman et al. 2013; fig. 10.24C, D). All the 
dentaries from the Milk River Formation observed during the course of this study have multiple tooth rows extending well posteriorly along the dentary (Fig. 19A, B), and so are referred to Estesesox foxi.

Esocoids and salmoniforms have a generalized centrum morphology in which the centra are simple spools with autogenous parapophyses and neural arches and with the neural arches and parapophyses placed relatively close together. In some centra, the parapophyses are partially fused to the centrum. Centra of this morphology described by Brinkman and Neuman (2002), Neuman and Brinkman (2005), and Brinkman et al. (2014) were assumed to be those of the esocoids represented by dentaries, although it was not possible to associate specific centrum and jaw morphotypes. However, only one centrum morphotype of this generalized salmoniform/esocoid morphology is present in the Milk River Formation (Fig. 19C, D). This is similar to centrum morphotype $\mathrm{NvC}$ from the Kaiparowits Formation illustrated by Brinkman et al. (2013; fig. 25A$\mathrm{C}$ ) in that a mid-ventral ridge separates two ventral fossae and the lateral edges of these fossae are bordered by ridges that converge anteriorly, and the parapophyseal articular pits do not extend the full length of the centrum.

Remarks: In the Grand Staircase/Escalante region

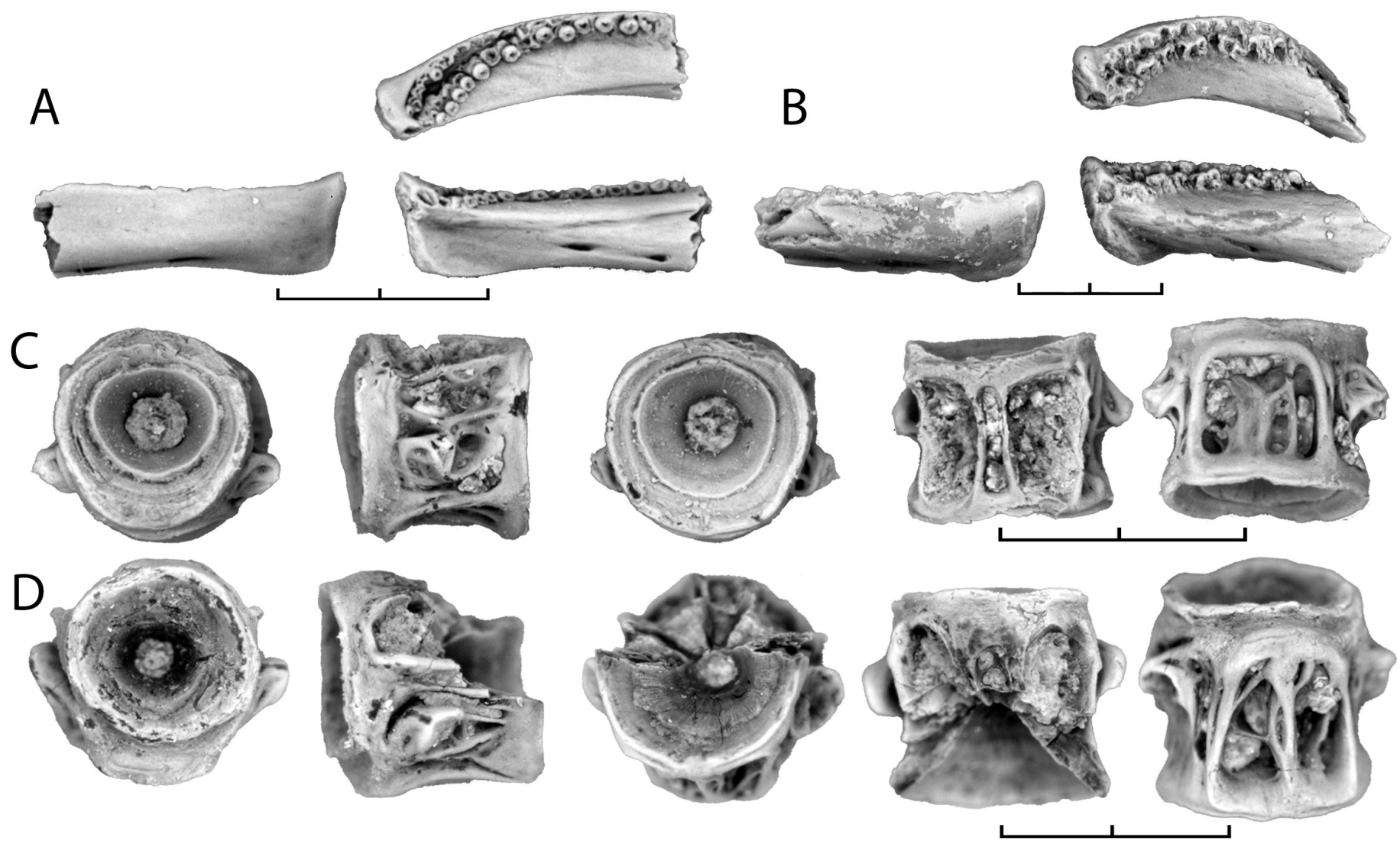

Figure 19. Esocoid elements from the Milk River Formation. A-B) dentaries of Estesesox foxi showing variation in the development of the tooth row: A dentary showing the presence of two rows of teeth at the anterior end of the tooth row, UALVP 56048b; B, dentary showing more extensive development of multiple tooth rows and more robust inner surface, UALVP 25653b. C-D) esocoid precaudal centra: C, UALVP 56048; D, UALVP 48866. Centra shown in anterior, left lateral, posterior, dorsal and ventral views. Scale bar equals $2 \mathrm{~mm}$. of Utah, esocids first occur in the late Campanian Kaiparowits Formation (Brinkman et al. 2013). Thus, the occurrence of Estesesox sp. in the Milk River Formation represents the first occurrence of an esocid in the Western Interior of North America.

\section{ACANTHOMORPHA Rosen 1973 (sensu Stiassny, 1986) Order indet. Genus et sp. indet.}

Fig. 20

Voucher specimens: UALVP 56052, first centrum, UALVP locality MR20, Verdigris Coulee, Alberta; UALVP 48903, first centrum, UALVP locality MR6, Verdigris Coulee, Alberta; TMP 2000.2.57, two first centra, from TMP locality Michael's Site, Verdigris Coulee, Alberta, TMP 2000.1.73, four precaudal centra, from TMP locality L1145, Verdigris Coulee, Alberta UALVP 48905, precaudal centrum, UALVP locality MR6, Verdigris Coulee, Alberta; UALVP 48907, precaudal centra, UALVP locality MR20, Verdigris Coulee, Alberta; UALVP 48904, precaudal centrum, from UALVP locality MR6, Verdigris Coulee, Alberta; UALVP 56893, eleven precaudal centra, from UALVP locality MR6, Verdigris Coulee, Alberta; UALVP 17397, two 
precaudal centra, UALVP locality MR8, Verdigris Coulee, Alberta; UALVP 56832, four precaudal centra, from UALVP locality MR8, Verdigris Coulee, Alberta.

Description: Acanthomorphs are represented in the Milk River Formation by centra (Fig. 20), and fin spines. Acanthomorph first centra have a tripartite anterior articular surface. Acanthomorph first centra from the Milk River Formation (Fig. 20A-C) are short, have exoccipital articular facets that contact one another above the basioccipital articular surface, lateral surfaces that are covered by a network of ridges, and a flat ventral surface bordered by distinct ridges. Neural arches are autogenous. In dorsal view, a pair of parasagittal ridges separates a narrow median area from large lateral fossae. The large lateral fossae are likely articulation pits for the neural arch.

Acanthomorph precaudal centra are distinctive in the presence of articular processes extending from the posterior ends of the centra. These were referred to as postzygopophyses by Patterson (1964), although because zygopohyses by definition are on the neural arch the more descriptive term of apophyses used by Courtemanche and Legrandre (1985) is adopted here. Also, surfaces for articulation with the ribs are located on the neural arch or high on the centra so are not visible on the preserved centra. A mid-dorsal ridge is variably developed on the acanthomorph precaudal centra from the Milk River Formation (Fig. 20D-F).

Remarks: Acanthomorph centra are easily identifiable on the basis of derived features of the tripartite anterior surface of the first centrum and apophyses on the posterior end of the anterior precaudal centra that articulate with a smooth surface on the anterior end of the more posterior centrum. The development of a mid-dorsal ridge is a feature that was considered of taxonomic significance by Brinkman et al. (2014), so it is likely that more than one taxon is present. However, because of the small sample size, the possibility that this represents variation within a single taxon cannot be ruled out at present. No tooth-bearing elements of acanthomorphs were recognized.

\section{Centra from teleosts of uncertain affiliations}

As in vertebrate microfossil assemblages from elsewhere within the Western Interior, morphologically distinctive elements are present that are of uncertain taxonomic position. Two centrum morphotypes are described here as distinct, followed by a discussion of their possible taxonomic affiliations.

Teleost indet. centrum type $\mathrm{O}$

Fig. 21

Voucher specimens: UALVP 48878, precaudal centrum, UALVP locality MR 20, Verdigris Coulee, Alberta; UALVP 56851, three precaudal centra, UALVP 56831, two centra morphotype $\mathrm{BvD}$, from UALVP locality MR8, Verdigris
Coulee, Alberta; UALVP 56833, two centra, from UALVP locality MR8, Verdigris Coulee, Alberta; TMP 2000.1.65, two precaudal centra, TMP locality L1145, Verdigris Coulee, Alberta; TMP 2000.2.58, one precaudal centrum; TMP locality Michael's Site, Verdigris Coulee, Alberta.

Description: Centra with the unusual feature of a convex anterior surface and a deeply excavated posterior surface were designated teleost centrum morphotype $\mathrm{O}$ by Brinkman et al. (2013). Specimens of centrum morphotype $\mathrm{O}$ without parapophyseal articular pits and lacking distinct pits in the wall of the centrum (Fig. 21A) are assumed to be from an anterior position along the vertebral column. The convexity of the anterior surface on these centra is well developed, with only a small dimple representing the notochordal pit. Centra with pits on the side of the centrum and with distinct, but short, parapophyses (Fig. 21B) are assumed to be from a more posterior position along the vertebral column. Centrum morphotype $\mathrm{O}$ from the Milk River Formation (Fig. 21A, B) do not differ significantly from those from Utah (Fig. 21C-F).

Taxonomic affiliations: Brinkman et al. (2013) assumed that centrum morphotype $\mathrm{O}$ was from a teleost, although they recognized the possibility that it may be from a more basal actinopterygian. The possibility that it is a regional variant from one of the fish recognized above is rejected because of its morphological distinctiveness and because variation among the centra present indicates that a good representation of the range of morphologies in the precaudal series is present. Thus it is concluded that centrum morphotype $\mathrm{O}$ documents an additional taxon in the Milk River fish assemblage, which, following Brinkman et al. (2013), is referred to as Teleost indet. type O.

Remarks: Although its relationships are uncertain, the distribution of Teleost indet. type $\mathrm{O}$ adds to the evidence for latitudinal zonation of fish assemblages in the late Campanian in the western interior of North America. It was one of the taxa that Brinkman et al. (2013) interpreted as being a member of a southern assemblage because it is present in the Kaiparowits Formation of Utah (Fig. 21E, F), as well as earlier localities in that region (Fig. 21C, D), but absent in the Belly River Group of Alberta and the Judith River Formation of Montana. Its presence in the Milk River Formation shows that in the late Santonian it extended further north than it did in the late Campanian.

Teleost indet. centrum type U-4

Fig. 22

Voucher specimens: UALVP 48869, precaudal centrum, UALVP locality MR6, Verdigris Coulee, Alberta; UALVP 48870, precaudal centrum, UALVP locality MR6, Verdigris Coulee, Alberta; UALVP 56852, nine cen- 
tra, UALVP 56831, two centra morphotype BvD, from UALVP locality MR8, Verdigris Coulee, Alberta; UALVP 56834, twelve centra, from UALVP locality MR8, Verdigris Coulee, Alberta; TMP 2000.001.0069, five precaudal centra, TMP locality L1145, Verdigris Coulee, Alberta,
TMP 2000.2.60, thirteen precaudal centra, TMP locality Michael's Site, Verdigris Coulee, Alberta.

Description: Teleost centrum morphotype U-4 includes small, simple, spool-shaped precaudal centra with a relatively flat anterior articular surface and deep neural arch
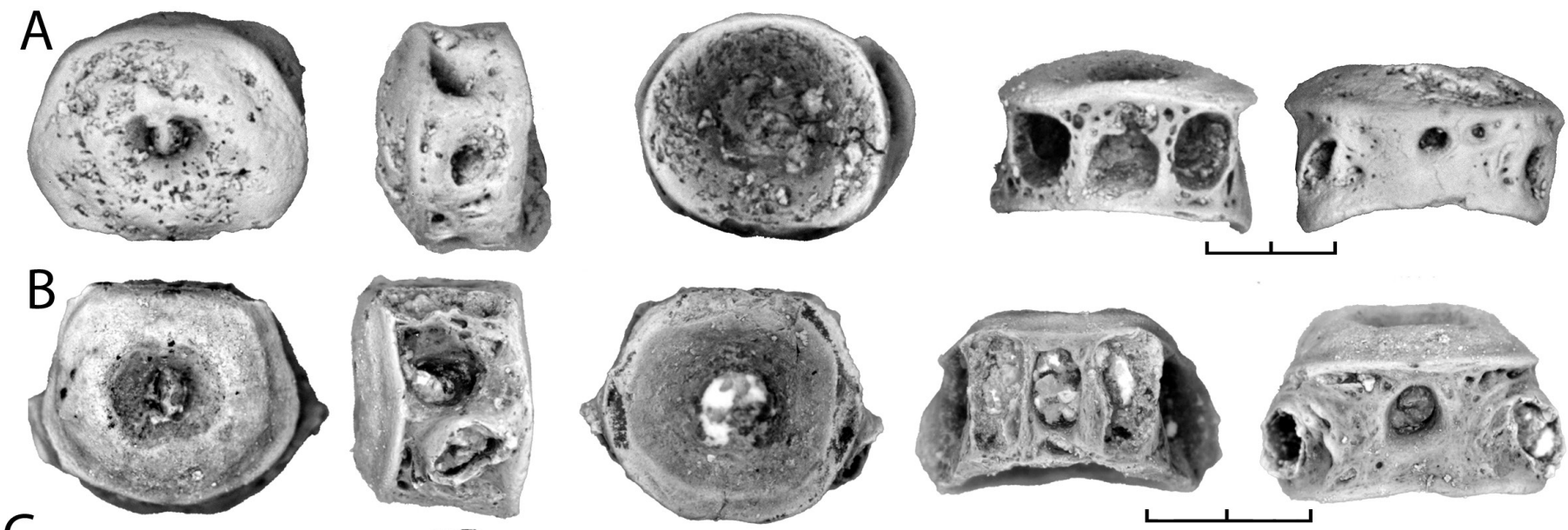

C
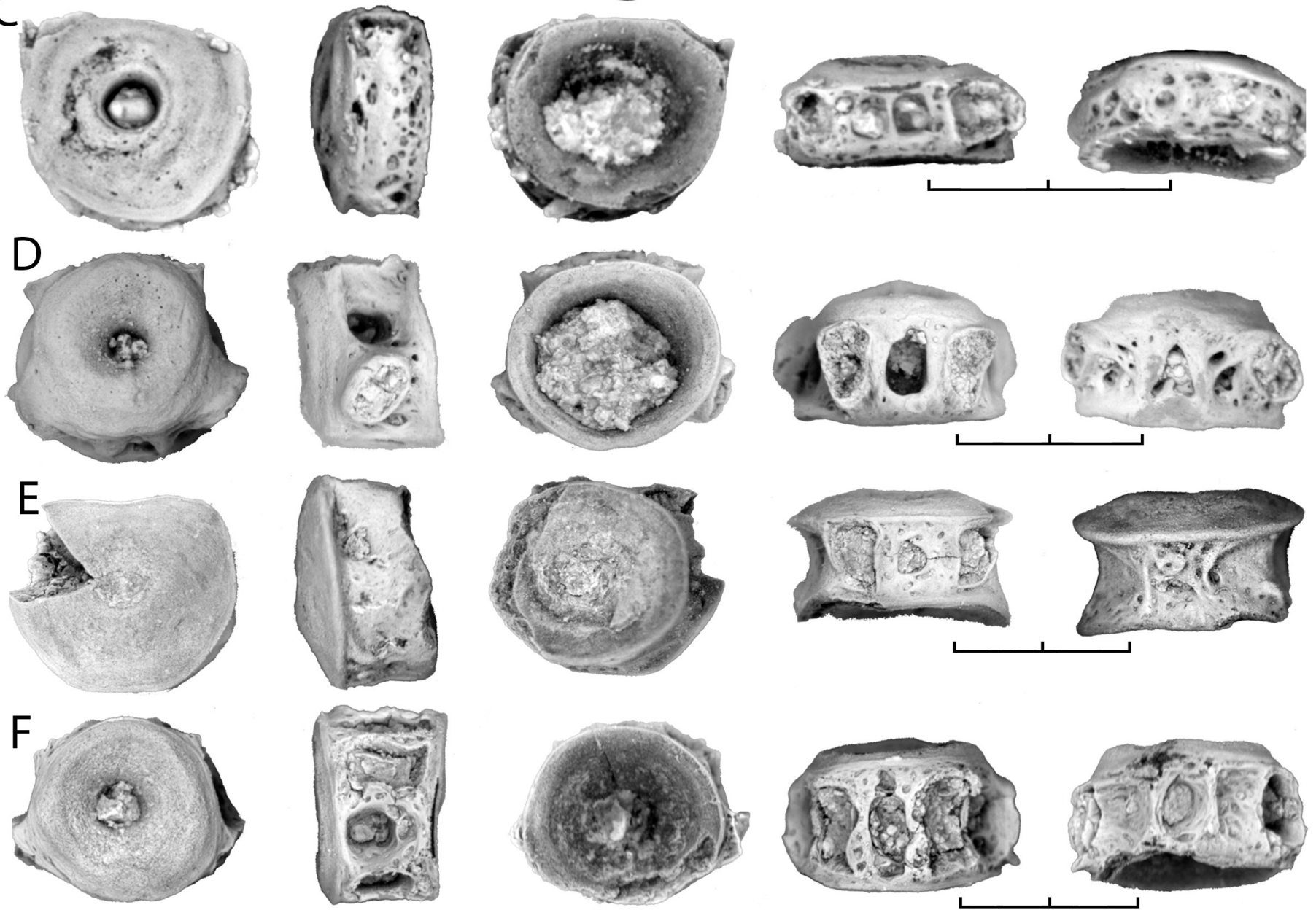

Figure 20. Acanthomorph centra from the Milk River Formation. A-C) first centra showing variation in the development of struts along the side of the centrum: A, UALVP 56052; B, UALVP 48903; C, TMP 2000.2.57. D-F) precaudal centra showing variation in development of struts and ridges on the lateral and dorsal surface of the centrum: D, UALVP 48907; E, UALVP 17397(a); F) UALVP 17397(b). Centra shown in anterior, left lateral, posterior, dorsal and ventral views. Scale bar equals $2 \mathrm{~mm}$. 
articular pits that are circular to oval in shape and widely separated from one another (Fig. 22A-C). A mid-dorsal pit is generally present between the neural arch articular pits. The lateral surfaces of the centrum are generally pierced by two or three foramina of moderate size. Distinct parapophyseal pits are absent. The ventral surface has a mid-ventral pit in about half of the available specimens (Fig. 22A), and the rest of the centra have a flat, ventral surface. In end
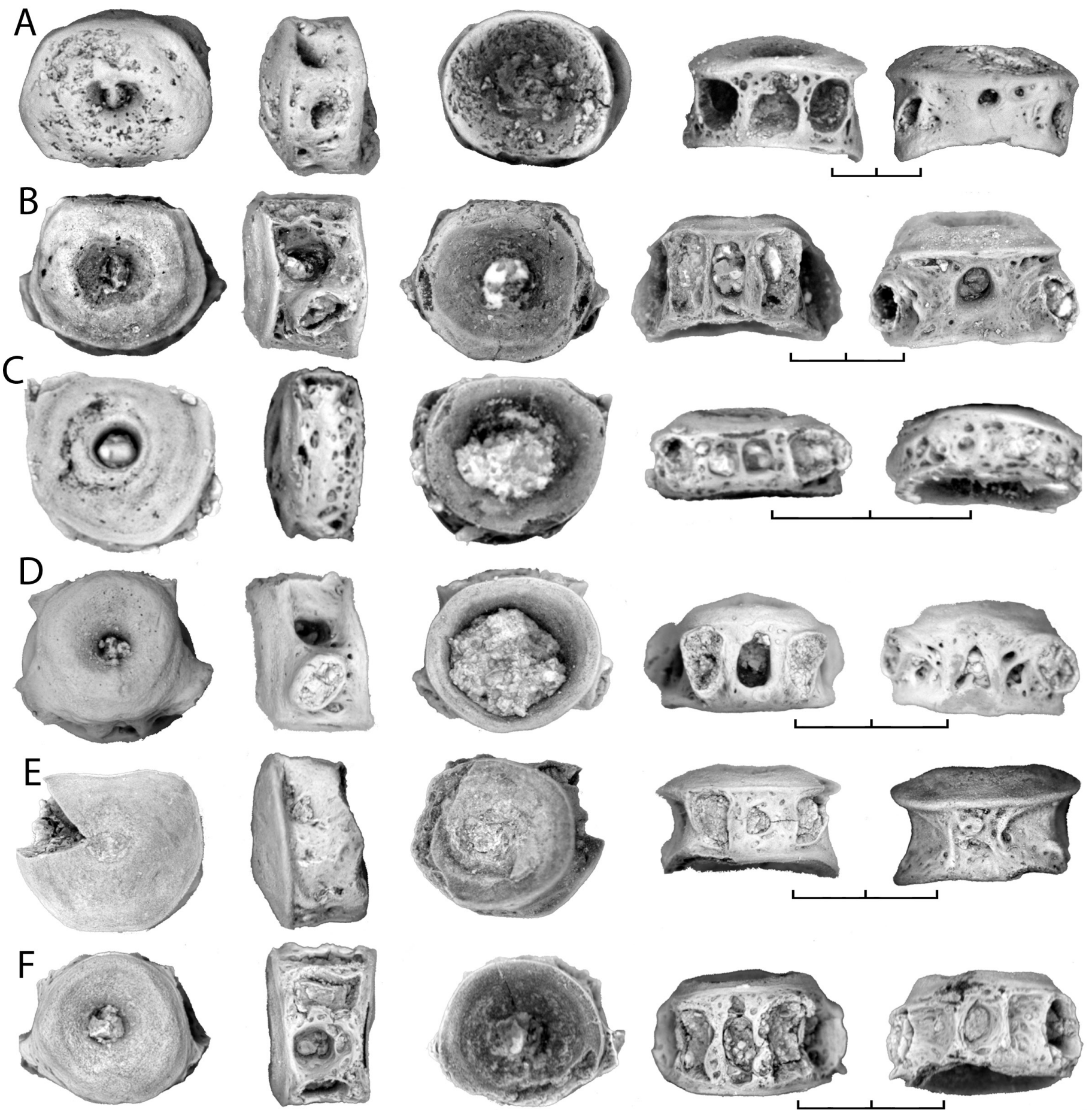

Figure 21. Precaudal centra of Teleostei indet. type $O$ from the Milk River Formation compared with specimens from Utah. A, B) centra of Teleost indet. type $O$ from the Milk River Formation: $A$, anterior precaudal centrum, specimen TMP 2000.1.65; B, mid to posterior precaudal centrum, specimen UALVP 48878. C) centra of Teleost indet. type O from the Cenomanian Dakota Formation, specimen MNA V10324. D) centra of Teleost indet. type O from the Turonian Smoky Hollow Member of the Straight Cliffs Formation, specimen OMNH 31322. E, F) centra of Teleost indet. type O from the late Campanian Kaiparowits Formation: E, specimen OMNH 23786; F, specimen OMNH 22030. Centra shown in anterior, left lateral, posterior, dorsal and ventral views. D from Brinkman et al. (2013: fig. 10.10D. Scale bar equals $2 \mathrm{~mm}$. 
view, the centra vary from being wider than high to being subequal in width and height or slighlty higher than wide.

Taxonomic affiliations: Centra from the Milk River Formation here attributed to morphotype U-4 (Fig. 22AC) are similar to those described by Brinkman et al. (2013) in the general shape of the neural arch articular pits and in having a nearly flat anterior surface. Development of the parapophyseal pits in assemblages described by Brinkman et al. (2013) is variable with some specimens having parapophyseal pits equal in size to the neural arch articular pits. This was assumed to be a result of variation along the vertebral column. However, none of the specimens from the Milk River Formation have well-developed parapophyseal pits. As well, some of the specimens of centrum morphotype U-4 from the Milk River Formation are higher than wide or subequal in height and width, while centra of morphotype U-4 from other localities are consistantly wider than high. These differences may have a taxonomic basis, although given the overall similarity of the centra this is likely at a low taxonomic level.

Since the absence of parapophyseal articular pits is a feature seen in the anterior-most centra of some teleosts, the possibility that specimens from the Milk River Formation referred to centrum morphotype U-4 are the anterior-most centra from a fish already recognized was considered. The most likely candidate for this is Wilsonichthys sp., since the centra of Wilsonichthys are of a similar size and proportions. However, this attribution was considered unlikely because the morphology of the lateral and ventral surfaces of the centrum differ significantly: in centrum morphotype U-4 the lateral surface of the centrum has a series of pits, while in Wilsonichthys it is solid. Thus, it is concluded that centrum morphotype U-4 most likely documents a distinct taxon, which, following Brinkman et al. (2013), is referred to as Teleostei indet. type U-4. Although the relationships of the teleost represented by these centra are unknown, it is likely that it is from a basal member of the group because of its simple spool-shaped morphology and the presence of little variation along the column.

Remarks: Centra of Teleostei indet. type U-4 are widely distributed in the Late Cretaceous. They first occur in the Cenomanian and extend to the late Campanian in Utah (Brinkman et al. 2013). They are found in high abundance in the late Turonian Smoky Hollow Member of the Straight Cliffs Formation of Utah (Brinkman et al. 2013) and the John Henry Member of the Straight Cliffs Formation (Fig. 22D). They are also present in the Belly River Group (Fig. 22E), Hell Creek Formation (Brinkman et al. 2014: fig. 10A, B), and the Paleocene Tullock Formation of Montana (Fig. 22F).

\section{DISCUSSION}

The review of fish remains from vertebrate microfossil localities in the Milk River Formation demonstrates that the diversity and relationships of elasmobranchs and basal actinopterygians was well documented by previous studies but teleosts are much more diverse than previously recognized. Four elasmobranchs are recognized, Lonchidion, Hybodus, an orectolobid, and Pseudomyledaphus, although the presence of an orectolobid is tentative because it is only represented by denticles and centra. The diversity of this assemblage of elasmobranchs is similar to contemporaneous assemblages from Utah (Kirkland et al. 2013). However, Lonchidion and Hybodus are rare compared to localities in Utah, Hybodus for example only being represented by two specimens. This rarity is likely of paleoecologial significance. Hybodontoids occur in both marine and non-marine sediments, suggesting that they occupied both environments (Kirkland et al. 2013; Brinkman et al. 2005). Where adjacent environments of deposition are present, they tend to be more abundant in the shallow marine than in the non-marine setting, and within non-marine beds, they are more abundant in localities that are more coastal than inland (Kirkland et al. 2013; Brinkman et al. 2005). Thus, the rarity of Lonchidion and Hybodus teeth in the Milk River Formation microvertebrate assemblages suggests that they are representative of a relatively more inland faunal assemblage.

Six basal actinopterygians are present in the Milk River assemblage: a polyodontid, the vidalamiine cf. Melvius, a generically indeterminate amiine, two lepisosteids, and Belonostomus. Two of the basal actinopterygians reported by Larson (2010), Lepidotes and Holostean A, are not identified as such by us. The teeth referred to Lepidotes by Larson (2010) (e.g., specimen TMP 2008.90.18) are low bulbous teeth with distinctly curved tips. However, Lepidotes palatal teeth do not have a recurved tip (Brinkman et al. 2013) so these specimens are more likely from some other actinopterygian, possibly Melvius. Holostean A was initially recognized by Brinkman (1990) on the basis of rectangular scales with well-developed peg and socket joints. Holostean A scales are similar to Gar Scale Type 2 in having peg and socket joints, but are different in lacking the tabs present on the antero-ventral corner of the scale. As well they are distinctly more rectangular, and the peg-socket joint is more strongly developed. The scales referred to Holostean A by Larson (2010) on the basis of the presence of distinct peg and socket joints (Larson 2010: Figs. 3-5) are here identified as Gar Scale Type 2 (the presumed scales of Lepisosteus). In this study, ten teleosts are recognized as being present in the Milk River Formation. Five of these, Ostariostoma sp., Wilsonichthys sp., Horseshoeichthys sp., the ostariophysan designated $\mathrm{U} 3 / \mathrm{BvD}$, and Estesesox foxi are represented by 

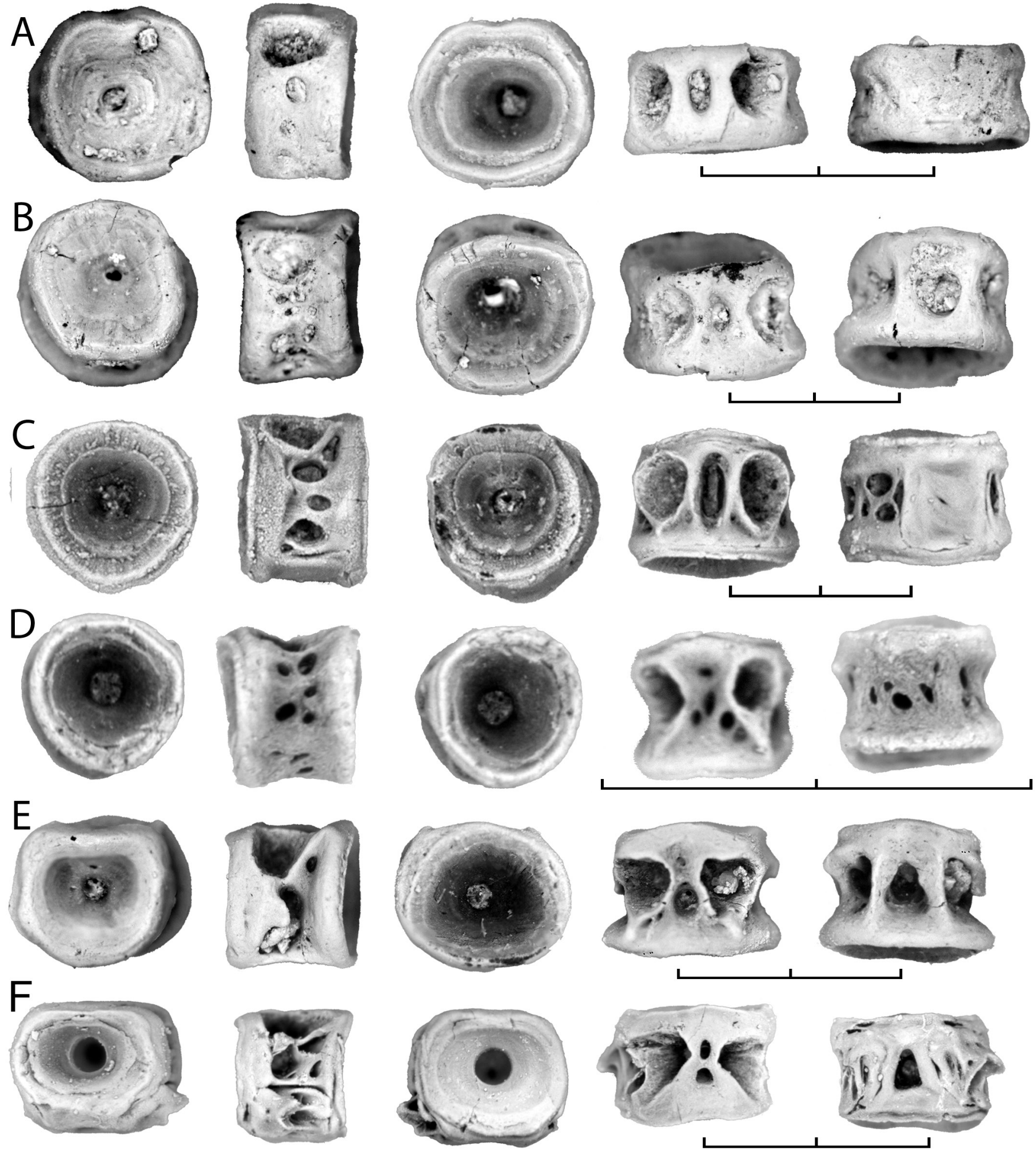

Figure 22. Centra of Telostei indet. type U-4 from the Milk River Formation compared with specimens from the Santonian of Utah, Campanian of Alberta, and Paleocene of Montana. A-C) Centra of Telostei indet. type U-4 from the Milk River Formation, showing variation in the development of a mid-ventral pit and in the length of the centrum: A, UALVP 48869; B, UALVP 48870; C, TMP 2000.001.0069. D) centrum of Telostei indet. type U-4 from the Santonian John Henry Member of the Straight Cliffs Formation, UMNH VP 19136. E) centra of Telostei indet. type U-4 from the Belly River Group, TMP 2015.060.0026. F) centrum from the early Paleocene Tullock Formation of Montana, specimen UCMP 230709/V2210. Centra shown in anterior, left lateral, posterior, dorsal and ventral views. D from Brinkman et al. (2013: fig. 10.23B). Scale bar equals $2 \mathrm{~mm}$. 
both dentaries and centra. Three teleosts, an elopomorph, a hiodontid, and an acanthomorph, are represented only by precaudal centra. In addition, two centrum morphotypes from teleosts of uncertain relationships, teleost centrum morphotype $\mathrm{O}$ and teleost centrum morphotype $\mathrm{U}-4$, are interpreted as being from taxonomically distinct kinds of fish.

The taxonomic composition of the teleost assemblage of the Milk River Formation recognized here differs from that presented by Larson (2010) in that Paralbula is not present. This difference is a result of the re-identification of the elements that had previously been identified as Paralbula teeth as crayfish gastroliths by Brinkman et al. (2014). No definitive Paralbula teeth were present in the samples that were studied during the course of this work.

\section{Latitudinal distribution patterns}

With this understanding of the diversity and, to some extent, relationships of the fishes present in the Deadhorse Coulee Member of the Milk River Formation, the stratigraphic and geographic patterns of distribution of the freshwater fishes of the Western Interior during the Late Cretaceous can be re-evaluated and refined.

The Milk River assemblage includes four taxa that Brinkman et al. (2013) considered members of a "southern" assemblage. These are: 1) the hybodontiform Lonchidion; 2) the lepisosteid with gar scales of type 2 morphology; 3) the vidalamiine cf. Melvius; and 4) Teleost indet. type O. All of these are present in the Campanian Kaiparowits Formation of Utah, as well as earlier assemblages in this region, but absent in the Campanian Belly River Group of Alberta and the contemporaneous Judith River Formation of Montana.

The Milk River Formation also has a strong "southern" aspect in the relatively high abundance of teleost $\mathrm{U} 3 / \mathrm{BvD}$, the presumed ostariophysan, compared to its abundance in the younger Belly River Group of Alberta. The relative abundance of this fish was estimated using number of centra of this fish compared with the number of centra of other teleosts. In the late Santonian lower John Henry Member of the Straight Cliffs Formation, centra of teleost $\mathrm{U} 3 / \mathrm{BvD}$ constitute $75 \%$ of teleost centra present in the samples documented (see Brinkman et al. 2013: table 10.2). In the Milk River Formation, centra of teleost U3/ $\mathrm{BvD}$, constitute $27 \%$ of teleost centra present (Table 1 ). In the Belly River Group of Alberta, centra of teleost U3/BvD are restricted to a few localities and are never abundant (see Brinkman et al. 2013; table 10.2). Thus the abundance of teleost $\mathrm{U} 3 / \mathrm{BvD}$ in the Milk River Formation assemblage is intermediate between that of Utah and that from the late Campanian of Alberta.

Conversely, four of the taxa that were considered to be characteristic of "northern" fish assemblages by Brinkman et al. (2013) are absent in the Milk River Formation. These are acipenseriforms, Holostean A, Holostean B, and Coriops. The first three of these are known from more northern localities in North America prior to the Santonian. A sturgeon was reported from the Cenomanian Dunvegan Formation of northern Alberta (Vavrek et al. 2012). Sturgeon are not represented in any of the microvertebrate localities in Utah but are present in the Belly River Group of Alberta. Similarly, scales of Holostean A and Holostean B morphology are present in the late Turonian of Axel Heiberg Island, but are not known from southern Alberta until the late Campanian, when they occur in the Belly River Group. Thus, the presence of these three taxa in the Belly River Group but not the Milk River Formation can be interpreted as a result of a southern shift in the distribution of these taxa sometime between the late Santonian and the late Campanian. Centra of Coriops are present in Utah in the Cenomanian Dakota Formation, but are absent in younger localities until the late Campanian, when they are present in the Kaiparowits Formation (Brinkman et al. 2013). Thus it is likely that the absence of Coriops in the Milk River Formation assemblage is also a result of shifts in its distribution pattern.

The presence of a fish assemblage with characteristics of "southern" assemblages in the Milk River Formation but not the younger Belly River Group is interpreted as indicating that "southern" assemblages extended further north in the late Santonian than they did in the late Campanian. Similarly, the absence of taxa characteristic of "northern" assemblages in the Milk River Formation is interpreted as indicating that "northern" assemblages did not extend as far south in the late Santonian as they did in the late Campanian. These distribution patterns are consistent with the hypothesis presented by Brinkman et al. (2013) that latitudinal distribution patterns shifted in response to changes in mean annual temperature. Leaf margin analysis of floras from the Western Interior (Upchurch and Wolf 1993) concluded that temperatures were high in the Santonian, decreased through the Campanian to a low in the early Maastrichtian, then increased again to near-Santonian levels in the late Maastrichtian. Isotope analyses of deep sea cores have documented a similar worldwide pattern of mean annual temperature changes (Jenkyns et al. 2004). The presence of "southern" taxa in Alberta during the Santonian can be hypothesized as the result of a northern extension in the distribution of these taxa in response to increased mean annual temperatures at that time. This resulted in the ranges of southern taxa extending farther north during this time of globally high mean annual temperature than they did during relatively cooler times. Despite the dominance of taxa typically indicative of "southern" faunas, the Milk River Formation fish assem- 
blage has features that are similar to assemblages from the Belly River Group and features that are intermediate between the assemblages of the Belly River Group and the John Henry Member of the Straight Cliffs Formation of Utah. These include the presence of Horseshoeichthys and the absence of the gar with lanceolate teeth, which is a dominant element in Santonian and Campanian assemblages in Utah (Brinkman et al. 2013). As well, as noted above, the abundance of the ostariophysan $\mathrm{U} 3 / \mathrm{BvD}$ is intermediate between the abundance of this teleost in Utah and in the Belly River Group. These features suggest that latitudinal patterns were present in the late Santonian, although they were expressed less strongly over the geographic area documented by the available localities.

\section{Stratigraphic distribution patterns}

In addition to differences that can be attributed to shifts in distribution in response to climate change, the Milk River Formation and Belly River Group fishes assemblages differ in aspects that can be interpreted as a result of either evolutionary change within lineages or the introduction of new groups into North America as a result of intercontinental dispersal events. A major faunal change in fish assemblage between the early Santonian and the late Campanian was previously recognized (Brinkman et al. 2013). The Milk River Formation fish assemblage allows this period of faunal change to be further constrained and characterized. With a minimum of 20 taxa present, 10 of which are teleosts, the diversity of the late Santonian Milk River acanthopterygian assemblage is intermediate between that of the well-known, early Santonian assemblages of Utah, such as that from the Lower John Henry Member, which has a minimum of 13 taxa, six of which are teleosts, and the late Campanian assemblages from Alberta, which have a minimum of 25 taxa, 15 of which are teleosts. This increase in the diversity of fishes within assemblages of the late Campanian can be attributed in part to the diversification of lineages present in the Santonian. For example, in the Milk River Formation, a single acanthomorph is recognized, while in the Dinosaur Park Formation this group is represented by a minimum of four taxa (Neuman and Brinkman 2005).

In addition, differences are present that may be a result of the introduction of new taxa into North America via intercontinental dispersal events. Two taxa that are present in the Belly River Group, but not the Milk River Formation or the pre-Campanian localities in Utah, may be Campanian immigrants into North America. These are Paralbula and a member of the Characiformes, both of which first appear in North America in the Campanian, but are known to occur on other continents at earlier times. Paralbula may have dispersed into North America in the
Campanian. The recognition that the elements from the Milk River Formation that were previously interpreted as teeth of Paralbula are actually crayfish gastroliths, places the first occurrence of this genus in North America in the late Campanian, at which time it occurs in both Utah and Alberta (Neuman and Brinkman 2005; Brinkman et al. 2013). However, Paralbula has been reported from the Early Cretaceous Wadhurst Clay Formation (Sweetman 2013) and the Cenomanian La Cabaña Formation (Vullo et al. 2009), both of which are in Europe. The presence of a characiform in the Dinosaur Park Formation was reported by Newbrey et al. (2009) on the basis of dentaries with distinctive symphyseal articulations. Although this is one of the earliest occurrences of the group, Newbrey et al. (2009) hypothesized that its presence in North America was the result of dispersal from the southern hemisphere, either directly from South America or via Europe.

Thus, the fish assemblage of the Milk River Formation supports the suggestion by Brinkman et al. (2013) that a major faunal event occurred between the late Santonian and the late Campanian. This event seems to have involved both intercontinental dispersal of several lineages into North America as well as a period of rapid diversification of lineages that were already present in North America in the Santonian.

\section{Aquatic Paleocommunities of the Milk River Formation}

A study of the composition and relative abundance of taxa of the aquatic paleocommunities represented in the Belly River Group was undertaken by Brinkman (2008) based on counts of centra from vertebrate microfossil localities. Centra are used for this because they are generally taphonomically equivalent, so differences in abundance are likely to reflect differences in abundance in the communities from which the fossil assemblages were derived, rather than a result of taphonomic biases. The abundance patterns are interpreted as regional, rather than habitat specific, because vertebrate microfossil assemblages are generally transported assemblages that contain a mixture of taxa from different habitats. For example, most vertebrate microfossil sites contain a high abundance of terrestrial taxa, even though they were deposited in a fluvial setting. Further evidence that the patterns are regional, rather than habitat specific, is the consistency of the pattern in multiple vertebrate microfossil localities within a geographic and stratigraphic zone (Table 1).

One of the striking features of the vertebrate microfossil assemblages of the Belly River Group that Brinkman (2008) recognized is the high abundance of urodeles relative to teleosts. The Milk River Formation assemblage is similar to those from the Belly River Group in that salamander centra are generally more abundant than any of the teleosts (Table 
1). Thus, as in the Campanian and Maastrichtian, urodeles would have been dominant members of the Santonian aquatic paleocommunities in terms of relative abundance.

The pattern of changes in abundance of amiids and lepisosteids in the Late Cretaceous is also of paleoecological significance because, based on counts of centra, both of these groups are more dominant relative to other fishes in the late Maastrichtian than they are in the late Campanian (Brinkman et al. 2014). In a sample from two localities in the late Maastrichtian Hell Creek Formation, amiids constituted $43 \%$ and lepisosteids $29 \%$ of the fish centra present (data from Brinkman et al. 2014: tab. 3). In contrast, in a sample of 12 localities from the late Campanian Belly River Group, amiids constituted $8 \%$ and lepisosteids $2 \%$ of the fish centra present (data from Brinkman et. al. 2014: tab. 4). In the Deadhorse Member of the Milk River Formation, amiid centra constituted $6 \%$ and lepisosteids $7 \%$ of the fish centra present (Table 1). Thus, the Milk River Formation assemblage is similar to assemblages of the late Campanian and different from those of the late Maastrichtian in that amiids and lepisosteids are of relatively low abundance compared to the teleosts. Thus the high abundance of amiids and lepisosteids in the Maastrichthian appears to reflect a change in the structure of the aquatic communities of this time. Interestingly, a similar trend for high abundance of lepisosteids in the late Maastrichtian has also been observed in Europe (Cavin 1999; Blanco et al. 2017).

A third change in the structure of aquatic paleocommunities through the Late Cretaceous is an increase in the importance of members of the Acanthomorpha relative to other teleosts. Both diversity and abundance relative to other teleosts can be used as a measure of this. As noted above, the diversity of acanthomorphs in the Campanian, with a minimum of four taxa (Neuman and Brinkman 2005), is greater than in the Santonian, where a single taxon is present. A further increase in diversity is seen in the late Maastrichtian with the introduction of new taxa, such as Priscacara, and an indeterminate acanthomorph taxon of large size (Brinkman et al. 2014).

Acanthomorphs also appear to be increasing in abundance relative to other teleosts through the Late Cretaceous. Brinkman et al. (2014) documented an increased abundance of acanthomorphs through the late Maastrichtian Hell Creek Formation: in the lower Hell Creek, 20\% of the teleost centra present are from acanthomorphs, while in the upper Hell Creek, they represent $50 \%$ of the teleost centra present. The high abundance of acanthomorphs in late Maastrichtian assemblages can be seen as the culmination of a trend for an increase abundance of the group in aquatic communities through the Late Cretaceous. Acanthomorphs first occur in non-marine assemblages of the Western Interior in the Coniacian, where they are documented by fin spines (Brinkman et al. 2014). Based on the abundance of acanthomorph centra relative to centra of other teleosts, successively younger samples showed an overall increase in the abundance of acanthomorphs (Fig. 23). In the early Santonian John Henry Member of the Straight Cliffs Formation of Utah, acanthomorphs constitute 6\% of teleost centra present. In the middle Campanian Wahweap Formation of Utah $15 \%$ of the teleost centra present were acanthomorphs. In the late Campanian Kaiparowits Formation of Utah $18 \%$ of the teleost centra were acanthomorphs, and in the late Campanian Belly River Group of Alberta 30\% of teleost centra present were from acanthomorphs. The abundance of acanthomorph centra relative to other teleost centra in the Milk River Formation (8\%) is intermediate between the early Santonian (6\%) and the middle Campanian (15\%) localities.

\section{CONCLUSION}

The late Santonian Milk River Formation fills a gap in the sequence of vertebrate microfossil localities that document change in terrestrial paleocommunities through the Late Cretaceous of the Western Interior. The fishes from this formation document a paleocommunity that is intermediate in diversity between those represented by assemblages from sites in Utah from the early Santonian lower John Henry Member of the Straight Cliffs Formation and the middle Campanian Wahweap Formation. Of particular interest are the teleosts, which, because of taphonomic biases against their preservation as articulated skeletons in non-marine fluvial settings, have been poorly understood members of the aquatic communities of the Late Cretaceous. A morphotype approach is used to incorporate all centra and tooth-bearing elements in estimates of their diversity. Ten taxa are recognized. Two of these are of unknown relationships, the remainder can be identified to at least a higher-level group within the Teleostei.

In its faunal composition and the relative abundance of taxa present, the Milk River Formation assemblage is more similar to those from the Turonian to late Campanian of Utah rather than younger assemblages from the same geographic area. This is interpreted as a result of shifts of distribution of taxa in response to climate change. These shifts demonstrate that latitudinal patterns in fish distribution during the Late Cretaceous were a result of latitudinal patterns in climate, rather than the presence of physical barriers preventing dispersal of taxa from southern and northern areas of the basin as has been suggested for some dinosaurs (Sampson et al. 2010). 


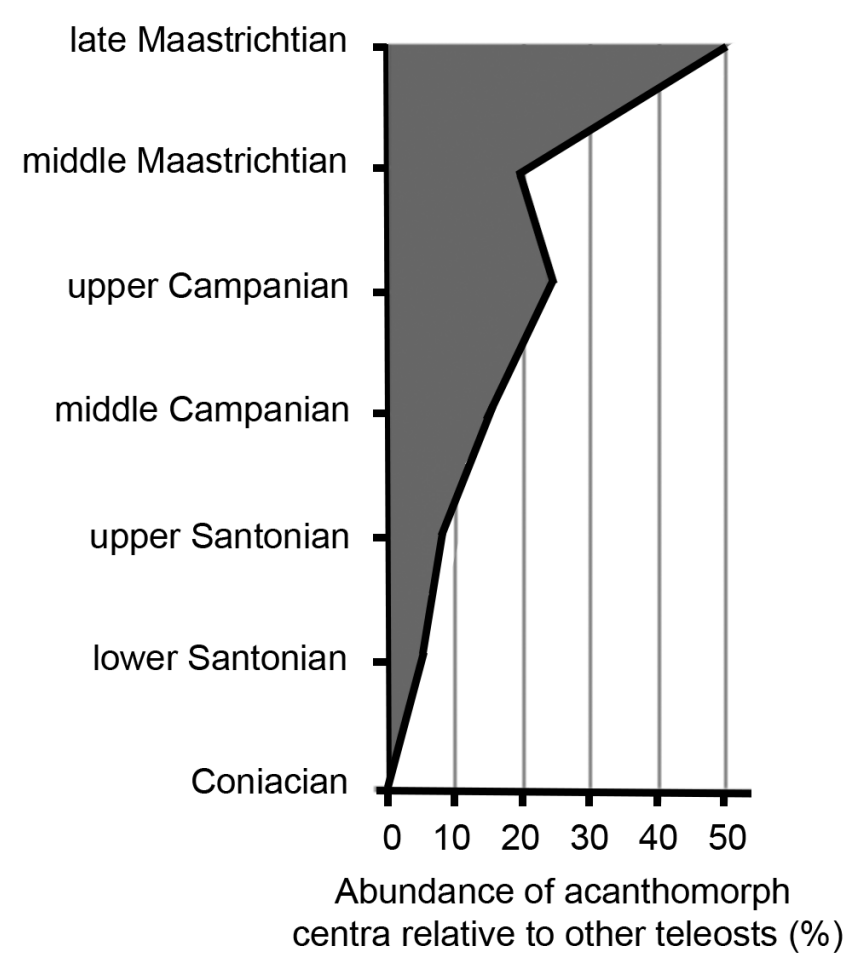

Figure 23. Graph showing the changing abundance of acanthomorph centra relative to the centra of other teleosts through the late Cretaceous. Lower Santonian based on localities in the lower John Henry Member of the Straight Cliffs Formation of Utah. Upper Santonian abundance based on counts of centra from localities in the Milk River Formation of Alberta. Middle Campanian abundance based on counts of centra from localities in the Wahweap Formation of Utah. Late Campanian abundance based on counts of centra from localities in the Kaiparowits Formation of Utah and the Belly River Group of Alberta. Middle Maastrichtian based on counts of centra from localities in the lower Hell Creek Formation of Montana. Upper Maastrichtian based on counts of centra from localities in the upper Hell Creek Formation of Montana. Data for the abundance of acanthomorphs from Utah from Brinkman et al. (2013; Table 10.2). Data for the abundance of acanthomorphs from the Milk River Formation in Table 1. Data for the abundance of acanthomorphs from the Belly River Group in Alberta and the upper and lower Hell Creek Formation from Brinkman et al. (2014: tables 3, 4). For the late Campanian, which is represented by localities in two widely separated geographic areas, the average of those two areas is used as a measure of the abundance of acanthomorphs at that time.

\section{ACKNOWLEDGEMENTS}

The authors would like to acknowledge Mark Wilson, Alison Murray, John Bruner, and Clive Coy for access to collections in the University of Alberta and support with equipment and space while studying material in these collections. We would also like to recognize the contribu- tion that Richard C. Fox has made to this study, and the study of vertebrate microfossils from the Late Cretaceous of Alberta generally, as a result of his efforts in screen-washing sites from the Milk River Formation and other Late Cretaceous formations of Alberta. Michael Ryan, Betsy Nicholls, and Jim McCabe aided in surveys of the Milk River Formation during the late 1990s which led to the discovery of two localities: TMP localities L1145 and Michael's Site. Sue Marsland, Jane Danis, John Maccogno, and members of the Alberta Paleontological Society provided assistance with sorting the microvertebrate concentrate resulting from screen-washing these localities. Alison Murray, Todd Cook and an anonymous reviewer provided significant comments that led to the improvement of this manuscript.

\section{LITERATURE CITED}

Agassiz, L. 1837. Recherches sur les Poissons fossiles. Neuchâtel. 5 volumes. 1420 pp. DOI: 10.5962/bhl.title.4275.

Applegate, S.P. 1972. Revision of the higher taxa of orectolobids. Journal of the Marine Biology Association of India 14:743-751.

Arratia, G. 1999. The monophyly of Teleostei and stem-group teleosts. Consensus and disagreements. Pp. 265-334 in G. Arratia and H.-P. Schultze (eds.). Mesozoic Fishes 2 - Systematics and Fossil Record. Verlag Dr. Friedrich Pfeil, München, Germany.

Arratia, G. 2001. The sister-group of Teleostei: Concensus and disagreements. Journal of Vertebrate Paleontology 21:767-773. DOI 10.1671/0272-4634(2001)021[0767:TSGOTC]2.0.CO;2

Bannikov, A.F., and F. Bacchia. 2000. A remarkable clupeomorph fish (Pisces, Teleostei) from a new Upper Cretaceous marine locality in Lebanon. Senckenbergianna Lethaea 80:3-11. DOI 10.1007/BF03043659.

Bardack, D. 1968. Belonostomus sp., the first holostean from the Austin Chalk (Cretaceous) of Texas. Journal of Paleontology 42:1307-1309.

Berg, L.S. 1936. The suborder Esocoidei (Pisces). Izvestia Biologicheskogo Nauchno-Issledovatel'skogo institute pri Permskom 10:385-391.

Berg, L.S., 1937. A classification of fish-like vertebrates. Bulletin de l'Académie des Sciences de l'URSS, 1937:1277-1280.

Berg, L.S. 1940. Classification of fishes, both Recent and fossil. Travaux de l'Institut Zoologique de l'Académie des Sciences de l'URSS 5:1-45.

Blanco, A., M. Szabó, À. Blanco-Lapaz, and J. Marmi. 2017. Late Cretaceous (Maastrichtian) Chondrichthyes and Osteichthyes from northeastern Iberia. Palaeogeography Palaeoclimatology Palaeoecology 465: 278-294. DOI: 10.1016/j.palaeo.2016.10.039.

Bleeker, P. 1859. Enumeratio speciorum piscium hucusque in Archipelago Indico observatarum. Acta Societatis Scientiarum Indo-Neêrlandae 6:1-276. 
Bonaparte, C.L. 1838. Selachorum tabula analytica. Nouvelles Annales des Sciences Naturelles 2:195-214.

Braman, D. 2002. Terrestrial palynomorphs of the upper Santonian -?lowest Campanian Milk River Formation. Palynology 25:57-107. DOI:10.2113/0250057.

Brinkman, D.B. 1990. Paleoecology of the Judith River Formation (Campanian) of Dinosaur Provincial Park, Alberta, Canada: Evidence from vertebrate microfossil localities. Palaeogeography, Palaeoclimatology, Palaeoecology 78:37-54. DOI 10.1016/0031-0182(90)90203-J.

Brinkman, D.B. 2003. A review of nonmarine turtles from the Late Cretaceous of Alberta. Canadian Journal of Earth Sciences 40:557-571. DOI 10.1139/E02-080.

Brinkman, D.B. 2008. The structure of Late Cretaceous (late Campanian) non-marine aquatic communities: A guild analysis of two vertebrate microfossil localities in Dinosaur Provincial Park, Alberta, Canada. Pp. 33-60 in J.T. Sankey and S. Baszio (eds.). Vertebrate Microfossil Assemblages, Their Role in Paleoecology and Paleobiogeography. Indiana University Press, Bloomington, Indiana.

Brinkman, D.B., and A.G. Neuman. 2002. Teleost centra from uppermost Judith River Group (Dinosaur Park Formation, Campanian) of Alberta, Canada. Journal of Paleontology 76:138-155. DOI 10.1017/S002233600001742X.

Brinkman, D.B., D.R. Braman, A.G. Neuman, P.E. Ralrick, and T. Sato, 2005. A vertebrate assemblage from marine shales of the Lethbridge Coal Zone. Pp. 486-500 in: P.J. Currie and E.B. Kopplelhus (eds.). Dinosaur Provincial Park, a Spectacular Ancient Ecosystem Revealed. Indiana University Press, Bloomington, Indiana.

Brinkman, D.B., M.G. Newbrey, A.G. Neuman, and J.G. Eaton. 2013. Freshwater Osteichthyes from the Cenomanian to late Campanian of Grand Staircase-Escalante National Monument, Utah. Pp. 195-236 in A.L. Titus and M.A. Lowen (eds.). At the Top of the Grand Staircase: The Late Cretaceous of Southern Utah. Indiana University Press, Bloomington, Indiana.

Brinkman, D.B., M.G. Newbrey, and A.G. Neuman. 2014. Diversity and paleoecology of actinopterygian fish from vertebrate microfossil localities of the Maastrichtian Hell Creek Formation of Montana. Pp. 247-270 in G.P. Wilson, W.A. Clemens, J.R. Horner, and J.H. Hartman (eds.). Through the End of the Cretaceous in the Type Locality of the Hell Creek Formation in Montana and Adjacent Areas. Geological Society of America Special Paper 503. DOI 10.1130/2014.2503(09).

Bryant, L. 1987. A new genus and species of Amiidae (Holostei; Osteichthyes) from the Late Cretaceous of North America, with comments on the phylogeny of the Amiidae. Journal of Vertebrate Paleontology 7:349-361. DOI 10.1080/02724634.1988.10011669.

Cavin, L. 1999. Osteichthyes from the Upper Cretaceous of Laño (Iberian Peninsula). Estudios del Museo de Ciencias Naturales de Álava 14 (Número especial 1):105-110.

Cappeta, H. 1980. Les sélaciens du Crétacé superieur du Liban. II. Batoïdes. Palaeontographica Abteilung A 168:69-148.
Case, G.R. 1978. A new selachian fauna from the late Campanian of Wyoming (Teapot Sandstone Member, Mesaverde Formation, Big Horn Basin). Palaeontographica Abteilung A 197:1-37.

Cook, T.D., M.G. Newbrey, D.B. Brinkman, and J.I. Kirkland. 2014. Euselachians from the freshwater deposits of the Hell Creek Formation of Montana. Pp. 229-246 in G.P. Wilson, W.A. Clemens, J.R. Horner, and J.H. Hartman (eds.). Through the End of the Cretaceous in the Type Locality of the Hell Creek Formation in Montana and Adjacent Areas: Geological Society of America Special Paper 503. DOI 10.1130/2014.2503(08).

Courtemanche, M. and V. Legendre. 1985. Os de poissons: nomenclature codifiée, noms anglais et français. Bibliothèque nationale du Québec, Montréal, Quebec.Cuvier, G. 1817. Le Règne Animal Distribué d'Aprés son Organisation Pour Servir de Base à l'Histoire Naturelle des Animaux et d'Introduction à l'Anatomie Comparée. Les Reptiles, les Poissons, les Mollusques et les Annélides (1 ed.); P.F. Paris: Didot le jeune. DOI 10.5962/bhl. title.49223.

Cuvier, G. 1825. Recherches sur les Ossemens Fossiles, où l'on Rétablit les Caractères de Plusieurs Animaux dont les Révolutions du Globe ont Détruit les Espèces. Third edition. Paris. DOI 10.5962/bhl.title.60807.

Cuvier, G., and A. Valenciennes. 1846. Histoire Naturelle Des Poissons, Volume 19: Société Géologique de France, Strasbourg [1969 facsimile reprint; A. Asher and Company, Amsterdam]. DOI 10.5962/bhl.title.7339.

Divay, J. D. 2015. Cenozoic ichthyofaunas of the North American western interior, and palaeoclimatic and palaeoenvironmental reconstructions. $\mathrm{PhD}$ dissertation, University of Alberta, Edmonton, Alberta, 523 pp. DOI 10.7939/ R3TM7271M.

Divay, J.D., and A.M. Murray, 2016. An early Eocene fish fauna from the Bitter Creek area of the Wasatch Formation of southwestern Wyoming, U.S.A. Journal of Vertebrate Paleontology e1196211:1-19. DOI 10.1080/02724634.2016.1196211.

Estes, R. 1964. Fossil vertebrates from the Late Cretaceous Lance Formation, Eastern Wyoming. University of California Publications in Geological Sciences 49:1-187.

Fink, S.V., and W.L. Fink. 1996. Interrelationships of ostariophysan fishes (Teleostei). Pp. 209-250 in M.L.J. Stiassny, L.R. Parenti, and G.D. Johnson, (eds.). Interrelationships of Fishes. Academic Press, San Diego, California.

Forsskål, P. 1775. Descriptiones Animalium Avium, Amphibiorum, Piscium, Insectorum, Vermium; Quae in Itinere Orientali Observavit; Post Mortem Auctoris Edidit Carsten Niebuhr. Hauniae. Descriptiones Animalium Quae in Itinere ad Maris Australis Terras per Annos, 1-20 + i-xxxiv + 1-164, map. DOI 10.5962/bhl.title.2154.

Fowler, H.W. 1941. Contributions to the biology of the Philippine archipelago and adjacent regions. The fishes of the groups Elasmobranchii, Holocephali, Isospondyli, and Ostariophysi obtained by the United States Bureau of Fisheries 
Steamer "Albatross" in 1907 to 1910, chiefly in Philippine Islands and adjacent Seas. Bulletin of the United States National Museum 13:1-879.

Garstang, W. 1931. The phyletic classification of Teleostei. Proceedings of the Leeds Philosophical and Literary Society. Scientific Section 2:240-260.

Gill, T.C. 1895. Notes on the genus Cephaleutherus of Rafinesque, and other rays with aberrant pectoral fins (Propterygia and Hieroptera). Proceedings of the United States National Museum 18:195-198. DOI 10.5479/si.00963801.18-1054.195.

Grande, L. 1985. Recent and fossil clupeomorph fishes with materials for revision of the subgroups of clupeiods. Bulletin of the American Museum of Natural History 131:231-272.

Grande, L. 2010. An empirical synthetic pattern study of gars (Lepisosteiformes) and closely related species, based mostly on skeletal anatomy. The resurrection of Holostei. American Society of Ichthyologists and Herpetologists Special Publication 6:1-871. DOI 10.1080/02724634.2016.1225747.

Grande L. and T.M. Cavender. 1991. Description and phylogenetic reassessment of the monotypic $†$ Ostariostomidae (Teleostei). Journal of Vertebrate Paleontology 11:405-416. DOI 10.1080/02724634.1991.10011412.

Grande, L., and W.E. Bemis. 1998. A comprehensive phylogenetic study of amiid fishes (Amiidae) based on comparative skeletal anatomy. An empirical search for interconnected patterns of Natural History. Society of Vertebrate Paleontology, Memoir 4:1-690.DOI 10.1080/02724634.1998.10011114.

Grande, L., F. Jin, Y. Yabumoto, and W.E. Bemis. 2002. $\dagger$ Protopsephurus liui, a well-preserved primitive paddlefish (Acipenseriformes: Polyodontidae) from the Early Cretaceous of China. Journal of Vertebrate Paleontology 22:209-237. DOI 10.1671/0272-4634(2002)022[0209:PLAWPP]2.0.CO;2.

Grayson, D.K. 1984. Quantitative Zooarchaeology, Topics in the Analysis of Archaeological Faunas. Academic Press, New York, N.Y.

Greenwood, P.H., D.E. Rosen, S.H. Weitzman, and G.S. Myers. 1966, Phyletic studies of teleostean fishes, with a provisional classification of living forms. Bulletin of the American Museum of Natural History 131:339-455.

Hay, O.P. 1902. Bibliography and catalogue of the fossil Vertebrata of North America. U.S. Geological Survey Bulletin 179:1-868. DOI: 10.5962/bhl.title.20094.

Hay, O.P. 1929. Second bibliography and catalogue of the fossil Vertebrata of North America. Publications of the Carnegie Institute of Washington 390:1-2003.

Herman, J. 1977. Additions to the Eocene fish fauna of Belgium: 3, Revision of the Orectolobiformes. Tertiary Research 1:127-138.

Huxley, T.H. 1880. On the application of laws of evolution to the arrangement of the Vertebrata and more particularly of the Mammalia. Proceedings of the Zoological Society of London 1880:649-662.

Jenkyns, H. C., A. Forster, S. Schouten, and J.S.S. Damsté. 2004. High temperatures in the Late Cretaceous Arctic Ocean. Nature 432:888-892. DOI 10.1038/nature03143.
Johnson, G. D., and C. Patterson. 1996. Relationships of lower euteleostean fishes. Pp. 251-332 in M.L J. Stiassny, L.R. Parenti, and G.D. Johnson (eds.). Interrelationships of Fishes. Academic Press, New York. DOI 10.1016/B978-012670950-6/50013-8.

Jordan, D.S., and H.W. Fowler. 1903. A review of the elasmobranchiate fishes of Japan. Proceedings of the U.S. National Museum 26:593-674.

Kirkland, J.I., J.G., Eaton, and D.B. Brinkman. 2013. Elasmobranchs from Upper Cretaceous freshwater facies in Southern Utah. Pp. 153-194 in A.L. Titus and M.A. Lowen (eds.). At the Top of the Grand Staircase: The Late Cretaceous of Southern Utah. Indiana University Press, Bloomington, Indiana.

Klein, E.E. 1885. Beiträge zur Bildung des Schädels der Knochenfische. II. Jahreshefte des Vereins für vaterländische Naturkunde in Württemberg 41:107-261.

Lambe, L.M. 1902. New genera and species from the Belly River Series (mid-Cretaceous). Geological Survey of Canada, Contributions to Canadian Palaeontology 2:23-81.

Larson, D.W. 2010. The occurrences of vertebrate fossils in the Deadhorse Coulee Member of the Milk River Formation and their implications for provincialism and evolution in the Santonian (Late Cretaceous) of North America. MSc thesis, University of Alberta, Edmonton, Alberta. DOI 10.7939/ R33S7C.

Leanza, H., and A. Zeiss. 1990. Upper Jurassic lithographic limestones from Argentina (Neuquén Basin): stratigraphy and fossils. Facies 22:169-186. DOI 10.1007/BF02536951.

Maisey, J.G. 1975. The interrelationships of phalacanthous selachians. Neues Jahrbuch für Geologie und Paläontologie Monatshefte 1975:553-567.

McAllister, D.E. 1968. The evolution of branchiostegals and associated opercular, gular, and hyoid bones, and the classification of teleostome fishes, living and fossil. National Museum of Canada Bulletin 221:1-239.

McAlpin, A. 1947. Palaeopsephurus wilsoni, a new polyodontid fish from the Upper Cretaceous of Montana, with a discussion of allied fishes, living and fossil. Contributions from the Museum of Paleontology University of Michigan 6:167-234.

Meyer, R., 1994. Shoreface to coastal-plain estuarine deposition in the Milk River Formation, southern Alberta, Canada. Canadian Society of Petroleum Geologists, Field Trip Guidebook, September 9-11, 1994, Calgary Alberta, 52 pp.

Müller, J. 1844. Ueber den Bau und die Grenzen der Ganoiden und über das natürliche System der Fische. Bericht über die zur Bekanntmachung geeigneten Verhandlungen der Akademie der Wissenschaften, Berlin 1846:117-216. [An 1846 English translation of this paper, translated by J. W. Griffith, can be found in Scientific Memoirs 4(16):499-558.]

Murray, A.M., M.G. Newbrey, A.G. Neuman, and D.B. Brinkman. 2016. New articulated osteoglossomorph from Late Cretaceous freshwater deposits (Maastrichtian, Scollard Formation) of Alberta, Canada. Journal of Vertebrate Paleontology:e1120737 (14 pages). DOI 10.1080/02724634.2016.1120737 
Nelson, J.S., 1994. Fishes of the World. Third edition. John Wiley and Sons, Inc. New York. 600 pp.

Nelson, J.S., T.C. Grande, and M.V.H. Wilson. 2016. Fishes of the World. Fifth edition. John Wiley and Sons, Inc. Hoboken, New Jersey. 707 pp.

Neuman, A.G., and D.B. Brinkman. 2005. Fishes of the fluvial beds. Pp. 167-185 in P.J. Currie and E.B. Kopplelhus (eds.). Dinosaur Provincial Park, a Spectacular Ancient Ecosystem Revealed. Indiana University Press, Bloomington, Indiana.

Newbrey, M.G., A.M. Murray, M.V.H. Wilson, D.B. Brinkman, and A.G. Neuman. 2009. Seventy-five-million-year-old tropical tetra-like fish from Canada tracks Cretaceous global warming. Proceedings of the Royal Society, B 276:3829-3833. DOI 10. 1098/rspb.2009.1047.

Newbrey, M., A.M. Murray, D.B. Brinkman, M.V.H. Wilson, and A.G. Neuman. 2010. A new articulated freshwater fish (Clupeomorpha, Ellimmichthyiformes) from the Horseshoe Canyon Formation, Maastrichtian, of Alberta, Canada. Canadian Journal of Earth Sciences 47:1183-1196. DOI 10.1139/E10-041.

Nicholson, H.A., and R. Lydekker. 1889. A Manual of Palaeontology, for the Use of Students; with a General Introduction on the Principles of Palaeontology. Second edition. W. Blackwood and Sons, Edinburgh and London. DOI 10.5962/bhl.title.61545.

Owen, R. 1846. Lectures on the Comparative Anatomy and Physiology of the Vertebrate Animals, Delivered at the Royal College of Surgeons of England in 1844 and 1846. Part 1. Fishes. Longman, Brown, Green, and Longmans, London, England. DOI 10.5962/bhl.title.13539.

Patterson, C. 1964. A review of Mesozoic acanthopterygian fishes, with special reference to those of the English Chalk. Philosophical Transactions of the Royal Society of London. Series B, Biological Sciences 247:213-482. DOI 10.1098/ rstb.1964.0003.

Patterson, C., and D.E. Rosen. 1977. A review of the ichthyodectiform and other Mesozoic teleost fishes, and the theory and practice of classifying fossils. Bulletin of the American Museum of Natural History 158:81-172.

Payenberg, T.H.D., D.R. Braman, and A.D. Miall. 2002. Litho- and chronostratigraphic relationships of the SantonianCampanian Milk River Formation in southern Alberta and Eagle Formation in Montana utilising stratigraphy, U-Pb geochronology, and palynology. Canadian Journal of Earth Science 39:1553-1577. DOI 10.1139/e02-050.

Regan, C.T. 1923. The skeleton of Lepidosteus, with remarks on the origin and evolution of the lower neopterygian fishes. Proceedings of the Zoological Society of London 1923:445461. DOI 10.1111/j.1096-3642.1923.tb02191.x.

Rogers, R.R., C.C. Swisher III, and J.H. Horner. 1993. $40 \mathrm{Ar} / 39 \mathrm{Ar}$ age and correlation of the nonmarine Two Medicine Formation (Upper Cretaceous), northwestern Montana, U.S.A. Canadian Journal of Earth Science 30: 1066-1075. DOI 10.1139/e93-090.
Rosen, D.E. 1973. Interrelationships of higher euteleostean fishes. Pp. 397-513 in P.H. Greenwood, R.S. Miles, and C. Patterson (eds.). Interrelationships of Fishes. Academic Press, London.

Rosen, D.E., and P.H. Greenwood. 1970. Origin of the Weberian apparatus and the relationships of the ostariophysan and gonorhynchiform fishes. American Museum Novitates 2428:1-5.

Rosen, D.E., P.L. Forey, B.G. Gardiner, and C. Patterson. 1981. Lungfishes, tetrapods, paleontology and plesiomorphy. Bulletin of the American Museum of Natural History 167:159-276.

Sagemehl, M. 1885. Beiträge zur vergleichenden Anatomie der Fische. III. Das Cranium der Characiniden nebst allgemeinen Bemerkungen über die mit einem Weber'schen Apparat versehenen Physostomenfamilien. Gegenbaurs Morphologisches Jahrbuch 10:1-119.

Sampson, S.D., M.A. Loewen, A.A, Farke, E.M. Roberts, C.A. Forster, J.A. Smith, and A.L. Titus. 2010. New horned dinosaurs from Utah provide evidence for intracontinental dinosaur endemism. PLoS One 5(9):e12292. DOI 10.1371/journal. pone.0012292.

Schaeffer, B. 1949. A teleost from the Livingston Formation of Montana. American Museum Novitates 1427:1-16.

Stiassny, M.L.J. 1986. The limits and relationships of the acanthomorph teleosts. Journal of Zoology 1(2):411-460. DOI 10.1111/j.1096-3642.1986.tb00644.x.

Sweetman, S. 2013. Albuliform fish remains (Teleostei, Elopomorpha) from the Lower Cretaceous (Valanginian) Wadhurst Clay Formation of the Wealden Supergroup of southeast England. Journal of Vertebrate Paleontology 33:12391243. DOI 10.1080/02724634.2013.758126.

Taverne, L. 1979. Ostéologie, phylogénèse et systématique des téléostéens fossiles et actuels du super-ordre des osteoglossomorphes. Troisième partie. Évolution des structures ostéologiques et conclusions générales relatives à la phylogénèse et à la systématique du super-ordre. Mémoires de la Classe des Sciences, Académie Royale de Belgique 43:1-168.

Tobias H.D., T.H.D. Payenberg, D.R. Braman, D.W. Davis, and A.D. Miall. 2003. Depositional environments and stratigraphic architecture of the Late Cretaceous Milk River and Eagle formations, southern Alberta and north-central Montana: relationships to shallow biogenic gas. Bulletin of Canadian Petroleum Geology 51:155-176. DOI 10.2113/51.2.155.

Underwood, C.J., and S.L. Cumbaa. 2010. Chondrichthyans from a Cenomanian (Late Cretaceous) bonebed, Saskatchewan, Canada. Palaeontology 53:903-944. DOI 10.1111/j.14754983.2010.00969.x.

Upchurch, G.R., Jr., and J.A. Wolfe. 1993. Cretaceous vegetation of the western interior and adjacent regions of North America. Geological Association of Canada, Special Paper 39:243-281. DOI: 10.1371/journal.pone.0096075.

Vavrek, M., A.M. Murray, and P.R. Bell. 2014. An early Late Cretaceous (Cenomanian) sturgeon (Acipenseriformes) from the Dunvegan Formation, northwestern Alberta, Canada. Canadian Journal of Earth Sciences 51:677-681. DOI 10.1139/cjes-2014-0052. 
Vernygora, O., and A.M. Murray, 2016. A new species of Armigatus (Clupeomorpha, Ellimmichthyiformes) from the Late Cretaceous of Morocco, and its phylogenetic relationships. Journal of Vertebrate Paleontology 36:e1031342 (9 pages). DOI 10.1080/02724634.2015.1031342.

Vullo, R., E. Bernárdez, and A.D. Buscalioni. 2009. Vertebrates from the middle?-late Cenomanian La Cabaña Formation (Asturias, northern Spain): Palaeoenvironmental and palaeobiogeographic implications. Palaeogeography, Palaeoclimatology, Palaeoecology 276:120-129. DOI 10.1016/j. palaeo.2009.03.004.

Whetstone, K.N. 1978. Belonostomus sp. (Teleostei, Aspidorhynchidae) from the Upper Cretaceous Tombigbee Sand of Alabama. The University of Kansas Paleontological Contributions, Paper 89:17-19.

Wilson, M.V.H., D.B. Brinkman, and A.G. Neuman. 1992. Cretaceous Esocoidea (Teleostei): early radiation of the pikes in North American fresh waters. Journal of Paleontology 66:839846. DOI 10.1017/S0022336000020849.

Zangerl, R. 1981. Chondrichthyes 1: Paleozoic Elasmobranchii. Pp. 1-115 in H.P. Schultze (ed.). Handbook of Paleoichthyology, 3A. Gustav Fischer Verlag, New York, Stuttgart. 